QA: QA

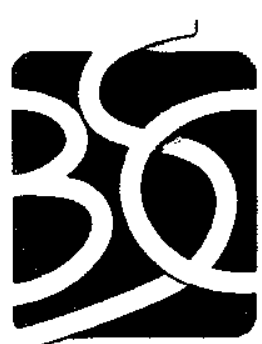

BECHTEL SAIC comparuc
NOTICE OF OPEN CHANGE DOCUMENTS - THIS DOCUMENT IS IMPACTED BY THE LISTED CHANGE DOCUMENT AND CANNOT BE USED WITHOUT IT.

1) ACN-001, DATED 06/06/2005

\title{
Post-Processing Analysis for THC Seepage
}

Prepared for:

U.S. Department of Energy

Office of Civilian Radioactive Waste Management

Office of Repository Development.

1551 Hillshire Drive

Las Vegas, Nevada 89134-6321

Prepared by:

Bechtel SAIC Company, LLC

1180 Town Center Drive

Las Vegas, Nevada 89144

Under Contract Number

DE-AC28-01RW12101 


\section{DISCLAIMER}

This report was prepared as an account of work sponsored by an agency of the United States Government. Neither the United States Government nor any agency thereof, nor any of their employees, nor any of their contractors, subcontractors or their employees, makes any warranty, express or implied, or assumes any legal liability or responsibility for the accuracy, completeness, or any third party's use or the results of such use of any information, apparatus, product, or process disclosed, or represents that its use would not infringe privately owned rights. Reference herein to any specific commercial product, process, or service by trade name, trademark, manufacturer, or otherwise, does not necessarily constitute or imply its endorsement, recommendation, or favoring by the United States Government or any agency thereof or its contractors or subcontractors. The views and opinions of authors expressed herein do not necessarily state or reflect those of the United States Government or any agency thereof. 
QA: QA

Post-Processing Analysis for THC Seepage ANL-NBS-HS-000045 REV 00

September 2004 


\begin{tabular}{|l|l|l|}
\hline \multirow{2}{*}{ OCRWM } & Scientific Analysis Signature Page/Change History & Page ij \\
\cline { 3 - 3 } & & 1. Total Pages: 116 \\
\hline
\end{tabular}

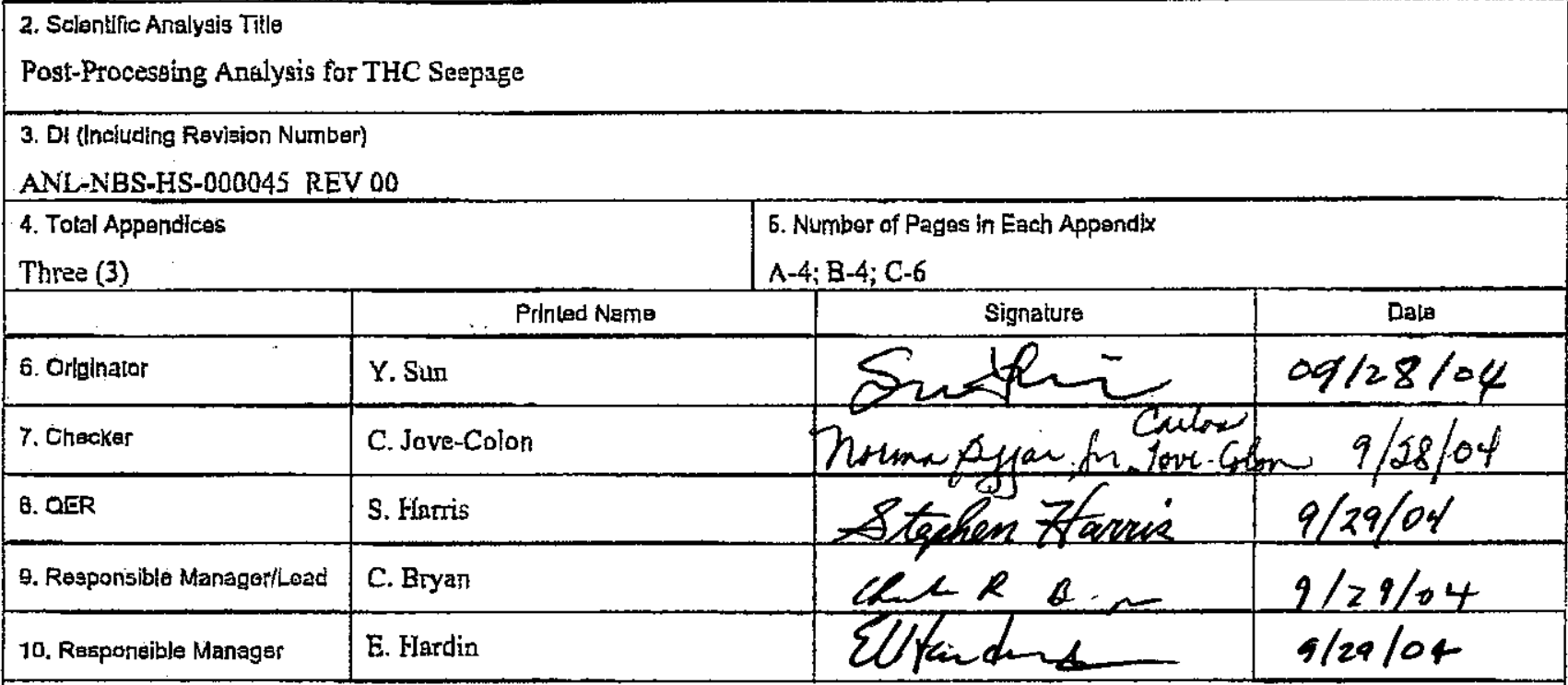

11. Remarks

Devid Shields performed the post-2.14 check.

\section{Change Hlstory}

\begin{tabular}{|l|l|}
\hline 12. Revision No. & \multicolumn{1}{|c|}{ 13. Description of Change atr } \\
\hline REV 00 & $\begin{array}{l}\text { Initial issue. Supersedes MDL-NBS-HS-000018 REV got } \\
\text { changed to reflect that this document was chenged from }\end{array}$ \\
\hline
\end{tabular}




\section{INTENTIONALLY LEFT BLANK}




\section{CONTENTS}

Page

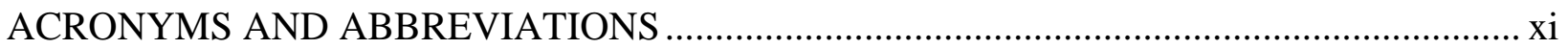

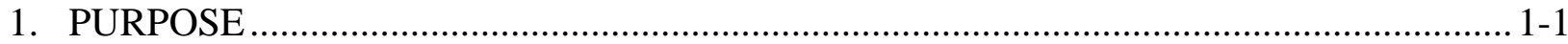

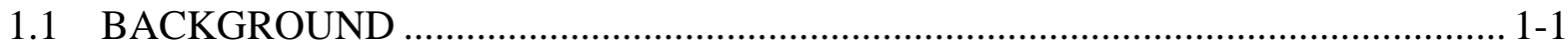

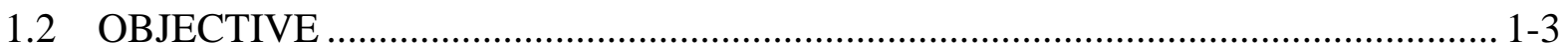

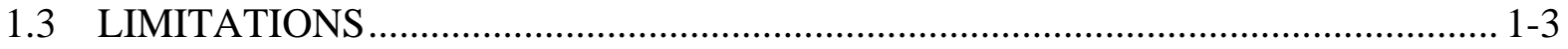

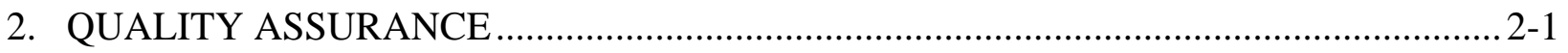

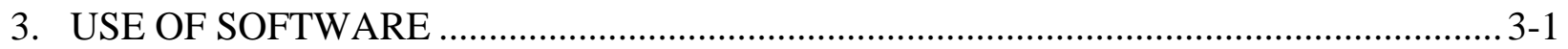

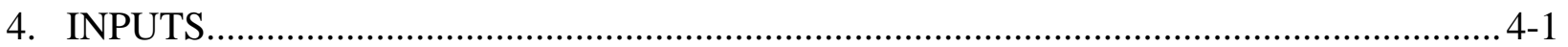

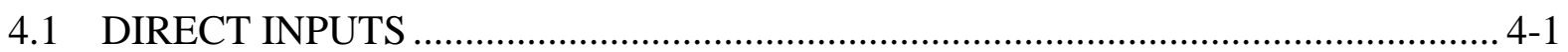

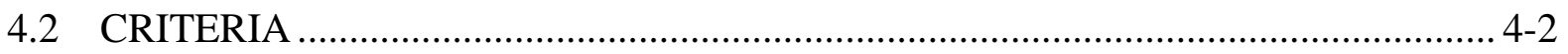

4.3 CODES, STANDARDS, AND REGULATIONS ...................................................... 4-5

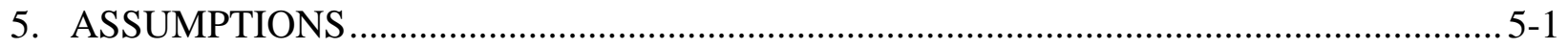

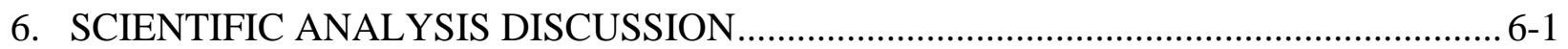

6.1 RELEVANT FEATURES, EVENTS, AND PROCESSES .................................... 6-1

6.2 THC SEEPAGE WATER SELECTION .............................................................. 6-2

6.2.1 Characterization of THC Data .................................................................. 6-2

6.2.1.1 Input Water Compositions............................................................... 6-3

6.2.1.2 Continua (Fractures and Matrix) ……………….............................6-5

6.2.1.3 Cross-Sectional Quadrants (TOP, SIDE, and BASE) ....................... 6-5

6.2.1.4 Saturation Zones (FRONT and HISAT) ………............................ 6-7

6.2.1.5 Time Periods............................................................................. 6-10

6.2.2 Discussion of THC Water Selection .............................................................. 6-11

6.2.3 Selection of Aqueous Species and $\mathrm{CO}_{2}$ Predicted Concentrations .................. 6-12

6.2.3.1 Water Compositions as a Function of Time................................... 6-14

6.2.3.1.1 Zone of Increased Liquid Saturation above the Drift (HISAT-TOP-fracture) ......................................... 6-20

6.2.3.1.2 Boiling/Wetting Front (FRONT Waters)..................... 6-21

6.2.3.2 Water Composition as a Function of Temperature and Liquid Saturation ............................................................................... 6-40

6.2.3.3 Summary of Water Selection for P\&CE ……................................ 6-48

6.2.4 Uncertainties of Aqueous Species and $\mathrm{CO}_{2}$ Predicted Concentrations ........... 6-52

6.3 JUSTIFICATION OF POST-PROCESSING ANALYSIS ..................................... 6-64

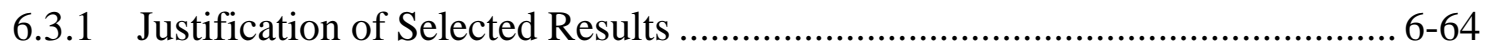

6.3.2 Repository-Wide Applicability of THC Model Results .................................. 6-65 


\section{CONTENTS (Continued)}

\section{Page}

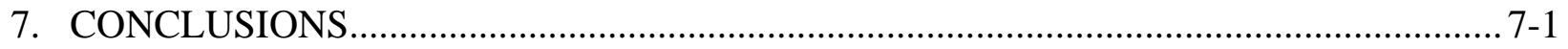

8. INPUTS AND REFERENCES .................................................................................. 8 -1

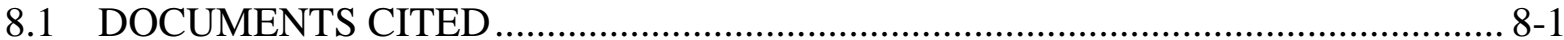

8.2 CODES, STANDARDS, REGULATIONS, AND PROCEDURES ........................... 8-2

8.3 SOURCE DATA, LISTED BY DATA TRACKING NUMBER ………………......... 8-3

8.4 OUTPUT DATA, LISTED BY DATA TRACKING NUMBER ……………............. 8-4

8.5 SOFTWARE CODES ........................................................................................... 8-4

APPENDIX A: LIST OF MODEL INPUT AND OUTPUT FILES ………………………..... A-1

APPENDIX B: SELECTED DATA STATISTICAL CALCULATIONS ..................................

APPENDIX C: INPUT WATER COMPOSITIONS ....................................................... 


\section{FIGURES}

Page

1-1. Relationships between the Post-Processing Analysis for THC Seepage (THC-PPA) and Other Closely Related Models and Their Functions in Providing Seepage Chemistry Information for TSPA-LA.......................................... 1-2

6.2-1. $\quad$ THC Seepage Model Mesh................................................................................. 6-4

6.2-2. Quadrant Designations for Data Selection from the THC Seepage Model ................. 6-6

6.2-3. Conceptual Model for Data Selection of In-Drift Seepage Water Chemistry .............. 6-9

6.2-4. Selection of Model Results around the Modeled Drift as a Function of Time: $\mathrm{pH}$

6.2-5. Selection of Model Results around the Modeled Drift as a Function of Time: Volume Fraction of Carbon Dioxide Gas

6.2-6. Selection of Model Results around the Modeled Drift as a Function of Time: Total Aqueous Carbonate Concentration

6.2-7. Selection of Model Results around the Modeled Drift as a Function of Time:

Total Aqueous Chloride Concentration

6.2-8. Selection of Model Results around the Modeled Drift as a Function of Time: Total Aqueous Nitrate Concentration ....

6.2-9. Selection of Model Results around the Modeled Drift as a Function of Time: Ratio of Total Aqueous Nitrate to Total Aqueous Chloride Concentrations.............. 6-28

6.2-10. Selection of Model Results around the Modeled Drift as a Function of Time: Total Aqueous Sulfate Concentration....

6.2-11. Selection of Model Results around the Modeled Drift as a Function of Time: Ratio of Total Aqueous Sulfate to Total Aqueous Chloride Concentrations.

6.2-12. Selection of Model Results around the Modeled Drift as a Function of Time: Total Aqueous Fluoride Concentration

6.2-13. Selection of Model Results around the Modeled Drift as a Function of Time: Total Aqueous Calcium Concentration....

6.2-14. Selection of Model Results around the Modeled Drift as a Function of Time: Ratio of Total Aqueous Calcium to Total Aqueous Chloride Concentrations

6.2-15. Selection of Model Results around the Modeled Drift as a Function of Time:

Ratio of Total Aqueous Calcium to Total Aqueous Carbonate Concentrations
Selection of Model Results around the Modeled Drift as a Function of Time:

6.2-16. Selection of Model Results around the Modeled Drift as a Function of Time:

6.2-17. Selaction of Model Results around the Modeled Drift as a Function of Time: 6-34 Total Aqueous Sodium Concentration

6.2-17. Selection of Model Results around the Modeled Drift as a Function of Time:

6.2-18. Selection of Model Results around the Modeled Drift as a Function of Time: Ratio of Total Aqueous Sodium to Total Aqueous Chloride Concentrations 6-36

6.2-19. Selection of Model Results around the Modeled Drift as a Function of Time: Total Aqueous Potassium Concentration.

6.2-20. Selection of Model Results around the Modeled Drift as a Function of Time: Total Aqueous Silica Concentration ....

6.2-21. Selection of Model Results around the Modeled Drift as a Function of

Drift-Wall Temperature: $\mathrm{pH}$ 6-39 $6-41$ 


\section{FIGURES (Continued)}

6.2-22. Selection of Model Results around the Modeled Drift as a Function of Drift-Wall Temperature: Volume Fraction of Carbon Dioxide Gas

6.2-23. Selection of Model Results around the Modeled Drift as a Function of Drift-Wall Temperature: Total Aqueous Chloride Concentration.

6.2-24. Selection of Model Results around the Modeled Drift as a Function of Drift-Wall Temperature: Ratio of Total Aqueous Calcium to Total Aqueous Carbonate Concentrations

6.2-25. Selection of Model Results around the Modeled Drift as a Function of Liquid Saturation: $\mathrm{pH}$ $6-45$

6.2-26. Selection of Model Results around the Modeled Drift as a Function of Liquid Saturation: Volume Fraction of Carbon Dioxide Gas.

6.2-27. Selection of Model Results around the Modeled Drift as a Function of Liquid Saturation: Total Aqueous Chloride Concentration.

6.2-28. Selection of Model Results around the Modeled Drift as a Function of Liquid Saturation: Ratio of Total Aqueous Calcium to Total Aqueous Carbonate Concentrations

6.2-29. Location of the Wetting Front in the Host Rock (Relative to Drift Center), as Calculated by the Thermal-Hydrological-Chemical- Seepage Model.

6.2-30. Ca to Cl Ratio in FRONT-TOP-Fracture Waters .... $6-51$

6.2-31. Fracture Saturation Level in FRONT-TOP-Fracture Waters. 6-52

C-1. Piper Plot of Water Compositions (meq/L) from Repository Units .C-3 


\section{TABLES}

Page

3.1. Qualified Software Used in This Report.......................................................... 3-1

4.1-1. Direct Inputs................................................................................................. 4-1

4.2-1. Project Requirements and YMRP Acceptance Criteria Applicable to This

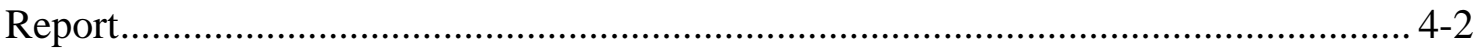

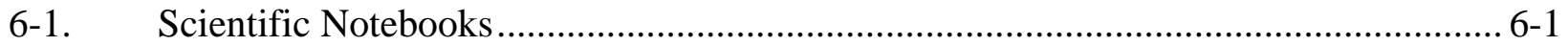

6.1-1. Features, Events, and Processes Addressed in This Report..................................... 6-2

6.2-1. Tptpll THC Model Runs Used for Post-Processing Analysis................................... 6-14

6.2-2. Standard Deviations in Water and Gas Compositions Predicted in Zones of High Liquid Saturation above the Drift Crown (HISAT - TOP, Fractures) ...................... 6-16

6.2-3. Standard Deviations in Water and Gas Compositions Predicted in Zones of High Liquid Saturation above the Drift Crown (FRONT - TOP, Fractures) ..................... 6-18

6.2-3a. Selected subset of THC Model Results for Selected Five Water Compositions

6.2-4. Comparison of Standard Deviations in Water and Gas Compositions Between Group 1 and Group 2 Simulations Predicted in Zones of High Liquid Saturation above the Drift Crown (HISAT - TOP, Fractures)

6.2-5. Comparison of Standard Deviations in Water and Gas Compositions Between Group 1 and Group 2 Simulations Predicted at the Boiling/Wetting Front in Fractures above the Drift Crown (FRONT - TOP, Fractures)

C-1. Input Pore-Water Compositions for the THC Seepage Model 


\section{INTENTIONALLY LEFT BLANK}




\section{ACRONYMS AND ABBREVIATIONS}

DIRS Document Input Reference System

DSCP drift-scale coupled processes

DST Drift-Scale Test

DTN data tracking number

FEPs features, events, and processes

HISAT high saturation zone

LA License Application

MSTHM multiscale thermohydrologic model

P\&CE physical and chemical environment

QA Quality Assurance

SD standard deviation

TDMS Technical Data Management System

$\mathrm{TH}$ thermal-hydrological

THC thermal-hydrological-chemical

THC-PPA Post-Processing Analysis for THC Seepage

Tptpll Topopah Spring Tuff lower lithophysal zone

Tptpmn Topopah Spring Tuff middle nonlithophysal zone

TSPA Total System Performance Assessment

TWP technical work plan

UZ unsaturated zone

YMRP Yucca Mountain Review Plan, Final Report 
INTENTIONALLY LEFT BLANK 


\section{PURPOSE}

\subsection{BACKGROUND}

This report describes the selection of water compositions for the total system performance assessment (TSPA) model of results from the thermal-hydrological-chemical (THC) seepage model documented in Drift-Scale THC Seepage Model (BSC 2004 [DIRS 169856]). The selection has been conducted in accordance with Technical Work Plan for: Near-Field Environment and Transport: Coupled Processes (Mountain-Scale TH/THC/THM, Drift-Scale THC Seepage, and Post-Processing Analysis for THC Seepage) Report Integration (BSC 2004 [DIRS 171334]). This technical work plan (TWP) was prepared in accordance with AP-2.27Q, Planning for Science Activities. Section 1.2.3 of the TWP describes planning information pertaining to the technical scope, content, and management of this report. The post-processing analysis for THC seepage (THC-PPA) documented in this report provides a methodology for evaluating the near-field compositions of water and gas around a typical waste emplacement drift as these relate to the chemistry of seepage, if any, into the drift. The THC-PPA inherits the conceptual basis of the THC seepage model, but is an independently developed process. The relationship between the post-processing analysis and other closely related models, together with their main functions in providing seepage chemistry information for the Total System Performance Assessment for the License Application (TSPA-LA), are illustrated in Figure 1-1. The THC-PPA provides a data selection concept and direct input to the physical and chemical environment (P\&CE) report that supports the TSPA model.

The purpose of the THC-PPA is further discussed in Section 1.2. The data selection methodology of the post-processing analysis (Section 6.2.1) was initially applied to results of the THC seepage model as presented in Drift-Scale THC Seepage Model (BSC 2004 [DIRS 169856]). Other outputs from the THC seepage model (DTN: LB0302DSCPTHCS.002 [DIRS 161976]) used in the P\&CE (BSC 2004 [DIRS 169860], Section 6.6) were also subjected to the same initial selection. The present report serves as a full documentation of this selection and also provides additional analyses in support of the choice of waters selected for further evaluation in Engineered Barrier System: Physical and Chemical Environment (BSC 2004 [DIRS 169860], Section 6.6).

The work scope for the studies presented in this report is described in the TWP (BSC 2004 [DIRS 171334]) and other documents cited above and can be used to estimate water and gas compositions near waste emplacement drifts. Results presented in this report were submitted to the Technical Data Management System (TDMS) under specific data tracking numbers (DTNs) as listed in Appendix A.

The major change from previous selection of results from the THC seepage model is that the THC-PPA now considers data selection in space around the modeled waste emplacement drift, tracking the evolution of pore-water and gas-phase composition at the edge of the dryout zone around the drift. This post-processing analysis provides a scientific background for the selection of potential seepage water compositions. 
- Analyses supporting the selection of waters in the P\&CE model for further abstraction

- Complete assessment of variability

- Guidance for TSPA:

- Variability of water compositions with time, temperature, and saturation.

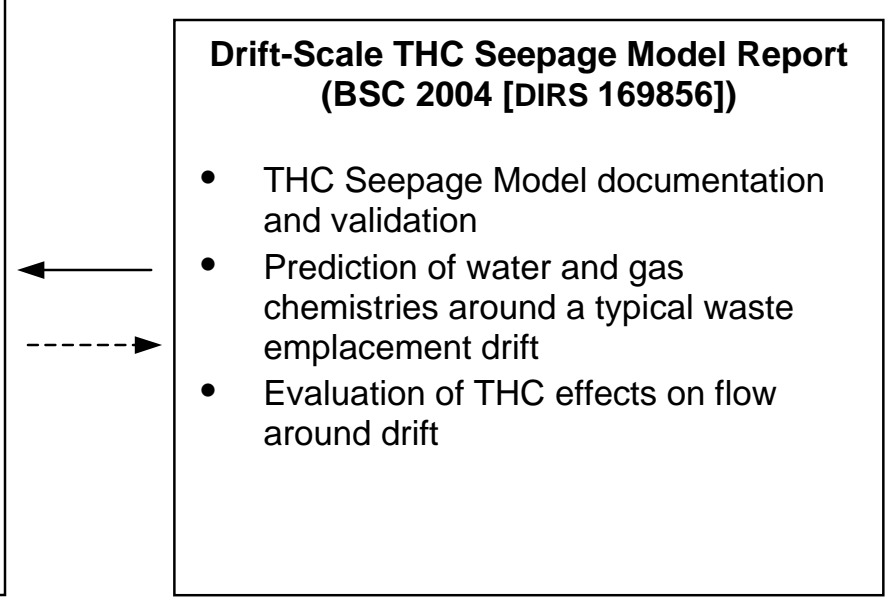

Physical and Chemical Environment Report (BSC 2004 [DIRS 169860])

- Evaluation of a subset of initially abstracted water compositions

- Inclusion of in-drift evaporation and effects of other in-drift interactions

- Direct input to TSPA-LA (lookup tables of seepage water compositions)

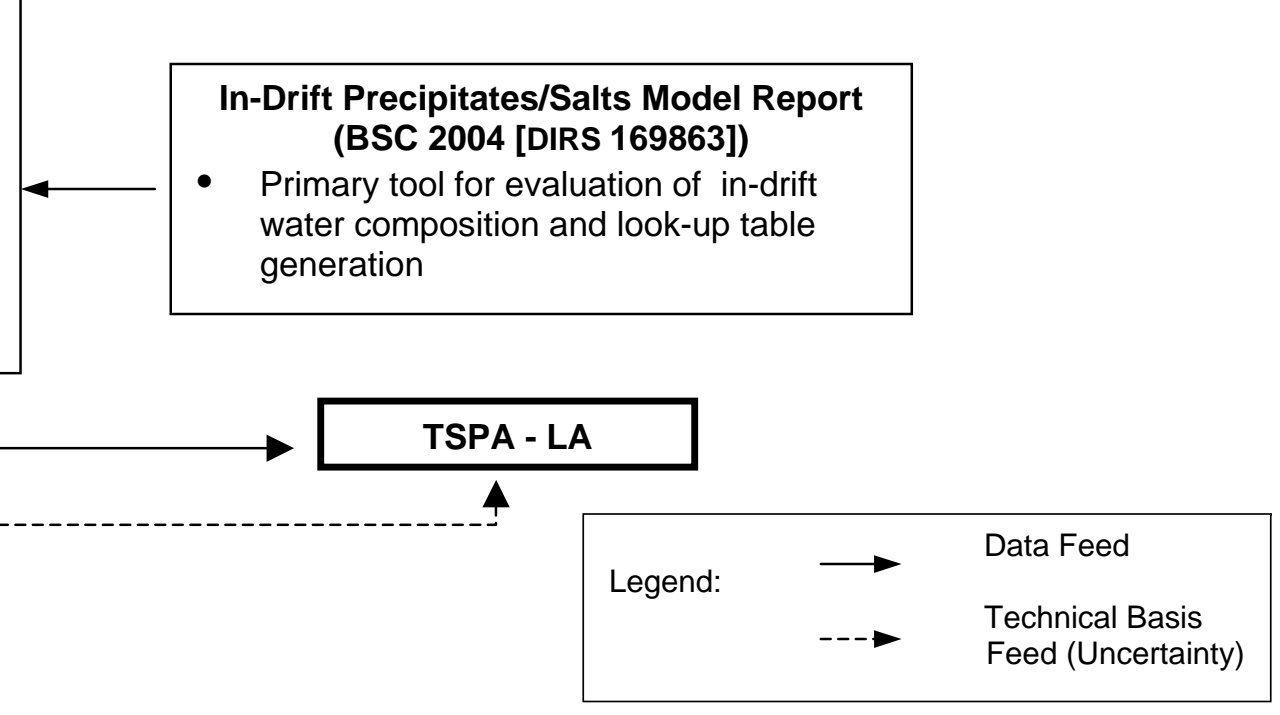

Figure 1-1. Relationships Between the Post-Processing Analysis for THC Seepage (THC-PPA) and Other Closely Related Models and Their Functions in Providing Seepage Chemistry Information for TSPA-LA 


\subsection{OBJECTIVE}

The purpose of the THC-PPA is to provide a methodology for evaluating the near-field host rock water and gas-phase compositions around a typical waste emplacement drift as these relate to the chemistry of seepage, if any, into the drift. This data selection concept inherits the conceptual basis from the drift-scale THC seepage model (BSC 2004 [DIRS 169856]), but it is an independently developed post-processing analysis (Figure 1-1).

The results from the THC-PPA are intended to be used only with the TSPA model, or those models directly feeding TSPA, for the estimation of water and gas compositions in the near-field around potential waste emplacement drifts. It is postulated that water and gases around waste emplacement drifts could enter the drifts at any time. The heating period includes both the preclosure, in which the repository drifts are ventilated, and the postclosure periods.

\subsection{LIMITATIONS}

In the drift-scale THC seepage model (BSC 2004 [DIRS 169856]), no water is predicted to enter emplacement drifts. Therefore, for selection of model results, a rationale must be used and implemented in a set of criteria to determine which results best represent potential seepage water into drifts (Section 6.2.1). Using no-seepage model to represent the potential seepage water compositions is the only limitation for the THC result selection. Drift-Scale THC Seepage Model (BSC 2004 [DIRS 169856], Sections 1.3 and 6.6) includes the discussion of additional model limitations and uncertainties. In addition to AP-SV.1Q, electronic management of information is also controlled under YMP-LBNL-QIP-SV.0 [DIRS 171082], Management of YMP-LBNL Electronic Data, which is not included in the TWP. Because YMP-LBNL-QIPSV.0 [DIRS 171082] is consistent with AP-SV.1Q, the deviation from the TWP for using YMPLBNL-QIP-SV.0 can be justified. 


\section{INTENTIONALLY LEFT BLANK}




\section{QUALITY ASSURANCE}

Development of this report and the post-processing activities are subject to the Office of Civilian Radioactive Waste Management quality assurance (QA) program as indicated in Technical Work Plan for: Near-Field Environment and Transport: Coupled Processes (Mountain-Scale TH/THC/THM, Drift-Scale THC Seepage, and Post-Processing Analysis for THC Seepage) Report Integration (BSC 2004 [DIRS 171334], Section 8). Approved QA procedures identified in the Section 4 of the TWP (BSC 2004 [DIRS 171334]) have been used to conduct and document the activities described in this report. Accordingly, this document has been prepared in accordance with AP-SIII.9Q, Scientific Analysis, and reviewed in accordance with AP-2.14Q, Document Review. The TWP also identifies the methods used to control the electronic management of data (BSC 2004 [DIRS 171334], Section 8.4) during post-processing and documentation activities. Electronic management of information was evaluated in accordance with AP-SV.1Q, Control of the Electronic Management of Information, as planned in the TWP (BSC 2004 [DIRS 171334], Section 8.4). In addition to AP-SV.1Q, data are also controlled under YMP-LBNL-QIP-SV.0 [DIRS 171082], Management of YMP-LBNL Electronic Data. Because YMP-LBNL-QIP-SV.0 [DIRS 171082] is consistent with AP-SV.1Q, the deviation from the TWP for using YMP-LBNL-QIP-SV.0 can be justified. All input data are identified and tracked in accordance with AP-3.15Q, Managing Technical Product Inputs.

This report provides analyses of data selection from drift-scale THC coupled processes in the unsaturated zone rocks surrounding the repository. These rocks are a natural barrier and are classified in the Q-List (BSC 2004 [DIRS 168361]) as "Safety Category" because they are important to waste isolation, as defined in AP-2.22Q, Classification Analyses and Maintenance of the Q-List. The results of this report are important to the demonstration of compliance with the postclosure performance objectives prescribed in 10 CFR Part 63 [DIRS 156605; DIRS 156671]. The report contributes to the analysis and modeling data used to support postclosure performance assessment; the conclusions do not directly impact engineered features important to preclosure safety, as defined in AP-2.22Q. 


\section{INTENTIONALLY LEFT BLANK}




\section{USE OF SOFTWARE}

Qualified software is used in this study (Table 3.1). This software package was baselined in accordance with AP-SI.1Q, Software Management, is appropriate for the intended use, has been used strictly within the range of validation, and was obtained from Software Configuration Management. The computer software was run on computers located in Lawrence Berkeley National Laboratory. Because those physical and chemical processes in the software have been qualified and validated for this use, it is the only software appropriate for the tasks indicated in the TWP (Table 8).

Microsoft Excel was used for the THC-PPA (Sections 6.2.1 and 6.2.3) (Excel 97). This report also uses the standard functions of Microsoft Excel (Section 6.2.1), which is exempt from qualification requirement in accordance with LP-SI.11Q-BSC (the new version of Software Management). The post-processing analysis was conducted in Windows NT 4.0 operating system. CUTCHEM only extracts data from THC seepage model results, which include pairs of entries (fracture/matrix) for each element. The extraction is limited to 30 variables, 20 elements, 30 data points for each saturation zone.

Table 3.1. Qualified Software Used in This Report

\begin{tabular}{|l|l|l|c|l|l|}
\hline \multirow{2}{*}{$\begin{array}{c}\text { Software Name } \\
\text { and Version }\end{array}$} & $\begin{array}{c}\text { Software } \\
\text { Tracking } \\
\text { Number) }\end{array}$ & Platform & Computer Used to Run Software & \multirow{2}{*}{ Range of Use } & $\begin{array}{c}\text { DIRS Reference } \\
\text { Number }\end{array}$ \\
\cline { 3 - 5 } CUTCHEM V1.0 & $10898-1.0-00$ & PC & Windows NT 4.0 & $\begin{array}{l}\text { Only for use with } \\
\text { TOUGHEACT } \\
\text { output files. Limit of } \\
\text { 30 extracted points } \\
\text { per general location } \\
\text { per point in time. }\end{array}$ & [DIRS 161127] \\
\hline
\end{tabular}




\section{INTENTIONALLY LEFT BLANK}




\section{INPUTS}

\subsection{DIRECT INPUTS}

This section summarizes direct inputs to the THC-PPA.

The inputs to the THC-PPA are output files from the THC seepage model described in Section 6.5 of Drift-Scale THC Seepage Model (BSC 2004 [DIRS 169856]). These inputs and descriptions are summarized in Table 4.1-1. It is re-emphasized that the THC-PPA consists of selecting model results. Therefore, the inputs are limited to the results of the corresponding process-level model (in this case, the THC seepage model).

Table 4.1-1. Direct Inputs

\begin{tabular}{|c|c|}
\hline DTN & Description of Input Parameters \\
\hline DTN: MO0407SEPFEPLA.000 [DIRS 170760] & FEPs discussed are listed in Table 6.1-1 \\
\hline DTN: LB0302DSCPTHCS.002 [DIRS 161976] & $\begin{array}{l}\text { Simulations referred to as "Group 1" in this report (Section } \\
6.2 .4 \text { ). }\end{array}$ \\
\hline $\begin{array}{l}\text { The following files were used: } \\
\text { thc6_w0_r.xls } \\
\text { thc6_w4_r.xls } \\
\text { thc6_w5_r.xls } \\
\text { thc6_w6_r.xls } \\
\text { thc6_w7_r.xls }\end{array}$ & $\begin{array}{l}\text { Modeled concentrations of aqueous species and } \mathrm{CO}_{2} \text { (gas), } \\
\text { temperature, and liquid saturation at various locations around } \\
\text { the emplacement drift (non-zero liquid saturation areas only). } \\
\text { These are results of THC seepage model simulations using } \\
\text { five different input water compositions (W0, W4, W5, W6, and } \\
\text { W7; see Appendix C). }\end{array}$ \\
\hline $\begin{array}{l}\text { thc6_w0_drift_r.xls } \\
\text { thc6_w4_drift_r.xls } \\
\text { thc6_w5_drift_r.xls } \\
\text { thc6_w6_drift_r.xls } \\
\text { thc6_w7_drift_r.xls }\end{array}$ & $\begin{array}{l}\text { Drift crown and base temperatures (at drift wall), and waste } \\
\text { package temperature for the same simulations as above. }\end{array}$ \\
\hline DTN: LB0307DSTTHCR2.002 [DIRS 165541] & $\begin{array}{l}\text { Simulations referred to as "Group 2" in this report (Section } \\
6.2 .4 \text { ). }\end{array}$ \\
\hline $\begin{array}{l}\text { The following files were used: } \\
\text { thc25_w0 } \\
\text { thc6_w0e3 } \\
\text { thc6_w0a } \\
\text { thc6_w0b }\end{array}$ & $\begin{array}{l}\text { Modeled concentrations of aqueous species and } \mathrm{CO}_{2} \text { (gas), } \\
\text { temperature, and liquid saturation at various locations around } \\
\text { the emplacement drift (non-zero liquid saturation areas only). } \\
\text { These are results of sensitivity studies using the THC } \\
\text { seepage model and one input water composition (WO; see } \\
\text { Appendix C). }\end{array}$ \\
\hline $\begin{array}{l}\text { thc25_w0_drift } \\
\text { thc6_w0e3_drift } \\
\text { c6_w0a_drift } \\
\text { thc6_w0b_drift }\end{array}$ & $\begin{array}{l}\text { Drift crown and base temperatures (at drift wall), and waste } \\
\text { package temperature for the same simulations as above. }\end{array}$ \\
\hline
\end{tabular}




\subsection{CRITERIA}

Technical requirements to be satisfied by TSPA are based on 10 CFR Part 63 [DIRS 156605]. These technical requirements are also identified in the Yucca Mountain Project Requirements Document (Canori and Leitner 2003 [DIRS 166275], Section 3). The acceptance criteria that will be used by the Nuclear Regulatory Commission to determine whether the technical requirements have been met are identified in the Yucca Mountain Review Plan, Final Report (YMRP) (NRC 2003 [DIRS 163274]). The pertinent requirements and acceptance criteria for this report are summarized in Table 4.2-1.

Table 4.2-1. Project Requirements and YMRP Acceptance Criteria Applicable to This Report

\begin{tabular}{|c|l|l|l|}
\hline $\begin{array}{c}\text { Requirement } \\
\text { Number }\end{array}$ & \multicolumn{1}{|c|}{ Requirement Title } & $\begin{array}{c}\text { 10 CFR Part 63 } \\
\text { Link }\end{array}$ & \multicolumn{1}{c|}{ YMRP Acceptance Criteria } \\
\hline PRD-002/T-015 $^{\mathrm{a}}$ & $\begin{array}{l}\text { Requirements for } \\
\text { Performance Assessment }^{\mathrm{a}}\end{array}$ & $\begin{array}{l}\text { 10 CFR Part } \\
\text { 63.114 [DIRS } \\
156605]\end{array}$ & $\begin{array}{l}\text { Acceptance Criteria 1 to } 5 \text { for Quantity and } \\
\text { Chemistry of Water Contacting Engineered } \\
\text { Barriers and Waste Forms }\end{array}$ \\
\hline
\end{tabular}

${ }^{a}$ From Canori and Leitner 2003 [DIRS 166275], Section 3.

b From NRC 2003 [DIRS 163274], Section 2.2.1.3.3.3.

The acceptance criteria identified in Sections 2.2.1.3.3.3 of the YMRP (NRC 2003 [DIRS 163274]) are given below, followed by pointers to sections in the upstream report describing the process model (BSC 2004 [DIRS 169856]) and the present report where these are addressed:

- Acceptance Criterion 1, System Description and Model Integration Are Adequate:

The applicable subcriteria are:

Subcriterion 1. The TSPA adequately incorporates important design features, physical phenomena and couplings, and uses consistent and appropriate assumptions throughout the quantity and chemistry of water contacting engineered barriers and the waste-form abstraction process. This subcriterion is addressed in Section 6.2.1 of this report.

Subcriterion 2. The abstraction of the quantity and chemistry of water contacting engineered barriers and waste forms uses assumptions, technical bases, data, and models that are appropriate and consistent with other related U.S. Department of Energy abstractions. Sections 5 and 6.2.1 of this report address this subcriterion regarding water chemistry.

Subcriterion 4. Spatial and temporal abstractions appropriately address physical couplings (thermal-hydrological-mechanical-chemical). Section 6.2.1 of this report addresses this subcriterion.

Subcriterion 5. Sufficient technical bases and justification are provided for TSPA assumptions and approximations for modeling coupled thermal-hydrological-mechanicalchemical effects on seepage and flow, the waste package chemical environment, and the chemical environment for radionuclide release. The effects of distribution of flow on the amount of water contacting the engineered barriers and waste forms are consistently 
addressed in all relevant abstractions. Water and gas compositions of possible seepage waters are presented in Section 6.2.

Subcriterion 8. Adequate technical bases are provided, including activities such as independent modeling, laboratory or field data, or sensitivity studies for inclusion of any thermal-hydrological-mechanical-chemical couplings and features, events, and processes (FEPs). FEPs are addressed in Section 6.1 of this report, technical bases in Section 6.2.1, and modeling and sensitivity studies in Section 6.2.4.

Subcriteria 3, 6, 7, 9, 10, 11, and 12 are not addressed by this report because design features (subcriteria 3, 7, and 11), expected range of environmental conditions (subcriterion 6), performance-affecting processes, (subcriterion 9), and container corrosion (subcriterion 10) are not included in the technical work plan.

- Acceptance Criterion 2, Data Are Sufficient for Model Justification:

The applicable subcriteria are:

Subcriterion 1. Geological, hydrological, and geochemical values used in the safety case are adequately justified, and that adequate descriptions of how data were used, interpreted, and appropriately synthesized into the parameters are provided. This subcriterion is addressed in Sections 4.1, 6.2, 6.3, and 6.4).

Subcriterion 2. Sufficient data were collected on the characteristics of the natural system and engineered materials to establish initial and boundary conditions for conceptual models of thermal-hydrological-chemical coupled processes that affect seepage, flow, and the waste package chemical environment. The process model report addresses this subcriterion by considering variations in pore-water compositions (Sections 6.2.3 and 6.2.4).

Subcriteria 3, 4, and 5 are not applicable because the model validation, formulation of conceptual approaches for water contact with the drip shield, engineering barriers (subcriterion 4), and waste forms, and the potential of microbial activities (subcriterion 5) are not included in the technical work plan.

- Acceptance Criterion 3, Data Uncertainty Is Characterized and Propagated Through the Model Abstraction:

The applicable subcriteria are:

Subcriterion 1. Models use parameter values, assumed ranges, probability distributions, and/or bounding assumptions that are technically defensible and reasonably account for uncertainties and variabilities. This subcriterion is partly addressed in Section 6.2.4 of this report.

Subcriterion 2. Parameter values, assumed ranges, probability distributions, and bounding assumptions used in the calculations of quantity and chemistry of water contacting engineered barriers and waste forms are technically defensible and reasonable, 
based on data from the Yucca Mountain region (i.e., DST), and a combination of techniques that include laboratory experiments, field measurements, and process-level modeling studies. This subcriterion is partly addressed in Section 6.2.4 of this report.

Subcriterion 4. Adequate representation of uncertainties in the characteristics of the natural system and engineered materials is provided in parameter development for conceptual models, process-level models, and alternative conceptual models. The Department of Energy may constrain these uncertainties using sensitivity analyses or conservative limits. This subcriterion is addressed in this report by evaluation of the spread of model results (Section 6.2.4).

Subcriteria 3 and 5 are not applicable. This subcriterion requires that U.S. Department of Energy use an appropriate range of input parameters for calculating the effective neutron multiplication factor if criticality is included in the total system performance assessment. This issue is not covered in this report.

- Acceptance Criterion 4, Model Uncertainty Is Characterized and Propagated Through the Model Abstraction:

The applicable subcriteria are:

Subcriterion 1. Alternative modeling approaches of FEPs consistent with available data and current scientific understanding are investigated. Results and limitations are appropriately considered in the abstraction. This subcriterion is addressed by reviewing FEPs (Section 6.1), considering alternative conceptual models (Section 6.3), and evaluating model limitations and uncertainty (Section 6.2.4).

Subcriterion 3. Consideration of conceptual model uncertainty is consistent with available site characterization data, laboratory experiments, field measurements, natural analogue information and process-level modeling studies; and the treatment of conceptual model uncertainty does not result in an under-representation of the risk estimate. This subcriterion is addressed in Section 6.2.4 of this report by considering ranges of key input parameters.

Subcriterion 4. Adequate consideration is given to effects of thermal-hydrologicalmechanical-chemical coupled processes in the assessment of alternative conceptual models. These effects may include: (1) thermal-hydrological effects on gas, water, and mineral chemistry; (2) effects of microbial processes on the waste package chemical environment for radionuclide release; (3) changes in water chemistry that may result from the release of corrosion products from the waste package and interactions between engineered materials and groundwater; and (4) changes in boundary conditions (e.g., drift shape and size) and hydrological properties, relating to the response of the geomechanical system to thermal loading. This subcriterion is addressed in Section of 6.2.3 of this report.

Subcriteria 2 and 5 are not applicable. Neither continuum model is used for the total system performance assessment abstraction nor the effect of coupled thermal-hydrologic- 
mechanical-chemical processes on calculated compliance with the postclosure public health and environmental standards is included in this report.

- Acceptance Criterion 5, Model Abstraction Output Is Supported by Objective Comparisons:

The applicable subcriteria are:

Subcriterion 1. Models implemented in this TSPA abstraction provide results consistent with output from detailed process-level models and/or empirical observations (laboratory and field testing and/or natural analogues). This subcriterion is addressed in Sections 6.2.4 and 7.

Subcriterion 2. Abstracted models for coupled thermal-hydrological-chemical effects on seepage and flow and the waste package chemical environment are based on the same assumptions and approximations demonstrated to be appropriate for process-level models. Abstractions of processes, such as thermo-chemically induced changes in hydrological properties, must be adequately justified by comparison to results of process-level modeling that are consistent with direct observations and field studies. This subcriterion is addressed in Sections 6.2.4 and 7.

Subcriterion 3. Accepted and well-documented procedures be used to construct and test the numerical models that simulate coupled thermal-hydrological-chemical effects on seepage and flow and waste package chemical environment. Analytical and numerical models must be appropriately supported, and abstracted model results must be compared with different mathematical models, to judge the robustness of results. This subcriterion is addressed in Section 6.2.4 of the present report.

Level of accuracy, precision, and representativeness of results are addressed in this report. This post-processing analysis report represents the selected information from the drift-scale THC seepage model (BSC 2004 [DIRS 169856]) without mathematical manipulation. The accuracy and precision are discussed in Section 6.3. The representativeness of THC seepage results is addressed in Section 6.2.1. Uncertainties associated with this post-processing analysis are in Section 6.2 .4 of this report.

\subsection{CODES, STANDARDS, AND REGULATIONS}

No specific formally established standards have been identified as applying to this post-processing activity. 


\section{INTENTIONALLY LEFT BLANK}




\section{ASSUMPTIONS}

Assumptions are used as statements or propositions that are taken to be true or representative in the absence of direct confirming data or evidence. In this report there are no such assumptions. Approximations and simplifications relating to the methodologies developed in this report are presented in Section 6.2.1. In addition, assumptions, approximations, and simplifications relating to the development and implementation of the process model applied to simulate drift-scale coupled processes are documented in Drift-Scale THC Seepage Model (BSC 2004 [DIRS 169856], Sections 5 and 6.4.6). 


\section{INTENTIONALLY LEFT BLANK}




\section{SCIENTIFIC ANALYSIS DISCUSSION}

This section presents the conceptual processes implemented in this study, and their results. Relevant FEPs are discussed in Section 6.1. Section 6.2 discusses the data selection and results from the THC seepage model. Although model validation is not required in the TWP (BSC 2004 [DIRS 171334]) for this report, Section 6.3 provides the confidence-building information on the selected data. The data and results are documented in the scientific notebooks (SNs) listed in Table 6-1. The intended use of output data from this report, as discussed in Section 1.1, is to support the physical and chemical environment report (BSC 2004 [DIRS 169860]), which directly feeds TSPA. Applicable acceptance criteria from the YMRP (NRC 2003 [DIRS 163274]) are discussed in Section 4.2, with pointers referring to sections addressing these criteria here and in the upstream reports documenting the process model (BSC 2004 [DIRS 169856]).

Output data from analyses presented in this section were submitted to the TDMS under DTNs as shown in Appendix A (and in tables and figures as appropriate).

Table 6-1. Scientific Notebooks

\begin{tabular}{|l|l|l|l|}
\hline LBNL Scientific Notebook ID & \multicolumn{1}{|c|}{$\begin{array}{c}\text { CRWMS M\&O Scientific } \\
\text { Notebook ID }\end{array}$} & \multicolumn{1}{c|}{ Relevant Pages } & \multicolumn{1}{c|}{ Citation } \\
\hline YMP-LBNL-YWT-JA-1A & SN-LBNL-SCI-005-V1 & 249 to 285 & $\begin{array}{l}\text { Wang 2003 [DIRS } \\
165562]\end{array}$ \\
\hline YMP-LBNL-DSM-ELS-1 & SN-LBNL-SCl-142-V2 & 124,126 to 129 & $\begin{array}{l}\text { Wang 2003 [DIRS } \\
165562]\end{array}$ \\
\hline YMP-LBNL-DSM-NS-2 & SN-LBNL-SCl-141-V2 & 151 to 153, 200 to 219 & $\begin{array}{l}\text { Wang 2003 [DIRS } \\
165562]\end{array}$ \\
\hline
\end{tabular}

LBNL = Lawrence Berkeley National Laboratory; CRWMS = Civilian Radioactive Waste Management System; $\mathrm{M} \& \mathrm{O}=$ Management and Operating Contractor.

\subsection{RELEVANT FEATURES, EVENTS, AND PROCESSES}

Table 6.1-1 presents a listing of relevant FEPs taken from the LA FEP List (DTN: MO0407SEPFEPLA.000 [DIRS 170760]).

The results of the drift-scale THC seepage model (BSC 2004 [DIRS 169856]) and analyses presented in the present report are part of the basis for the treatment of FEPs as discussed in Total System Performance Assessment License Application Methods and Approach (BSC 2002 [DIRS 166296], Section 3.2.2). The results of the present report, of the upstream process model (BSC 2004 [DIRS 169856]), and other relevant model reports are used to fully document the technical basis for the include/exclude status of these FEPs for TSPA-LA. The included FEPs listed in Table 6.1-1 are addressed in this report in accordance with Section 2.1.5 of the TWP (BSC 2004 [DIRS 171334]). 
Table 6.1-1. Included Features, Events, and Processes Addressed in This Report

\begin{tabular}{|l|l|l|}
\hline LA FEP Number & \multicolumn{1}{|c|}{ FEP Name } & \multicolumn{1}{|c|}{ Sections Discussing FEPs-Related Items } \\
\hline 2.2.07.10.0A & Condensation zone forms around drifts & Sections 6.2, 6.2.1. \\
\hline 2.2.07.11.0A & Resaturation of geosphere dryout zone & Sections 6.2.1.4, 6.2.2, 6.2.3. \\
\hline 2.2.08.04.0A & $\begin{array}{l}\text { Redissolution of precipitates directs } \\
\text { more corrosive fluids to containers }\end{array}$ & Sections 6.2.1, 6.2.2, 6.2.3. \\
\hline 2.2.08.12.0A & Chemistry of water flowing into the drift & Section 6.2 Section 6.2.1, Figures 6.2-4 to 6.2-31 \\
\hline
\end{tabular}

The coupled processes of vapor condensation forming a condensation cap above the drifts and occurrence of "shedding" between drifts are explicitly simulated in the drift-scale THC seepage model (BSC 2004 [DIRS 169856], Sections 6.2.1.1 and 6.5.5.3; BSC 2004 [DIRS 169131]) and in the TH seepage model (BSC 2004 [DIRS 170338]). Using this model, the impact of condensation and drainage on seepage water chemistry is assessed for various simulation cases (BSC 2004 [DIRS 169856], Section 6.5) (also see Section 6.2). Therefore, the results from the THC seepage model and their selection for use in TSPA (Section 6.2 of this report; summary tables of concentrations through time submitted under DTNs LB0302DSCPTHCS.002 [DIRS 161976], and LB0307DSTTHCR2.002 [DIRS 165541], and tables of concentrations and summary statistics through time submitted under DTN: LB0311ABSTHCR2.001 [DIRS 166714]) explicitly include these effects. Resaturation of the dryout zone around drifts, and the potential of condensate back to the drifts with precipitation and dissolution of solutes, are explicitly simulated with the drift-scale THC seepage model (BSC 2004 [DIRS 169856], Sections 6.2.1.1, 6.5.5.1 to 6.5.5.3). The impact of resaturation on reflux chemistry is included as part of the selection methodology (i.e., the compositions of selected "FRONT" waters represent concentration increases due to the dissolution of salts precipitated during dryout; see Section 6.2.3).

\subsection{THC SEEPAGE WATER SELECTION}

\subsubsection{Characterization of THC Data}

The conceptualization of drift-scale coupled processes underlying the THC seepage model is presented in Drift-Scale THC Seepage Model (BSC 2004 [DIRS 169856], Section 6.2). Multi-dimensional output data are available for various input water compositions, infiltration scenarios, vapor pressure lowering options, and $\mathrm{CO}_{2}$ diffusion coefficients. In order to extract the data appropriately from THC model results, the conceptualization and principles of the data selection are examined. The intention of the THC seepage model is to represent the effect of THC processes in the rock around waste emplacement drifts (BSC 2004 [DIRS 169856]), including:

- Composition of waters and gases that could enter the drifts

- The effect of THC processes on seepage into drifts.

However, the THC seepage model does not simulate actual seepage of water into drifts because the range of simulated infiltration rates (including rates for future climate conditions of high infiltration) remains well below the theoretical seepage threshold for rocks around the drift 
(e.g., BSC 2004 [DIRS 170338], Section 6.2.2.1.2). Instead, the model is used to compute the compositions of pore water and gas in the repository host-rock (matrix and fractures) around a typical drift (Figure 6.2-1). Predicted compositions for seepage and the associated gas-phase compositions are obtained from locations (around the modeled drift) from which it is possible that fluids could seep into the drift. Water and gas compositions predicted at the drift wall are also considered, although, as discussed in Section 6.2.1.1, water composition data at the drift wall are not available during the time that the drift wall remains dry.

Predicted concentration gradients near the drift are steep, resulting from sharp temperature and liquid saturation gradients. Therefore, selected water compositions depend strongly on the location (around the drift) chosen for selection. Because of the transient nature of the thermal pulse, predicted water compositions also change significantly through time. Therefore, selection of THC model results is based on selection over space (cross-sectional quadrants), time, input water composition, fracture and matrix continua, and saturation zones as further examined below.

CUTCHEM V1.0 (CUTCHEM V1.0, STN: 10898-1.0-00 [DIRS 161127]) is selected and used for selecting data from THC results because it is the only available software for selecting THC model results. There are no alternate approaches and technical methods available for the intended use. CUTCHEM was specially developed for the intended purpose of post-processing THC model results. Using CUTCHEM, data are extracted from THC model results for input waters, fractures and matrix, sectional-quadrants, saturation zones, and time periods within a radial distance of $25 \mathrm{~m}$ from drift centerline. Supporting data include the following modeled information around the drift from the drift-scale THC seepage model (BSC 2004 [DIRS 169856], DTNs: LB0302DSCPTHCS.002 [DIRS 161976]; LB0307DSTTHCR2.002 [DIRS 165541]):

- Concentrations of aqueous species and $\mathrm{CO}_{2}$ (gas)

- Temperature

- Liquid saturation.

\subsubsection{Input Water Compositions}

The THC seepage model consists of a two-dimensional, half-drift (symmetric) chimney model extending vertically from near the ground surface down to the water table, and horizontally from drift center to the midpoint between drifts (BSC 2004 [DIRS 169856], Section 6.5.1) (Figure 6.2-1). The most recent revision of this model (BSC 2004 [DIRS 169856], Section 6.5.1) considers a geographic location near the center of the repository block (at approximately Nevada State Plane coordinates E170572, N233195), with a drift located in the Tptpll hydrogeologic unit. This location pertains to all model results discussed in this report, although the results are applicable to other locations. The single chimney model at these coordinates is developed with various input water compositions to represent uncertainty and variability. 


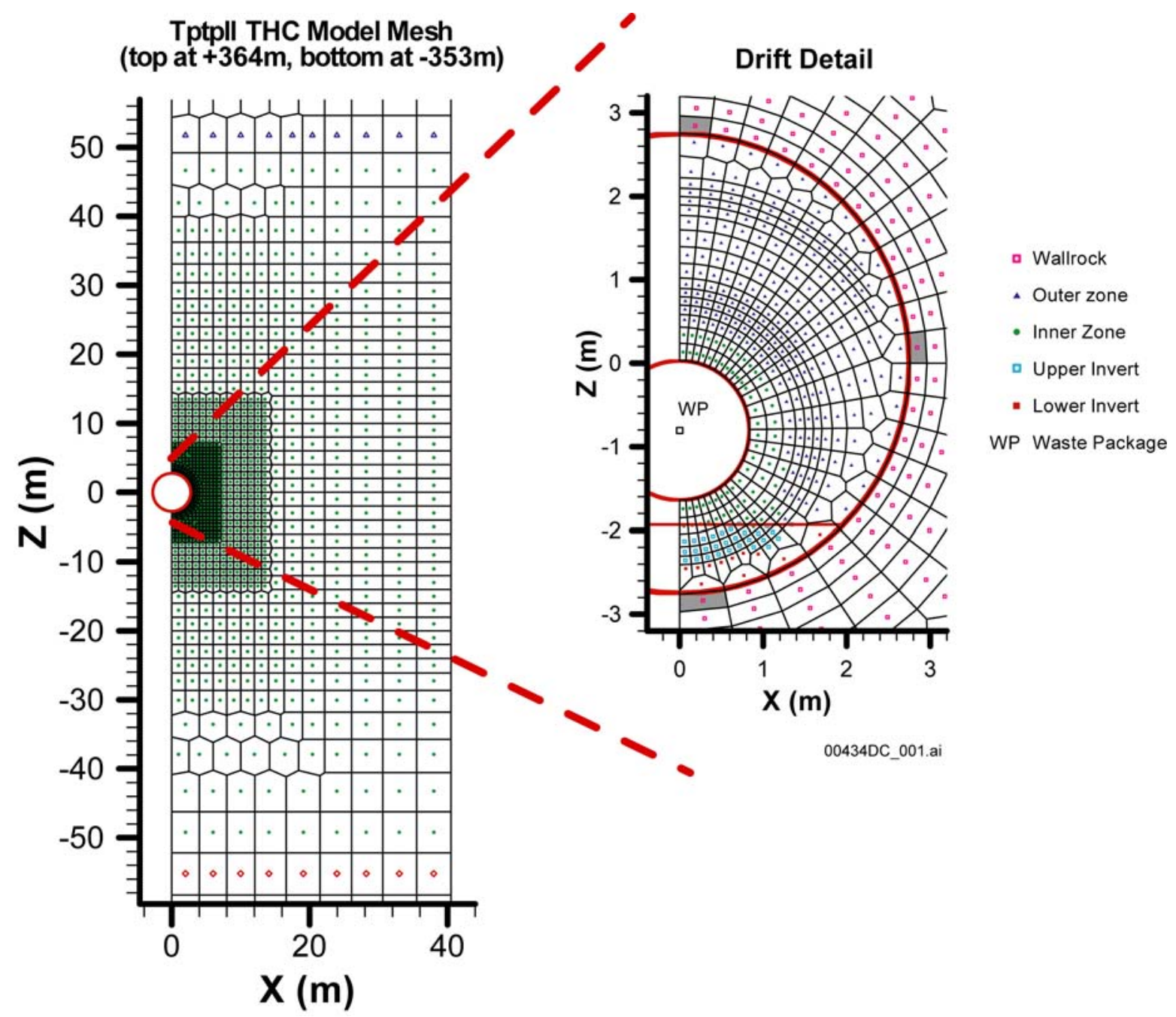

Grid source DTN: LB0011DSTTHCR1.002 [DIRS 161282].

NOTE: Shaded gridblocks around the drift are those previously selected for data selection at the drift wall.

Figure 6.2-1. THC Seepage Model Mesh

Simulations considering a significantly different location (using the stratigraphy at the location of borehole SD-9) and a drift in the Tptpmn hydrogeologic unit were run in a previous revision of the model. This alternative conceptualization is documented in Drift-Scale THC Seepage Model (BSC 2004 [DIRS 169856], Section 6.3) and indicates that, in terms of predicted water and gas compositions, differences in model results caused by changes in geographic location and repository host rock unit are not as significant as differences resulting from the variability in input water compositions and spatial location around the modeled drift (BSC 2004 [DIRS 169856], Section 6.5.5). This variability could be reasonably regarded as encompassing a range of potential geographic locations, implicitly representing changes in stratigraphy, rock properties, and infiltration rates throughout the repository. For these reasons, results of the THC seepage model as examined here are for one geographic location but include the variability and uncertainty represented by using different water compositions and locations around the modeled drift, and are deemed to be applicable to other locations within the proposed repository footprint 
(BSC 2004 [DIRS 169856], Section 6.5.1). Those input water compositions are defined as shown in Appendix C as W0, W4, W5, W6, and W7 (see DTN: GS020808312272.004 [DIRS 166569]).

\subsubsection{Continua (Fractures and Matrix)}

Whether to use predicted concentrations from the fracture or matrix continuum is also part of the water composition selection. The permeability of fractures around the drift is several orders of magnitude higher than the permeability of the matrix. Also, fractures have much lower capillarity than the matrix. Therefore, any water potentially seeping into the drift by gravity is likely to be fracture water, and the composition of that water is used for all areas above the drift. In contrast, matrix water enters the drift opening by imbibition, where the drift invert contacts wallrock. For this reason both fracture and matrix waters are examined in areas below the drift.

\subsubsection{Cross-Sectional Quadrants (TOP, SIDE, and BASE)}

Previous selection of water compositions from this model (CRWMS M\&O 2000 [DIRS 123916]) considered single points (model gridblocks) each at the crown, side, and base of the drift. However, points at these three locations provide only limited information on the chemistry of waters that could seep into drifts. These locations did not capture the spatial variability of model results around the drift and, more importantly, did not provide water compositions during the dryout period. In this report, a new selection concept is defined such that results are extracted for three subzones around the drift (crown, side, and base of the drift) and also following the expanding-and-receding boiling (wetting) front, as described below.

The cross-sectional area around the drift is divided into four quadrants. Since only a half-drift (symmetry model) is modeled, three quadrants, corresponding to the crown, side, and base of the drift, are addressed with the following spatial characteristics and assigned attributes (Figure 6.2-2):

- TOP Quadrant: The first quadrant encompassing the area above the drift, defined by model gridblocks having a ratio of their vertical $(\mathrm{Z})$ to their horizontal $(\mathrm{X})$ coordinate greater or equal to 1 ( $45^{\circ}$ arc from crown).

- SIDE Quadrant: The second quadrant encompassing the area to the side of the drift, defined by model grid blocks having their $\mathrm{Z} / \mathrm{X}$ ratio ranging from -1 to $+1\left(45^{\circ} \mathrm{arc}\right.$ above and $45^{\circ}$ below the drift spring line).

- BASE Quadrant: The third quadrant encompassing the area below the drift, defined by model gridblocks having their $\mathrm{Z} / \mathrm{X}$ ratio less than -1 ( $45^{\circ}$ arc from base).

Correspondingly to single point selection (TOP, SIDE, and BASE), Quadrants are defined with respect to the potential for seepage from the matrix by imbibition and fractures by gravity-driven flow. 


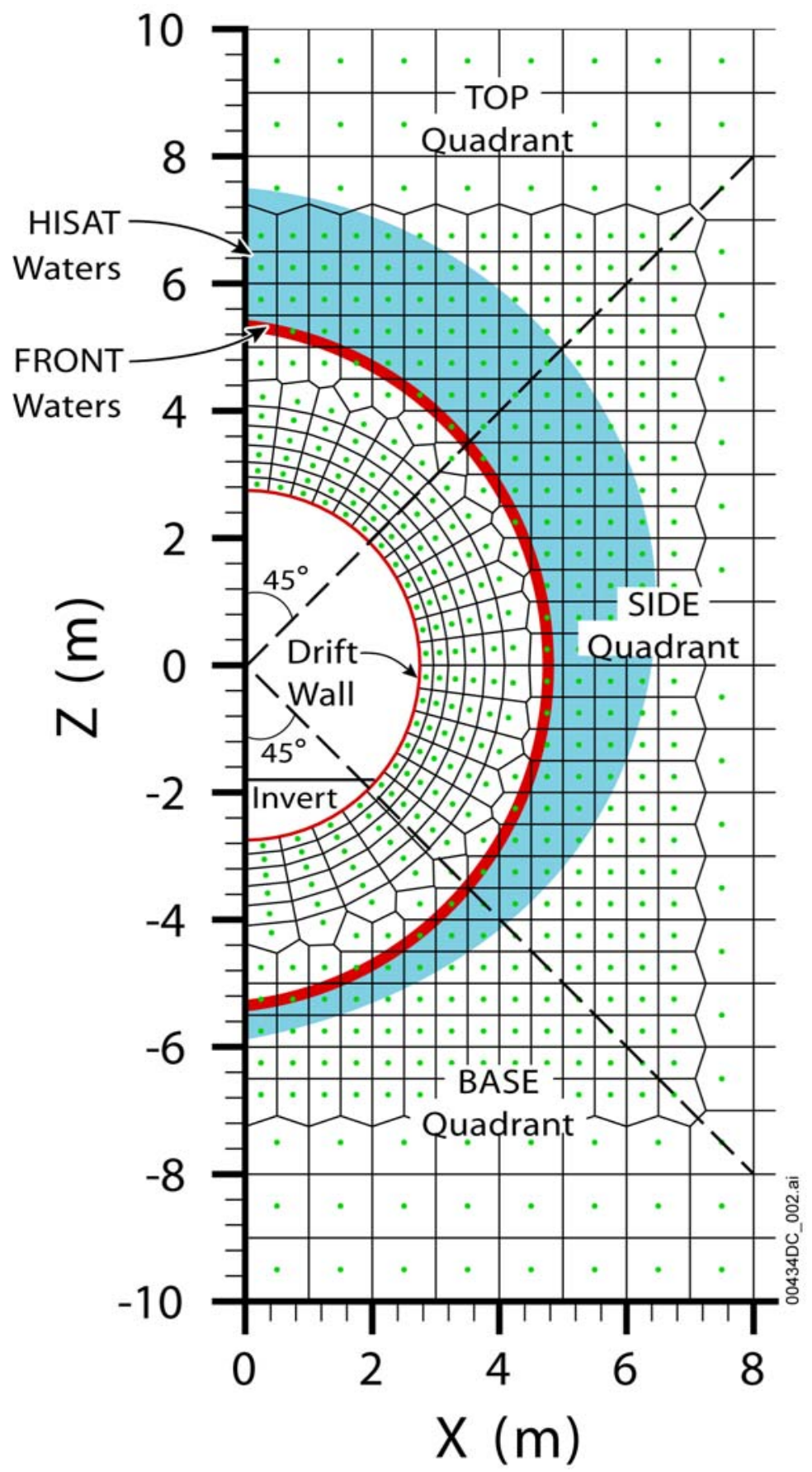

Grid source DTN: LB0011DSTTHCR1.002 [DIRS 161282].

NOTE: The areas delineating high saturation zone (HISAT) and FRONT waters are for illustrative purposes only. The extent of these areas varies through time and is different for fracture and matrix waters. Since only half-symmetry is modeled, both TOP and BASE represent a half quadrant.

Figure 6.2-2. Quadrant Designations for Data Selection from the THC Seepage Model 


\subsubsection{Saturation Zones (FRONT and HISAT)}

First, two types of locations are considered for waters that potentially seep into a drift:

- HISAT: Waters in zones around the drift where liquid saturations are higher than in surrounding host rock (e.g., condensation zones).

- FRONT: Waters from zones closest to the drift, where nonzero liquid saturations occur.

Model results for gridblocks from the defined quadrants are further distinguished FRONT and HISAT locations. The methodology for identifying the FRONT and HISAT locations is described in the following:

FRONT waters (boiling/wetting front) — At each time interval, model results are extracted for gridblocks according to the following criteria (in order of preference):

1. Search radius of $25 \mathrm{~m}$ from drift center to cover the dryout and rewetting zone, then,

2. Nonzero liquid saturation (in matrix or fractures depending on which is selected) then,

3. First six gridblocks with smallest radial distance from drift center-these are ranked with attribute INDX $=1$ through 6 from the closest to the farthest from the drift center. However, if ties occur (same radial distance), the gridblocks and corresponding indexes INDX are selected and ranked in order of decreasing liquid saturation, then decreasing absolute values of $\mathrm{Z}$ coordinates (Figure 6.2-2).

HISAT waters (zone of increased liquid saturation) - At each time interval, model results are extracted for gridblocks according to the following criteria (in order of preference):

1. Search radius of $25 \mathrm{~m}$ from drift center to cover the dryout and re-wetting zone, then,

2. First six gridblocks with highest liquid saturation (in matrix or fractures depending on the selected medium) — these are ranked with attribute INDX=1 through 6 from most to least liquid saturated. However, if ties occur (same liquid saturation), then gridblocks and corresponding indexes INDX are selected and ranked in order of increasing radial distance from drift center, then decreasing absolute values of $\mathrm{Z}$ coordinates (Figure 6.2-2).

Thus, for FRONT waters, preference is given to gridblocks that are wet and closest to the drift wall. If two or more selected wet gridblocks occur at the same distance from drift center, then the wettest ones are selected. If two or more of them have the same liquid saturation (and are located at the same distance from the drift), then the gridblocks most directly above or below the drift are selected.

In contrast, for HISAT waters, preference is given to gridblocks that are the wettest within a given distance $(25 \mathrm{~m})$ from drift center. If two or more selected wet gridblocks have the same liquid saturation, then the one closest to drift center is selected. If two or more gridblocks are 
located at the same distances from the drift center (and with the same liquid saturation), then those most directly above or below the drift are selected.

The selection of six gridblocks for each water at each time step stems from the configuration of the numerical grid. In this grid, each successive radially distributed row of gridblocks in the TOP quadrant, from the drift wall outwards, contains approximately six gridblocks (Figure 6.2-2). The number of sampling points is dependent on the grid resolution. By limiting the number of selected gridblocks, extraction of data over a wide area is avoided, and the potential for overlapping HISAT and FRONT waters is limited. Note that extracted fracture and matrix data following the procedure described above do not necessarily correspond to the same gridblocks.

The described selection method is used to extract simulated water and $\mathrm{CO}_{2}$ concentrations for six points (gridblocks) per time interval for each run, for each extracted type of water (FRONT or HISAT) in each quadrant (TOP, SIDE, and BASE). In this way, the method captures the spatial variability of model results around the drift for each given model run. It also captures the predicted compositions of waters closest to the drift during and after the dryout period. The method is used with both fracture and matrix waters. The large quantity of data extracted in this way is then narrowed down to consider only waters deemed most susceptible to seep into drifts, namely:

- HISAT waters for the fracture medium in the TOP quadrant

- FRONT waters for the fracture medium in the TOP quadrants

- FRONT waters for the fracture medium in the BASE quadrants

- FRONT waters for the matrix medium in the BASE quadrant.

This constitutes the main conceptualization for water selection (Figure 6.2-3). The data from the SIDE quadrant are not considered further in this report, because most in-drift seepage is expected to occur by gravity drainage above the drift, while a small fraction may occur by imbibition into the invert at the base of the drift (BSC 2004 [DIRS 169565]).

It can be argued that HISAT waters (from zones with increased liquid saturation) would evolve towards the composition of FRONT waters (boiling/wetting front) as they migrate towards the drift. Thus, the FRONT waters could be considered more representative of potential in-drift seepage than HISAT waters. As discussed later, the compositions of FRONT waters display more variability than HISAT waters because they have been evaporated to a more variable degree than HISAT waters, depending on their proximity to the boiling front. Finally, during the dryout period, when model data are extracted from gridblocks away from the drift wall, this selection method does not capture in-drift gas compositions. However, gas compositions are obtained from data extracted for gridblocks directly adjacent to the drift crown, springline (side), and base reported in Drift-Scale THC Seepage Model (BSC 2004 [DIRS 169856], Section 6.5.5.2.1). These in-drift gas compositions, at any given time, are much more spatially homogenous than pore-water compositions around the drift. The selected waters are sufficiently similar to the process model predictions because they are a subset of the predictions that represent potential seepage. Therefore, the criteria used to select THC seepage model results are sufficiently accurate and adequate to represent water compositions around drift. 


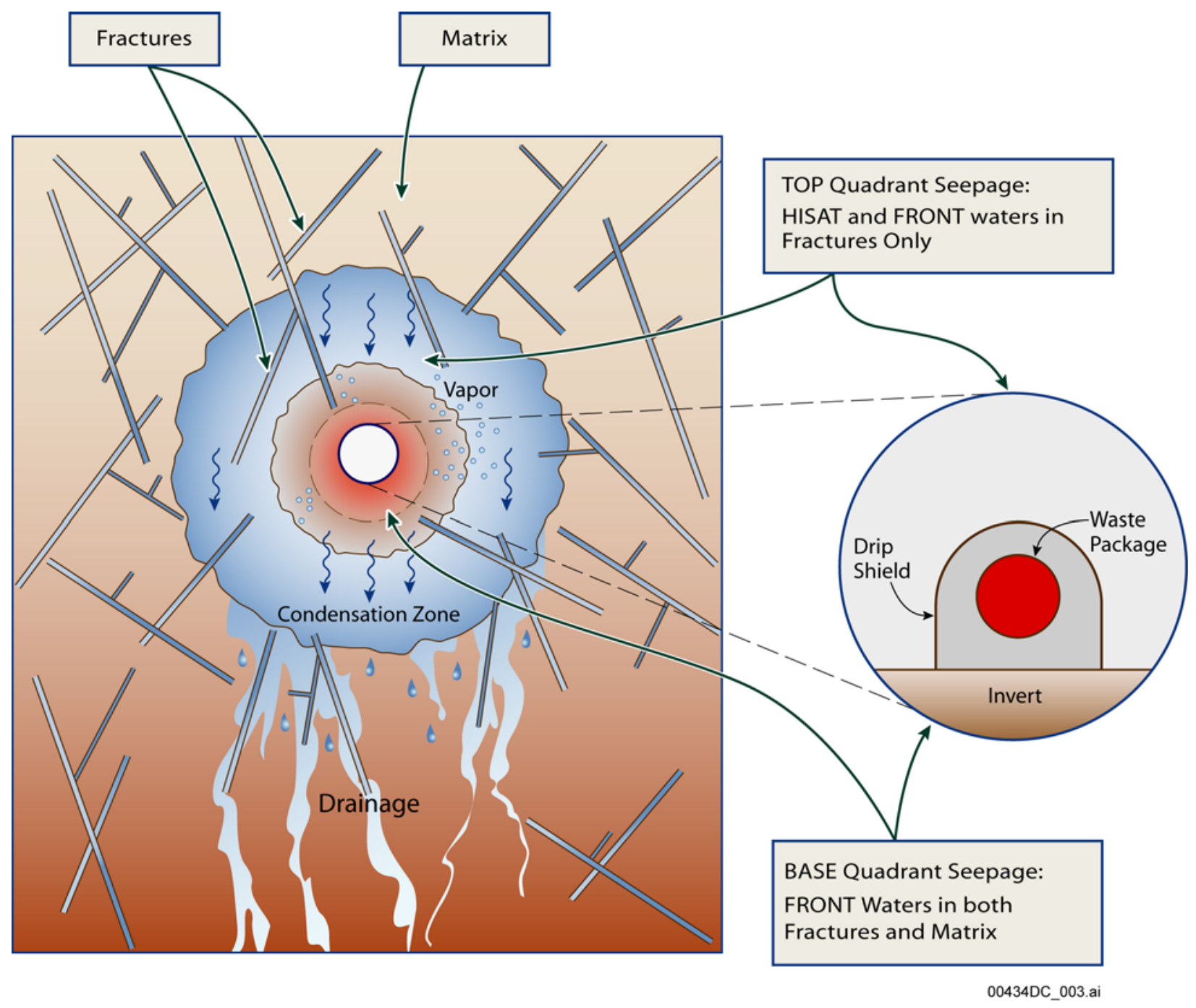

NOTE: Wavy downward arrows show drainage.

Figure 6.2-3. Conceptual Model for Data Selection of In-Drift Seepage Water Chemistry 


\subsubsection{Time Periods}

Time histories of pore-water compositions reported in Drift-Scale THC Seepage Model (BSC 2004 [DIRS 169856], Section 6.5.5.2.2) for the zone of increased liquid saturation above the drift (HISAT waters) show that the following successive stages in the evolution of water composition:

1. A dilution stage occurs when the dryout zone is expanding, roughly from 50 to 100 to 150 years. It is caused by water vapor originating from boiling in the rock matrix then migrating and condensing in fractures (BSC 2004 [DIRS 169856], Section 6.2.1.1).

2. An evaporative concentration stage takes place while the zone of increased liquid saturation remains essentially stationary. The water in fractures is concentrated by boiling the percolating water, with little or no additional influx of condensation water derived from boiling matrix water. This stage lasts approximately from 150 years to 600 years for most waters, but is shorter by several hundred years under the higher infiltration rate (as shown by chloride profiles in BSC 2004 [DIRS 169856], Figure 6.5-27).

3. A "back-to-ambient" stage starts while boiling is still occurring, after approximately 600 years (and earlier at higher infiltration rates), then continuing after the collapse of the boiling front. During this stage, the dilution by percolating waters overcomes the effect of evaporative concentration and brings concentrations back to their ambient values.

These three stages could be used to further define time-periods for predicted concentrations of pore waters. The first and second stage could bound minimum and maximum concentrations, respectively, while the third stage would be representative of long-term ambient conditions.

Note that the temperature histories and lengths of the boiling period are expected to vary over the repository footprint, because of spatial differences in infiltration rates and host-rock geologic units, and heat loss at the edge of the proposed repository. These effects are captured by the multiscale thermohydrologic model (MSTHM) (BSC 2004 [DIRS 169565], Section 6.3.1.1). For a mean infiltration case similar to that used in the THC seepage model, the MSTHM predicts the time (after closure) when boiling ceases at the drift wall to be a maximum of about 1,300 years, and approximately 1,000 years for $90 \%$ of investigated locations for the mean infiltration flux case (BSC 2004 [DIRS 169565], Table 6.3-5). This time is defined in the MSTHM as the time when the average drift wall temperature drops below $96^{\circ} \mathrm{C}$. With the THC seepage model, when chemistry effects are disabled (TH only), the rewetting of fractures at the modeled drift crown is predicted to occur about 1400 years after closure (BSC 2004 [DIRS 169856], Section 6.5.5.5). This time window is constrained by a 200 -year printout interval used in the model. Within this time window, predicted temperatures around the drift also drop below $96^{\circ} \mathrm{C}$. Therefore, when water-rock interactions are not considered, the THC seepage model predicts temperatures similar to those predicted with the MSTHM at the hottest locations. This is mostly because the THC seepage model does not account for heat loss at the edge of the repository (BSC 2004 [DIRS 169856], Section 1.3) or three-dimensional heat transfer effects in the host rock. In-drift heat transfer (from the waste package to the drift wall) is also treated somewhat differently in the 
MSTHM compared to the THC seepage models. However, this does not result in significant differences between these models in predicted drift- wall temperatures for given waste package temperatures. For example, the maximum waste-package and drift-wall temperatures from the THC seepage model are approximately $164^{\circ} \mathrm{C}$ and $141^{\circ} \mathrm{C}$, respectively (BSC 2004 [DIRS 169856], Figure 6.5-3 ). With the MSTH model for a similar mean infiltration case, the same waste package temperature (approximately $164^{\circ} \mathrm{C}$ ) corresponds to a drift-wall temperature of approximately $139^{\circ} \mathrm{C}$ (BSC 2004 [DIRS 169565], Figure 6.3-2).

When mineral precipitation is taken into effect, the THC seepage model predicts that fractures at the drift crown rewet several hundred years later (1,750 to 2,150 years after closure, depending on the initial water composition). This is because mineral precipitation above the drift causes a reduction in fracture permeability and subsequent partial diversion of percolation waters around the drift (BSC 2004 [DIRS 169856], Section 6.5.5.3). For these THC simulations, the temperature drops below $96^{\circ} \mathrm{C}$ at the drift wall between 1,350 and 1,550 years after closure, which is approximately 200 years longer than for the case when the effect of water-rock interaction is ignored (with all other input parameters kept identical).

Because boiling and temperature affect water-rock interactions, and thus predicted water and gas compositions, the selection of the THC seepage model results in time would need to take into account the variability of temperature histories and boiling lengths throughout the repository. Because the THC seepage model results apply to the hottest locations within the repository, where boiling would prevail for the longest time, water compositions at those locations are expected to yield more concentrated waters than in cooler areas. This is appropriate to represent the entire repository because the use of water compositions (bin histories) from hotter repository center locations is conservative with respect to corrosion of the engineered barriers, relative to cooler repository-edge waters. As noted earlier, differences in water and gas chemistries related to geographic location but not to temperature (i.e., stratigraphy and infiltration rates,) are likely reflected in the variability of model results. This is because the THC seepage model considers a range of input water compositions (Appendix C) that span the demonstrated range of sensitivity changes in mineralogy, rock properties, and infiltration rates as they may vary throughout the proposed repository

\subsubsection{Discussion of THC Water Selection}

- THC model results for potential seepage waters are characterized in Section 6.2.1 by five input water compositions (W0, W4, W5, W6, and W7), two porous media (fractures and matrix), three cross-sectional quadrants (TOP, SIDE, and BASE), two saturation zones (FRONT and HISAT), six gridblock indices, and a series of discrete time steps. As discussed in Drift-Scale THC Seepage Model (BSC 2004 [DIRS 169856], Section 6.2.3) only a subset of the THC model results needs to be examined to represent potential seepage water compositions. As mentioned in Section 6.2.1, the main difficulty in selecting water compositions from the THC seepage model is that the model does not predict in-drift seepage to occur, even under conditions of increased infiltration from climate change. Therefore, the decision as to which water compositions to extract from the model forms the most important basis for water selection. 
As discussed in Drift-Scale THC Seepage Model (BSC 2004 [DIRS 169856], Section 6.5.5.2.2), the variation of predicted water compositions in zones of highest liquid saturation provides a better means of evaluating model sensitivity to various input data and model conceptualizations than variation of predicted water compositions directly at the boiling front. This is because waters at the boiling front are more variable, resulting from a larger range in the degree of evaporative concentration. However, to represent the compositional variability of waters that could seep into a drift during the boiling period (by somehow penetrating the dryout zone), the water composition at the boiling front is considered. For this reason, both water types (HISAT and FRONT) are considered here (Section 6.2.3 below).

The data selection concept described in Section 6.2.1 addresses spatial selection for given times. Alternatively, the same data (extracted as described in Section 6.2.1) can be reformatted for examination as a function of drift wall temperature (which relates more directly to the potential for in-drift seepage) and of liquid saturation (which also relates more directly to mobility). Water compositions may also be expressed as time histories for specific locations. These two alternatives are also considered (Section 6.2.4.2).

The mathematical formulations that underlie the THC seepage model are described in detail in Drift-Scale THC Seepage Model (BSC 2004 [DIRS 169856], Section 6.4). The spatial selection methodology described in Section 6.2.1 was implemented using CUTCHEM V1.0, with further information on point selection provided in Section 6.2.1 and in the qualification documentation for this software. Data manipulation was implemented using MS Excel97, using standard functions to calculate summary statistics and sort, filter, and plot the extracted data (Appendix B).

The following summary statistics were computed with the data: mean, minimum, maximum, and standard deviation (SD). These statistics were computed on log-transformed data, except for $\mathrm{pH}$, because predicted concentrations (and concentration ratios) vary over several orders of magnitude. Also, the chemical potential for the aqueous species that drives reactions is a logarithmic function of concentration. As a result, distributions of these concentrations in the model output are closer to lognormal than normal. Because $\mathrm{pH}$ is itself a function of the negative logarithm of the hydrogen ion concentration (more precisely activity), this model output variable was not log-transformed.

\subsubsection{Selection of Aqueous Species and $\mathrm{CO}_{2}$ Predicted Concentrations}

In this section, the selection approach discussed in Sections 6.2.1 and 6.2.2 is applied to results of the THC seepage model simulations reported in Drift-Scale THC Seepage Model (BSC 2004 [DIRS 169856], Section 6.5.5). The available THC simulations cover a range of input data for various conceptualizations, as follows:

- Five different input initial water compositions (BSC 2004 [DIRS 169856], Section 6.2.2.1): W0, the base-case composition, and alternative compositions W4 through W7 (Appendix C). 
- Three different infiltration scenarios (using water W0): stepwise increase from 6, to 16, to $25 \mathrm{~mm} / \mathrm{yr}$, fixed $6 \mathrm{~mm} / \mathrm{yr}$, and fixed $25 \mathrm{~mm} / \mathrm{yr}$ (BSC 2004 [DIRS 169856], Table 6.5-3).

- Two different water vapor-pressure options implemented in TOUGHREACT V3.0 (TOUGHREACT V3.0, STN: 10396-3.0-00 [DIRS 161256], modules EOS4 and EOS3) respectively with and without vapor-pressure lowering due to capillary pressure (simulations using water W0).

- Two values of $\mathrm{CO}_{2}$ diffusion coefficient (using water W0) resulting in a difference in the $\mathrm{CO}_{2}$ gas diffusion coefficient by a factor of six (BSC 2004 [DIRS 169856], Section 6, Table 6-1).

Note that EOS3 neglects vapor pressure lowering due to capillary pressure and EOS4 takes this effect into account. To facilitate sensitivity analysis, these simulations were consolidated into two different groups: Group 1, including the simulations using the five different input water compositions (W0, W4, W5, W6, and W7 to represent different host rock materials), and Group 2, including only runs for sensitivity studies using water composition W0 with different infiltration scenarios, vapor pressure lowering options (two cases), and $\mathrm{CO}_{2}$ diffusion coefficients (two different diffusion coefficients, also a total of five simulations) (Table 6.2-1). Thus, Group 1 simulations reflect the spread of model results caused by the variability of water compositions in the repository units, whereas Group 2 simulations reflect the sensitivity of model results to other important input parameters and model conceptualizations (as listed above). Therefore, the post-processing analysis of potential seepage waters is only limited to Group 1 model results in this section (Section 6.2.3) and the same methodology was also used in Section 6.2.4 for sensitivity analyses due to other infiltration scenarios and model options in Group 2. 
Table 6.2-1. Tptpll THC Model Runs Used for Post-Processing Analysis

\begin{tabular}{|c|c|c|c|c|c|c|}
\hline Group & $\begin{array}{c}\text { Input } \\
\text { Water }^{\mathrm{a}}\end{array}$ & $\begin{array}{c}\text { Infiltration Rate } \\
\text { (mm/yr) }\end{array}$ & $\begin{array}{c}\text { Vapor } \\
\text { Pressure } \\
\text { Lowering }^{c} \\
\end{array}$ & $\begin{array}{c}\mathrm{CO}_{2} \\
\text { Diffusion } \\
\end{array}$ & Run ID & Source Data $^{f}$ \\
\hline \multirow{5}{*}{1} & WO & Stepped 6/16/25 & Yes & Higher & thc6_w0 & $\begin{array}{l}\text { LB0302DSCPTHCS.002 } \\
{[\text { [DIRS 161976] }}\end{array}$ \\
\hline & W4 & Stepped 6/16/25 & Yes & Higher & thc6_w4 & $\begin{array}{l}\text { LB0302DSCPTHCS.002 } \\
{[\text { [DIRS 161976] }}\end{array}$ \\
\hline & W5 & Stepped 6/16/25 & Yes & Higher & thc6_w5 & $\begin{array}{l}\text { LB0302DSCPTHCS.002 } \\
{[\text { [DIRS 161976] }}\end{array}$ \\
\hline & W6 & Stepped 6/16/25 & Yes & Higher & thc6_w6 & $\begin{array}{l}\text { LB0302DSCPTHCS.002 } \\
\text { [DIRS 161976] }\end{array}$ \\
\hline & W7 & Stepped 6/16/25 & Yes & Higher & thc6_w7 & $\begin{array}{l}\text { LB0302DSCPTHCS.002 } \\
\text { [DIRS 161976] }\end{array}$ \\
\hline \multirow{5}{*}{2} & wo & Stepped 6/16/25 & Yes & Higher & thc6_w0 & $\begin{array}{l}\text { LB0302DSCPTHCS.002 } \\
\text { [DIRS 161976] }\end{array}$ \\
\hline & WO & Stepped 6/16/25 & No & Higher & thc6_w0e3 & $\begin{array}{l}\text { LB0307DSTTHCR2.002 } \\
\text { [DIRS 165541] }\end{array}$ \\
\hline & WO & Constant 6 & Yes & Higher & thc6_w0a & $\begin{array}{l}\text { LB0307DSTTHCR2.002 } \\
\text { [DIRS 165541] }\end{array}$ \\
\hline & wo & Constant 25 & Yes & Higher & thc25_w0 & $\begin{array}{l}\text { LB0307DSTTHCR2.002 } \\
\text { [DIRS 165541] }\end{array}$ \\
\hline & wo & Stepped 6/16/25 & Yes & Lower & thc6_w0b & $\begin{array}{l}\text { LB0307DSTTHCR2.002 } \\
\text { [DIRS 165541] }\end{array}$ \\
\hline
\end{tabular}

a Appendix C.

b BSC 2004 [DIRS 169856], Table 6.5-3.

c TOUGHREACT V3.0 flow modules: EOS3 neglects vapor pressure lowering due to capillary pressure; EOS4 takes this effect into account.

d Six-fold increase between runs labeled "Higher" and "Lower" due to input $\mathrm{CO}_{2}$ molecular diameter of $1 \times 10^{-10} \mathrm{~m}$ versus $2.5 \times 10^{-10} \mathrm{~m}$, respectively (see BSC 2004 [DIRS 169856], Section 6.5.3).

e THC seepage model simulations from BSC 2004 [DIRS 169856], Section 6.5.

f See Table 4.1-1 for source data files.

Carbon dioxide concentration can be expressed either by its partial pressure or volume fraction. The THC seepage model outputs the total gas pressure and $\mathrm{CO}_{2}$ volume fraction (see DTN: LB0302DSCPTHCS.002 [DIRS 161976]). The partial pressure of $\mathrm{CO}_{2}$ in gas phase is obtained by multiplying the volume fraction of $\mathrm{CO}_{2}$ by the total gas pressure.

\subsubsection{Water Compositions as a Function of Time}

As discussed previously in Section 6.2.1, potential seepage waters include:

- HISAT-TOP-fracture water

- FRONT-TOP-fracture water

- FRONT-BASE-fracture water

- FRONT-BASE-matrix water.

In this subsection, statistical comparisons are performed to support the choice of FRONT-TOP to represent potential seepage water, to evaluate the use of gridblock index for representing the variation of water and gas compositions. 
Summary statistics (minimum, maximum, mean, and standard deviation) of extracted data were calculated at each specific time for Group 1 simulation results. These data reflect 30 observations at each time step (i.e., 5 runs $\times 6$ extracted data points indexed INDX=1 to 6). The standard deviations for Group 1 results are summarized in Tables 6.2-2 and 6.2-3.

The summary statistics for Group 1 are shown in Figures 6.2-4 through 6.2-20 in the form of "whisker" plots defining concentration profiles through time. In these figures, "whiskers" show minimum and maximum values tied with a vertical line, superposed with a wide bar representing two standard deviations centered on the mean. The mean is itself represented by a symbol (filled circle). These "whiskers" are superposed with lines representing minimum, maximum, and mean concentrations for waters assigned to the same specific INDX value (INDX=5 for HISAT waters, and INDX $=4$ for FRONT waters, as determined further below). In the discussion below, FRONT and HISAT waters with these INDX values are chosen as subsets of the complete data (i.e., those including INDX 1 through 6) which are most representative of the complete set.

Note that, for convenience, Figures 6.2-4 through 6.2-20 do not display data for all simulated points in time. These data are displayed for the times shown on Tables 6.2-2 and 6.2-3. The figures capture the general behavior of the data, although in some instances data for times not shown in these figures may display a somewhat larger scatter (mostly in the period between 50 and 100 years). Profiles as functions of temperature and liquid saturation discussed later (and excluding summary statistics) include data for all points in time (Section 6.2.4.2). 
Table 6.2-2. Standard Deviations in Water and Gas Compositions Predicted in Zones of High Liquid Saturation above the Drift Crown (HISAT - TOP, Fractures)

\begin{tabular}{|c|c|c|c|c|c|c|c|c|c|c|c|c|c|c|c|c|c|c|c|}
\hline $\begin{array}{c}\text { Time } \\
(\mathrm{yr})\end{array}$ & $\mathrm{pH}$ & $\mathrm{Ca}$ & $\mathrm{Mg}$ & $\mathrm{Na}$ & Chloride & Silica & Carbonate & Sulfate & K & Fluoride & Nitrate & $\begin{array}{c}\mathrm{CO}_{2} \\
\text { (gas) }\end{array}$ & $\mathrm{Ca} / \mathrm{Na}$ & $\mathrm{NO}_{3} / \mathrm{Cl}$ & $\mathrm{HCO}_{3} / \mathrm{Cl}$ & $\mathrm{SO}_{4} / \mathrm{Cl}$ & $\mathrm{Na} / \mathrm{Cl}$ & $\mathrm{Ca} / \mathrm{CO}_{3}$ & $\mathrm{Ca} / \mathrm{Cl}$ \\
\hline 0 & 0.11 & 0.11 & 0.52 & 0.18 & 0.29 & 0.08 & 0.14 & 0.37 & 0.06 & 0.30 & 0.27 & 0.23 & 0.25 & 0.38 & 0.40 & 0.22 & 0.36 & 0.19 & 0.24 \\
\hline 53 & 0.14 & 0.15 & 0.82 & 0.25 & 0.37 & 0.20 & 0.22 & 0.44 & 0.24 & 0.25 & 0.35 & 0.32 & 0.30 & 0.38 & 0.44 & 0.22 & 0.27 & 0.33 & 0.31 \\
\hline 100 & 0.13 & 0.04 & 0.23 & 0.11 & 0.31 & 0.06 & 0.16 & 0.39 & 0.11 & 0.08 & 0.30 & 0.29 & 0.11 & 0.38 & 0.43 & 0.22 & 0.29 & 0.19 & 0.27 \\
\hline 150 & 0.15 & 0.07 & 0.20 & 0.08 & 0.31 & 0.05 & 0.20 & 0.38 & 0.08 & 0.07 & 0.28 & 0.35 & 0.11 & 0.38 & 0.48 & 0.22 & 0.30 & 0.27 & 0.24 \\
\hline 200 & 0.09 & 0.23 & 0.38 & 0.16 & 0.40 & 0.14 & 0.23 & 0.46 & 0.16 & 0.12 & 0.33 & 0.32 & 0.23 & 0.38 & 0.58 & 0.22 & 0.32 & 0.45 & 0.21 \\
\hline 300 & 0.10 & 0.40 & 0.35 & 0.26 & 0.46 & 0.19 & 0.30 & 0.51 & 0.27 & 0.18 & 0.42 & 0.34 & 0.31 & 0.37 & 0.70 & 0.22 & 0.28 & 0.68 & 0.19 \\
\hline 400 & 0.11 & 0.35 & 0.38 & 0.24 & 0.40 & 0.16 & 0.22 & 0.44 & 0.24 & 0.13 & 0.40 & 0.25 & 0.18 & 0.37 & 0.58 & 0.22 & 0.19 & 0.53 & 0.12 \\
\hline 500 & 0.15 & 0.41 & 0.49 & 0.29 & 0.44 & 0.17 & 0.13 & 0.51 & 0.29 & 0.12 & 0.39 & 0.13 & 0.18 & 0.37 & 0.54 & 0.22 & 0.17 & 0.51 & 0.11 \\
\hline 600 & 0.17 & 0.42 & 0.47 & 0.26 & 0.40 & 0.16 & 0.13 & 0.45 & 0.27 & 0.13 & 0.41 & 0.08 & 0.25 & 0.38 & 0.50 & 0.22 & 0.16 & 0.54 & 0.17 \\
\hline 800 & 0.10 & 0.20 & 0.28 & 0.12 & 0.30 & 0.04 & 0.07 & 0.37 & 0.12 & 0.07 & 0.28 & 0.07 & 0.12 & 0.38 & 0.35 & 0.22 & 0.18 & 0.27 & 0.14 \\
\hline 1,000 & 0.09 & 0.16 & 0.23 & 0.10 & 0.29 & 0.02 & 0.06 & 0.37 & 0.10 & 0.05 & 0.27 & 0.03 & 0.08 & 0.38 & 0.35 & 0.22 & 0.20 & 0.22 & 0.15 \\
\hline 1,200 & 0.09 & 0.15 & 0.22 & 0.09 & 0.29 & 0.02 & 0.08 & 0.37 & 0.09 & 0.04 & 0.27 & 0.01 & 0.07 & 0.38 & 0.37 & 0.22 & 0.21 & 0.23 & 0.15 \\
\hline 1,400 & 0.08 & 0.17 & 0.19 & 0.08 & 0.29 & 0.02 & 0.07 & 0.37 & 0.08 & 0.05 & 0.27 & 0.01 & 0.09 & 0.38 & 0.36 & 0.22 & 0.21 & 0.24 & 0.13 \\
\hline 1,600 & 0.07 & 0.16 & 0.18 & 0.08 & 0.29 & 0.01 & 0.07 & 0.37 & 0.08 & 0.06 & 0.27 & 0.01 & 0.08 & 0.38 & 0.35 & 0.22 & 0.22 & 0.23 & 0.13 \\
\hline 1,800 & 0.06 & 0.13 & 0.15 & 0.06 & 0.23 & 0.01 & 0.06 & 0.28 & 0.06 & 0.05 & 0.33 & 0.01 & 0.08 & 0.38 & 0.28 & 0.22 & 0.17 & 0.19 & 0.11 \\
\hline 2,000 & 0.08 & 0.18 & 0.19 & 0.08 & 0.32 & 0.01 & 0.07 & 0.38 & 0.08 & 0.07 & 0.28 & 0.01 & 0.09 & 0.38 & 0.39 & 0.22 & 0.23 & 0.25 & 0.15 \\
\hline 2,200 & 0.06 & 0.18 & 0.17 & 0.06 & 0.29 & 0.02 & 0.08 & 0.37 & 0.07 & 0.07 & 0.27 & 0.03 & 0.12 & 0.38 & 0.36 & 0.22 & 0.23 & 0.26 & 0.12 \\
\hline 2,400 & 0.06 & 0.18 & 0.17 & 0.06 & 0.29 & 0.02 & 0.07 & 0.37 & 0.07 & 0.07 & 0.27 & 0.02 & 0.12 & 0.38 & 0.36 & 0.22 & 0.23 & 0.25 & 0.12 \\
\hline 5,000 & 0.05 & 0.14 & 0.14 & 0.06 & 0.29 & 0.01 & 0.07 & 0.37 & 0.07 & 0.06 & 0.27 & 0.04 & 0.08 & 0.38 & 0.36 & 0.22 & 0.23 & 0.21 & 0.15 \\
\hline 7,000 & 0.05 & 0.14 & 0.12 & 0.06 & 0.29 & 0.01 & 0.08 & 0.37 & 0.06 & 0.05 & 0.27 & 0.06 & 0.08 & 0.38 & 0.36 & 0.22 & 0.24 & 0.19 & 0.18 \\
\hline 10,000 & 0.03 & 0.14 & 0.10 & 0.06 & 0.29 & 0.01 & 0.08 & 0.37 & 0.06 & 0.05 & 0.27 & 0.08 & 0.08 & 0.38 & 0.35 & 0.22 & 0.25 & 0.17 & 0.20 \\
\hline 20,000 & 0.04 & 0.14 & 0.11 & 0.06 & 0.29 & 0.01 & 0.09 & 0.37 & 0.06 & 0.06 & 0.27 & 0.12 & 0.08 & 0.38 & 0.35 & 0.22 & 0.26 & 0.15 & 0.22 \\
\hline 50,000 & 0.05 & 0.14 & 0.09 & 0.05 & 0.29 & 0.02 & 0.10 & 0.37 & 0.05 & 0.06 & 0.27 & 0.12 & 0.09 & 0.38 & 0.36 & 0.22 & 0.26 & 0.15 & 0.24 \\
\hline 100,000 & 0.03 & 0.13 & 0.08 & 0.05 & 0.29 & 0.02 & 0.10 & 0.37 & 0.05 & 0.05 & 0.27 & 0.11 & 0.08 & 0.38 & 0.37 & 0.22 & 0.26 & 0.15 & 0.24 \\
\hline
\end{tabular}


Table 6.2-2. Standard Deviations in Water and Gas Compositions Predicted in Zones of High Liquid Saturation above the Drift Crown (HISAT - TOP, Fractures) (Continued)

\begin{tabular}{|c|c|c|c|c|c|c|c|c|c|c|c|c|c|c|c|c|c|c|c|}
\hline $\begin{array}{c}\text { Interval } \\
(\mathrm{yr})\end{array}$ & $\mathrm{pH}$ & $\mathrm{Ca}$ & $\mathrm{Mg}$ & $\mathrm{Na}$ & Chloride & Silica & Carbonate & Sulfate & $\mathbf{K}$ & Fluoride & Nitrate & $\begin{array}{c}\mathrm{CO}_{2} \\
\text { (gas) } \\
\end{array}$ & $\mathrm{Ca} / \mathrm{Na}$ & $\mathrm{NO}_{3} / \mathrm{Cl}$ & $\mathrm{HCO}_{3} / \mathrm{Cl}$ & $\mathrm{SO}_{4} / \mathrm{Cl}$ & $\mathrm{Na} / \mathrm{Cl}$ & $\mathrm{Ca} / \mathrm{CO}_{3}$ & $\mathrm{Ca} / \mathrm{Cl}$ \\
\hline $\begin{array}{l}0- \\
100,000 \\
\end{array}$ & 0.09 & 0.19 & 0.26 & 0.12 & 0.32 & 0.06 & 0.12 & 0.39 & 0.12 & 0.09 & 0.31 & 0.13 & 0.14 & 0.38 & 0.42 & 0.22 & 0.24 & 0.28 & 0.18 \\
\hline $150-600$ & 0.13 & 0.31 & 0.38 & 0.22 & 0.40 & 0.15 & 0.20 & 0.46 & 0.22 & 0.13 & 0.37 & 0.24 & 0.21 & 0.37 & 0.56 & 0.22 & 0.24 & 0.49 & 0.17 \\
\hline $\begin{array}{l}600- \\
2,000\end{array}$ & 0.09 & 0.20 & 0.24 & 0.11 & 0.30 & 0.04 & 0.08 & 0.37 & 0.11 & 0.06 & 0.30 & 0.03 & 0.11 & 0.38 & 0.37 & 0.22 & 0.20 & 0.27 & 0.14 \\
\hline $\begin{array}{l}2,000- \\
100,000\end{array}$ & 0.05 & 0.15 & 0.13 & 0.06 & 0.29 & 0.01 & 0.08 & 0.37 & 0.06 & 0.06 & 0.27 & 0.07 & 0.09 & 0.38 & 0.36 & 0.22 & 0.24 & 0.20 & 0.18 \\
\hline Maximum & 0.17 & 0.42 & 0.82 & 0.29 & 0.46 & 0.20 & 0.30 & 0.51 & 0.29 & 0.30 & 0.42 & 0.35 & 0.31 & 0.38 & 0.70 & 0.22 & 0.36 & 0.68 & 0.31 \\
\hline
\end{tabular}

Input DTNs: $\quad$ LB0302DSCPTHCS.002 [DIRS 161976]; LB0307DSTTHCR2.002 [DIRS 165541]

Output DTN: $\quad$ LB0311ABSTHCR2.001 [DIRS 166714]

NOTE: $\quad$ Standard deviation values are shown for Group 1 simulations using input water compositions W0, W4, W5, W6, and W7. The data of standard deviation are extracted from spreadsheet stdev, in top-hisat_f1.xls (DTN: LB0311ABSTHCR2.001 [DIRS 166714]). For pH, standard deviation is given in $( \pm) \mathrm{pH}$ units. For other data, standard deviation of logarithmic values of total molality for aqueous species, volume fraction for $\mathrm{CO}_{2}$, and unitless molal ratios, thus representing a $( \pm$ ) change in log10 values of concentrations and concentration ratios around the mean of log10 values (e.g., 0.5 corresponds to total spread of one order of magnitude). The bottom of the table shows averages of individual standard deviations over the time intervals shown. See Appendix B for details. 
Table 6.2-3. Standard Deviations in Water and Gas Compositions Predicted in Zones of High Liquid Saturation above the Drift Crown (FRONT - TOP, Fractures)

\begin{tabular}{|c|c|c|c|c|c|c|c|c|c|c|c|c|c|c|c|c|c|c|c|}
\hline Time (yr) & $\mathrm{pH}$ & $\mathrm{Ca}$ & Mg & $\mathrm{Na}$ & Chloride & Silica & Carbonate & Sulfate & K & Fluoride & Nitrate & $\begin{array}{c}\mathrm{CO}_{2} \\
\text { (gas) }\end{array}$ & $\mathrm{Ca} / \mathrm{Na}$ & $\mathrm{NO}_{3} / \mathrm{Cl}$ & $\mathrm{HCO}_{3} / \mathrm{Cl}$ & $\mathrm{SO}_{4} / \mathrm{Cl}$ & $\mathrm{Na} / \mathrm{Cl}$ & $\mathrm{Ca} / \mathrm{CO}_{3}$ & $\mathrm{Ca} / \mathrm{Cl}$ \\
\hline 0 & 0.11 & 0.11 & 0.52 & 0.18 & 0.29 & 0.08 & 0.14 & 0.37 & 0.06 & 0.30 & 0.27 & 0.23 & 0.25 & 0.38 & 0.40 & 0.22 & 0.36 & 0.19 & 0.24 \\
\hline 53 & 0.34 & 0.72 & 0.70 & 0.88 & 0.92 & \begin{tabular}{|l|}
0.88 \\
\end{tabular} & 0.58 & 0.95 & 0.88 & 0.87 & 0.92 & 0.28 & 1.28 & 0.38 & 0.90 & 0.22 & 0.27 & 1.28 & 1.19 \\
\hline 100 & 0.06 & 0.22 & 0.25 & 0.24 & 0.37 & 0.26 & 0.25 & 0.45 & 0.24 & 0.23 & 0.35 & 0.30 & 0.26 & 0.38 & 0.58 & 0.22 & 0.30 & 0.46 & 0.21 \\
\hline 150 & 0.08 & 0.26 & 0.34 & 0.33 & 0.48 & 0.27 & 0.26 & 0.51 & 0.39 & 0.26 & 0.57 & 0.32 & 0.38 & 0.39 & 0.64 & 0.21 & 0.31 & 0.51 & 0.36 \\
\hline 200 & 0.06 & 0.27 & 0.26 & 0.12 & 0.37 & 0.10 & 0.25 & 0.42 & 0.12 & 0.11 & 0.33 & 0.31 & 0.26 & 0.37 & 0.59 & 0.22 & 0.32 & 0.51 & 0.15 \\
\hline 300 & 0.10 & 0.46 & 0.37 & 0.26 & 0.45 & 0.18 & 0.32 & 0.49 & 0.26 & 0.19 & 0.43 & 0.34 & 0.37 & 0.37 & 0.71 & 0.22 & 0.27 & 0.76 & 0.21 \\
\hline 400 & 0.14 & 0.44 & 0.49 & 0.32 & 0.46 & 0.20 & 0.23 & 0.49 & 0.33 & 0.15 & 0.46 & 0.25 & 0.24 & 0.37 & 0.63 & 0.22 & 0.18 & 0.63 & 0.15 \\
\hline 500 & 0.17 & 0.44 & 0.54 & 0.35 & 0.45 & 0.21 & 0.12 & 0.49 & 0.35 & 0.15 & 0.46 & 0.12 & 0.22 & 0.37 & 0.55 & 0.22 & 0.14 & 0.54 & 0.16 \\
\hline 600 & 0.20 & 0.48 & 0.55 & 0.35 & 0.45 & 0.20 & 0.14 & 0.48 & 0.35 & 0.16 & 0.46 & 0.09 & 0.28 & 0.38 & 0.54 & 0.22 & 0.14 & 0.60 & 0.21 \\
\hline 800 & 0.10 & 0.20 & 0.28 & 0.12 & 0.30 & 0.04 & 0.07 & 0.37 & 0.12 & 0.07 & 0.28 & 0.07 & 0.12 & 0.38 & 0.35 & 0.22 & 0.18 & 0.26 & 0.14 \\
\hline 1,000 & 0.08 & 0.16 & 0.22 & 0.10 & 0.29 & 0.02 & 0.06 & 0.37 & 0.10 & 0.05 & 0.28 & 0.03 & 0.08 & 0.38 & 0.35 & 0.22 & 0.20 & 0.22 & 0.14 \\
\hline 1,200 & 0.09 & 0.15 & 0.21 & 0.08 & 0.29 & 0.02 & 0.08 & 0.37 & 0.08 & 0.04 & 0.27 & 0.01 & 0.07 & 0.38 & 0.37 & 0.22 & 0.21 & 0.23 & 0.15 \\
\hline 1,400 & 0.08 & 0.17 & 0.19 & 0.08 & 0.29 & 0.02 & 0.07 & 0.37 & 0.08 & 0.05 & 0.27 & 0.01 & 0.09 & 0.38 & 0.36 & 0.22 & 0.21 & 0.24 & 0.13 \\
\hline 1,600 & 0.07 & 0.16 & 0.18 & 0.08 & 0.29 & 0.01 & 0.07 & 0.37 & 0.08 & 0.06 & 0.27 & 0.01 & 0.08 & 0.38 & 0.35 & 0.22 & 0.22 & 0.22 & 0.13 \\
\hline 1,800 & 0.17 & 0.56 & 0.44 & 0.53 & 0.62 & 0.12 & 0.15 & 0.67 & 0.58 & 0.14 & 0.88 & 0.02 & 0.31 & 0.36 & 0.72 & 0.34 & 0.16 & 0.69 & 0.31 \\
\hline 2,000 & 0.24 & 0.63 & 0.49 & 0.43 & 0.48 & \begin{tabular}{|l|}
0.07 \\
\end{tabular} & 0.19 & 0.58 & 0.45 & 0.16 & 0.63 & 0.01 & 0.54 & 0.36 & 0.58 & 0.39 & 0.12 & 0.81 & 0.50 \\
\hline 2,200 & 0.06 & 0.13 & 0.15 & 0.06 & 0.23 & \begin{tabular}{|l|}
0.02 \\
\end{tabular} & 0.06 & 0.29 & 0.06 & 0.05 & 0.33 & 0.01 & 0.07 & 0.38 & 0.29 & 0.22 & 0.17 & 0.19 & 0.11 \\
\hline 2,400 & 0.06 & 0.15 & 0.17 & 0.07 & 0.28 & 0.02 & 0.06 & 0.36 & 0.07 & 0.06 & 0.28 & 0.01 & 0.08 & 0.38 & 0.33 & 0.22 & 0.21 & 0.20 & 0.13 \\
\hline 5,000 & 0.06 & 0.15 & 0.15 & 0.07 & 0.29 & 0.01 & 0.06 & 0.37 & 0.07 & 0.06 & 0.27 & 0.04 & 0.08 & 0.38 & 0.35 & 0.22 & 0.22 & 0.20 & 0.15 \\
\hline 7,000 & 0.04 & 0.14 & 0.15 & 0.07 & 0.30 & 0.00 & 0.07 & 0.38 & 0.07 & 0.06 & 0.27 & 0.06 & 0.08 & 0.38 & 0.35 & 0.22 & 0.24 & 0.19 & 0.17 \\
\hline 10,000 & 0.03 & 0.14 & 0.14 & 0.06 & 0.30 & 0.01 & 0.07 & 0.38 & 0.06 & 0.05 & 0.27 & 0.08 & 0.07 & 0.38 & 0.35 & 0.22 & 0.25 & 0.16 & 0.20 \\
\hline 20,000 & 0.04 & 0.14 & 0.13 & 0.06 & 0.30 & 0.01 & 0.09 & 0.38 & 0.06 & 0.05 & 0.27 & 0.12 & 0.08 & 0.38 & 0.35 & 0.22 & 0.26 & 0.15 & 0.22 \\
\hline 50,000 & 0.04 & 0.14 & 0.09 & 0.05 & 0.29 & 0.02 & 0.10 & 0.37 & 0.05 & 0.06 & 0.27 & 0.12 & 0.09 & 0.38 & 0.37 & 0.22 & 0.27 & 0.16 & 0.23 \\
\hline 100,000 & 0.02 & 0.13 & 0.08 & 0.05 & 0.29 & 0.02 & 0.10 & 0.37 & 0.05 & 0.05 & 0.27 & 0.12 & 0.08 & 0.38 & 0.37 & 0.22 & 0.27 & 0.16 & 0.23 \\
\hline
\end{tabular}


Table 6.2-3. Standard Deviations in Water and Gas Compositions Predicted in Zones of High Liquid Saturation above the Drift Crown (FRONT - TOP, Fractures) (Continued)

\begin{tabular}{|c|c|c|c|c|c|c|c|c|c|c|c|c|c|c|c|c|c|c|c|}
\hline $\begin{array}{c}\text { Interval } \\
\text { (yr) }\end{array}$ & $\mathrm{pH}$ & $\mathrm{Ca}$ & Mg & $\mathrm{Na}$ & Chloride & Silica & Carbonate & Sulfate & $\mathbf{K}$ & Fluoride & Nitrate & $\begin{array}{c}\mathrm{CO}_{2} \\
\text { (gas) }\end{array}$ & $\mathrm{Ca} / \mathrm{Na}$ & $\mathrm{NO}_{3} / \mathrm{Cl}$ & $\mathrm{HCO}_{3} / \mathrm{Cl}$ & $\mathrm{SO}_{4} / \mathrm{Cl}$ & $\mathrm{Na} / \mathrm{Cl}$ & $\mathrm{Ca} / \mathrm{CO}_{3}$ & $\mathrm{Ca} / \mathrm{Cl}$ \\
\hline $\begin{array}{l}0- \\
100,000\end{array}$ & 0.10 & 0.27 & 0.30 & 0.21 & 0.38 & 0.12 & 0.15 & 0.44 & 0.21 & 0.14 & 0.39 & 0.12 & 0.23 & 0.38 & 0.47 & 0.23 & 0.23 & 0.40 & 0.24 \\
\hline $\begin{array}{l}150- \\
600\end{array}$ & 0.12 & 0.39 & 0.42 & 0.29 & 0.44 & 0.19 & 0.22 & 0.48 & 0.30 & 0.17 & 0.45 & 0.24 & 0.29 & 0.38 & 0.61 & 0.22 & 0.23 & 0.59 & 0.21 \\
\hline \begin{tabular}{|l|}
$600-$ \\
2,000 \\
\end{tabular} & 0.13 & 0.31 & 0.32 & 0.22 & 0.38 & 0.06 & 0.10 & 0.45 & 0.23 & 0.09 & 0.42 & 0.03 & 0.20 & 0.37 & 0.45 & 0.26 & 0.18 & 0.41 & 0.21 \\
\hline \begin{tabular}{|l|}
$2,000-$ \\
100,000 \\
\end{tabular} & 0.07 & 0.20 & 0.17 & 0.10 & 0.31 & 0.02 & 0.09 & 0.39 & 0.10 & 0.07 & 0.32 & 0.06 & 0.13 & 0.38 & 0.37 & 0.24 & 0.22 & 0.25 & 0.22 \\
\hline Maximum & 0.34 & 0.72 & 0.70 & 0.88 & 0.92 & 0.88 & 0.58 & 0.95 & 0.88 & 0.87 & 0.92 & 0.34 & 1.28 & 0.39 & 0.90 & 0.39 & 0.36 & 1.28 & 1.19 \\
\hline
\end{tabular}

Input DTNS: LB0302DSCPTHCS.002 [DIRS 161976]; LB0307DSTTHCR2.002 [DIRS 165541].

Output DTN: LB0311ABSTHCR2.001 [DIRS 166714].

NOTE: $\quad$ Standard deviation values are shown for Group 1 simulations using input water compositions W0, W4, W5, W6, and W7. The data of standard deviation are extracted from spreadsheet stdev, in top-front f1.xls (DTN: LB0311ABSTHCR2.001 [DIRS 166714]). For pH, standard deviation is given in ( \pm ) pH units. For other data, standard deviation of logarithmic values of total molality for aqueous species, volume fraction for CO2, and unitless molal ratios, thus representing a $( \pm)$ change in log10 values of concentrations and concentration ratios around the mean of log10 values (e.g., 0.5 corresponds to total spread of one order of magnitude). The bottom of the table shows averages of individual standard deviations over the time intervals shown. See Appendix B for details. 


\subsection{Zone of Increased Liquid Saturation above the Drift (HISAT-TOP-fracture)}

When temperatures around the drift exceed the boiling point of water (the boiling period), HISAT-TOP waters from the fracture continuum represent the condensation zone above the drift. After the boiling period, these waters represent the zone of increased liquid saturation above the drift resulting from the diversion of percolating water by the drift opening and/or zones of lower permeability created by mineral precipitation during the boiling period (e.g., BSC 2004 [DIRS 169856], Section 6.5.5.3).

The predicted compositions of HISAT-TOP waters in fractures, and associated $\mathrm{CO}_{2}$ partial pressures, were analyzed in Drift-Scale THC Seepage Model (BSC 2004 [DIRS 169856], Section 6.5.5.2.2). The analysis here includes runs using five different input water compositions, for six gridblock indices. Therefore the sample size is 30 (5 input waters and 6 indices). Standard deviations in concentrations of aqueous species and $\mathrm{CO}_{2}$ gas in fractures predicted from Group 1 simulations are given in Drift-Scale THC Seepage Model (BSC 2004 [DIRS 169856], Section 6.6.2). These deviations of component concentrations and concentration ratios are more thoroughly shown here in Table 6.2-2. The "whisker" plots for all HISAT-TOP waters in fractures (including points assigned to INDX=1 through 6) (Figures 6.2-4c through 6.2-20c) were visually compared to the minimum, maximum, and mean concentrations for subsets of these waters assigned to a single INDX value. In doing so, waters assigned to INDX=5 were found to provide a reasonably representative subset of the full data. The time profiles of the minimum, maximum, and mean concentrations for these waters (INDX=5) are shown superposed on the "whiskers" in Figures 6.2-4c through 6.2-20c. These figures show that these waters have mean concentrations (dashed lines) close to the means for the complete data set (filled circles) at most points in time. Also, the minimum and maximum concentrations (solid lines) of these waters typically encompass the two standard deviations (wide bars) calculated from the full data set.

The shapes, through time, of predicted concentration profiles for HISAT-TOP waters in fractures, and the reasons behind these shapes, are discussed in Drift-Scale THC Seepage Model (BSC 2004 [DIRS 169856], Section 6.5.5.2.2). Here, the focus is given to variations in relative spread through time for these model results. From Figures 6.2-4c through 6.2-20c, the concentrations of most aqueous species show a larger spread during the evaporative concentration period (from $\sim 150$ to 600 years) than at later times. Examples are calcium, magnesium, sodium, and potassium (Figures 6.2-13a, 6.2-16a, 6.2-17a, and 6.2-19a). During this time period, spatial variation in the degree of evaporative concentration above the drift is expected to add variability to predicted concentrations. This is supported by the plots of concentration ratios to chloride (e.g., Figures 6.2-9c, 6.2-14c, 6.2-18c), which show smaller differences in spread than the plots of individual concentrations for the time period from 150 to 600 years and beyond (e.g., Figures 6.2-8c, 6.2-13c, and 6.2-17c).

In general, Figures 6.2-4 through 6.2-20 (and in Tables 6.2-2 and 6.2-3) show that the two-standard-deviation spread in predicted concentrations and concentration ratios for Group 1 remains mostly below one order of magnitude. The decreased spread at later times is caused by incoming waters that become less variable because of reaction with the wallrock (same mineral assemblage in all runs) and evolve along similar temperature paths (e.g., BSC 2004 [DIRS 169856], Figure 6.5-22). The most visible examples of such homogenization are concentration 
profiles for aqueous species constrained by near-saturation with respect to fast reacting minerals, such as fluoride constrained by fluorite (Figure 6.2-12c) and aqueous silica constrained by amorphous silica (Figure 6.2-20c). The spread in predicted $\mathrm{CO}_{2}$ concentrations for some time after the evaporative concentration stage (Figure 6.2-5c) is also sharply reduced. This reduction in spread is attributed to incoming waters impacted (in each run) to a similar extent with $\mathrm{CO}_{2}$ exsolved from matrix water and mobilized into fractures (i.e., impact by $\mathrm{CO}_{2}$ enriched condensate) (BSC 2004 [DIRS 169856], Section 6.5.5.2.2).

\subsection{Boiling/Wetting Front (FRONT Waters)}

The other three potential seepage waters from the boiling/wetting front are those with attributes FRONT-TOP and FRONT-BASE in fractures, and FRONT-BASE in the matrix (Section 6.2.1.1). As mentioned earlier, these waters could be considered more representative of potential in-drift seepage than HISAT waters because the latter would likely evolve towards the composition of FRONT waters as they percolate towards the drift.

Summary statistics for FRONT waters are calculated and displayed in the same manner as done previously with HISAT waters. Standard deviations are, in general, larger for FRONT waters (Table 6.2-3) than for HISAT waters (Table 6.2-2). The spread for FRONT waters is expected to be somewhat larger than for HISAT waters, because wet model gridblocks closest to the boiling/wetting front exhibit liquid saturations that are smaller and more variable than in zones of higher liquid saturation. The increase in the variability of liquid saturation translates into an increase in the variability of evaporative concentration effects, thus affecting the variability of predicted concentrations. Note that standard deviations in Tables 6.2-2 and 6.2-3 represent only the TOP quadrant data. Standard deviations for FRONT-BASE waters (fractures and matrix) are included in data files accompanying this report (Appendix B) and are generally also larger than for HISAT waters. These data are also shown in Figures 6.2-4 through 6.2-20 for Group 1 model results.

Summary statistics for FRONT waters from Group 1 are plotted as done previously for other waters (Figures 6.2-4a, b, d through 6.2-20a, b, d). FRONT waters assigned to INDX=4 provide a reasonably representative subset of the complete data (i.e., including INDX values 1 through 6) because of numerical oscillation of predicted concentrations for very low saturation. For this reason, concentration data at those gridblocks with the saturation below threshold is avoided.

FRONT-TOP waters show an increased spread in predicted concentrations for many constituents during the evaporative concentration period (approximately 150 to 600 years), most noticeably for calcium, magnesium, sodium, and potassium (Figures 6.2-13a, 6.2-16a, 6.2-17a, and 6.2-19a). A similar increase was noted with HISAT-TOP waters, although to a somewhat lesser extent (e.g., Figures 6.2-13c, 6.2-16c, 6.2-17c, and 6.2-19c). For FRONT-TOP waters, however, the spread also increases sharply at around 2,000 years. This pattern is not observed with the other waters (HISAT-TOP or FRONT-BASE) and results from the dissolution of salts when the boiling front recedes towards the drift wall at around 2,000 years. These salts were deposited as the result of dryout in fractures around the drift (see BSC 2004 [DIRS 169856], Sections 6.4.5 and 6.5.5.3). 
This effect is not noticeable in HISAT waters because the zone of high liquid saturation does not immediately collapse back to the drift wall when the boiling front recedes. This is because percolation waters are partly diverted by, and accumulate above (and within) a thin lowpermeability zone formed above the drift at the edge of the dryout zone during the boiling period, primarily as the result of silica precipitation by evaporative concentration. This low-permeability zone persists after boiling ends (BSC 2004 [DIRS 169856], Section 6.5.5.3) and stabilizes the area of higher liquid saturation above the drift. In other words, FRONT water represents seepage water better than HISAT water does. Therefore, the saturation zones (HISAT and FRONT) can be further narrowed down to FRONT water zone only.

The matrix rewets sooner (at approximately 200 to 300 years) than fractures (at approximately 2,000 years), and matrix dryout is not as extensive as in fractures. As a result, profiles for FRONT-BASE matrix waters (Figures 6.2-7d, 6.2-13d, 6.2-17d) mostly do not show an increase in spread around 2,000 years, as do FRONT-BASE fracture waters (e.g., Figures 6.2-7b, 6.2-13b, and $6.2-17 \mathrm{~b}$ ). Instead, some increase in spread is noticeable at around 200 to 400 years, mainly for magnesium, sodium, and potassium (Figures 6.2-16d, 6.2-17d, and 6.2-19d). Since flow of FRONT-BASE water in fractures is dominated by gravity, it is unlikely to be imbibed back to the drift. The FRONT-BASE water in the matrix better represents the water imbibition from the invert.

Note that the larger spread of $\mathrm{pH}$ values at 5,000 and 7,000 years for FRONT-BASE waters (Figure 6.2-4b) is an artifact that occurs when liquids saturation approaches zero. It is caused by $\mathrm{pH}$ values near 8.8 and 9.5 in a single model gridblock that escaped rewetting until this time period, and for which water was not fully chemically speciated, because of constraints on ionic strength during speciation computations (BSC 2004 [DIRS 169856], Section 6.5.5.2). This also explains the lack of a similar spread increase in the $\mathrm{CO}_{2}$ concentration profile during the same time period (Figure 6.2-5b).

Similar to HISAT waters, the two-standard-deviation spread in predicted concentrations for FRONT waters typically remains within one order of magnitude (Figures 6.2-4 through 6.2-20 and Table 6.2-3). As observed with HISAT waters, the spread is often smaller at later times, particularly for aqueous species, such as fluoride and aqueous silica (Figures 6.2-12 and 6.2-20), constrained by near-saturation with respect to fast reactions. The spread of $\mathrm{CO}_{2}$ after the evaporative concentration stage (after $\sim 600$ years) (Figure 6.2-5) also decreases, for the same reasons discussed earlier for HISAT waters.

In summary, predicted concentrations of water and gas, as functions of time, show more variability for FRONT-TOP water in fractures and for FRONT-BASE water in matrix. For both FRONT-TOP-fracture and FRONT-BASE-matrix waters, INDX=4 provides a reasonably representative subset of the complete data. 
(a)

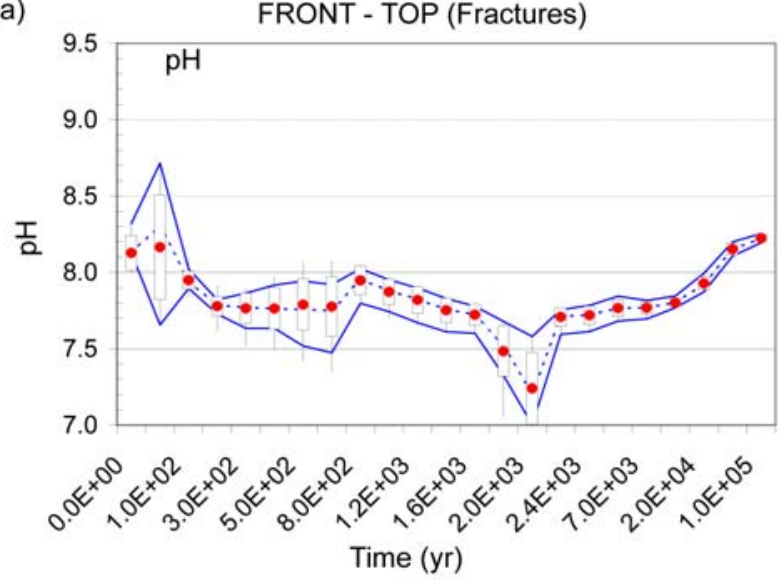

(c)

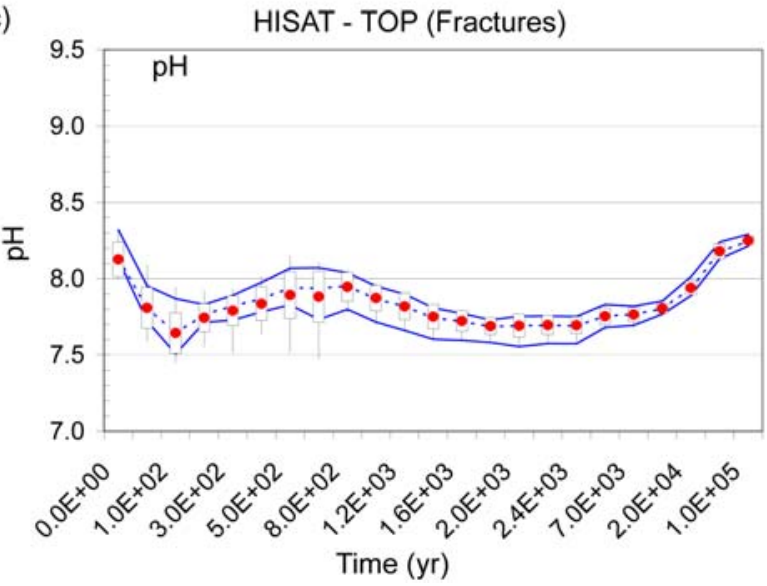

(b)

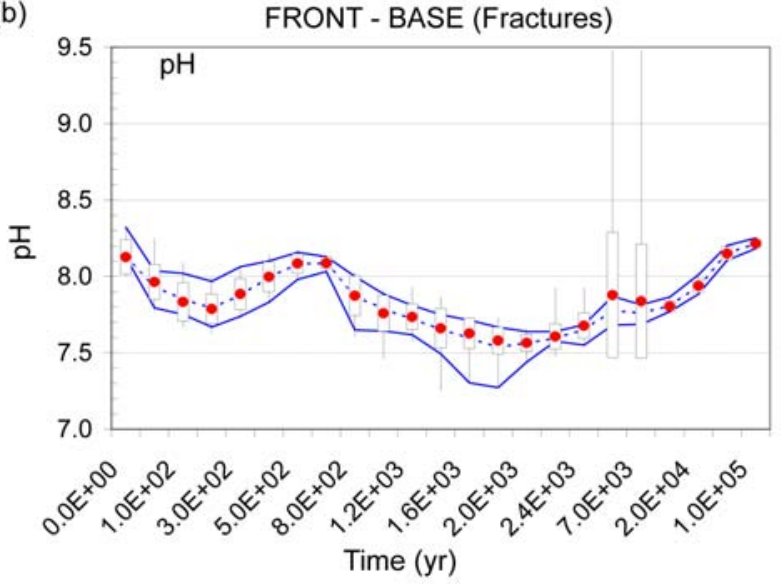

(d)

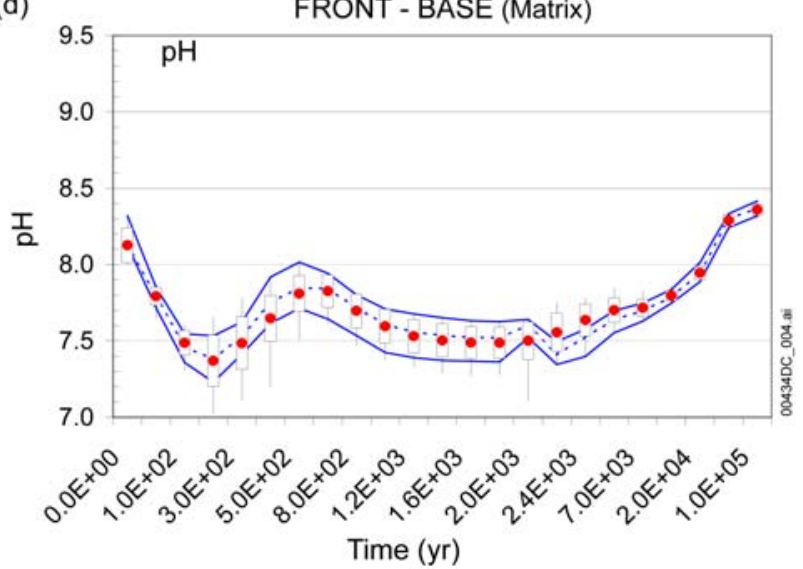

Input DTNs: $\quad$ LB0302DCSPTHCS.002 [DIRS 161976]; LB0307DSTTHCR2.002 [DIRS 165541].

Output DTN: LB0311ABSTHCR2.001 [DIRS 166714].

NOTE: Results for Group 1 simulations. Vertical lines define the spread between minimum and maximum values. Wide vertical bars define two times the standard deviation, centered around the mean (solid circles). Line profiles represent minimum and maximum values (solid lines) and mean (dashed lines) for subsets of data represented by INDX=4 for FRONT waters and INDX=5 for HISAT waters. See text (Section 6.2.3). The spacing of time values on the horizontal axis is not to scale.

Figure 6.2-4. Selection of Model Results around the Modeled Drift as a Function of Time: $\mathrm{pH}$ 
(a)

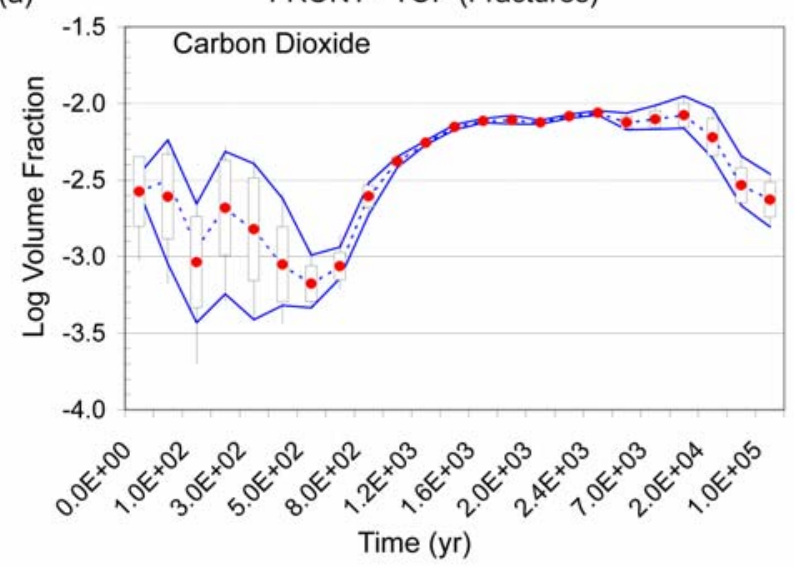

(c)

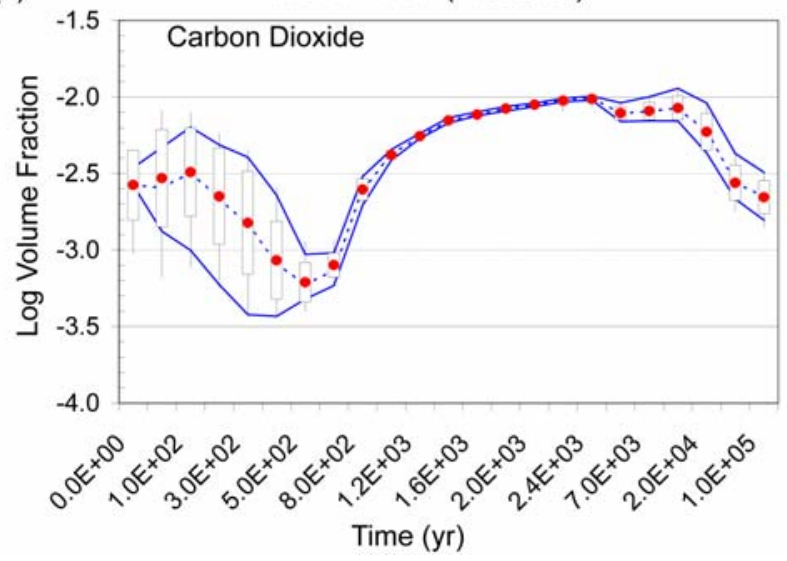

(b)

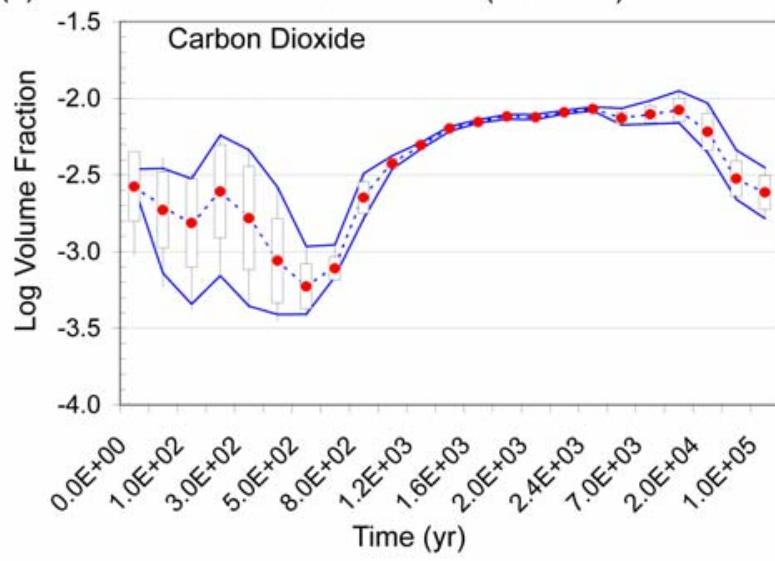

(d)

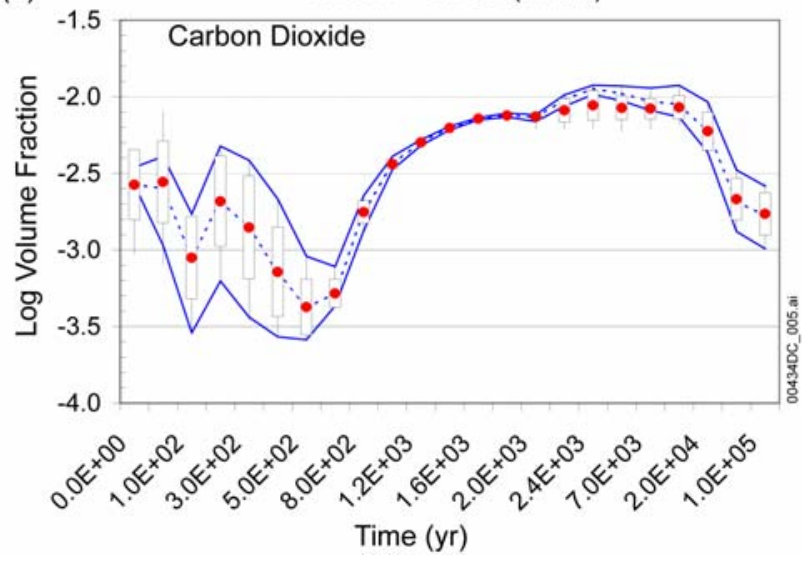

Input DTNs: $\quad$ LB0302DCSPTHCS.002 [DIRS 161976]; LB0307DSTTHCR2.002 [DIRS 165541].

Output DTN: LB0311ABSTHCR2.001 [DIRS 166714].

NOTE: Results for Group 1 simulations, log-transform data. Vertical lines define the spread between minimum and maximum values. Wide vertical bars define two times the standard deviation, centered around the mean (solid circles). Line profiles represent minimum and maximum values (solid lines) and mean (dashed lines) for subsets of data represented by INDX $=4$ for FRONT waters and INDX $=5$ for HISAT waters. See text (Section 6.2.3). The spacing of time values on the horizontal axis is not to scale.

Figure 6.2-5. Selection of Model Results around the Modeled Drift as a Function of Time: Volume Fraction of Carbon Dioxide Gas 
(a)

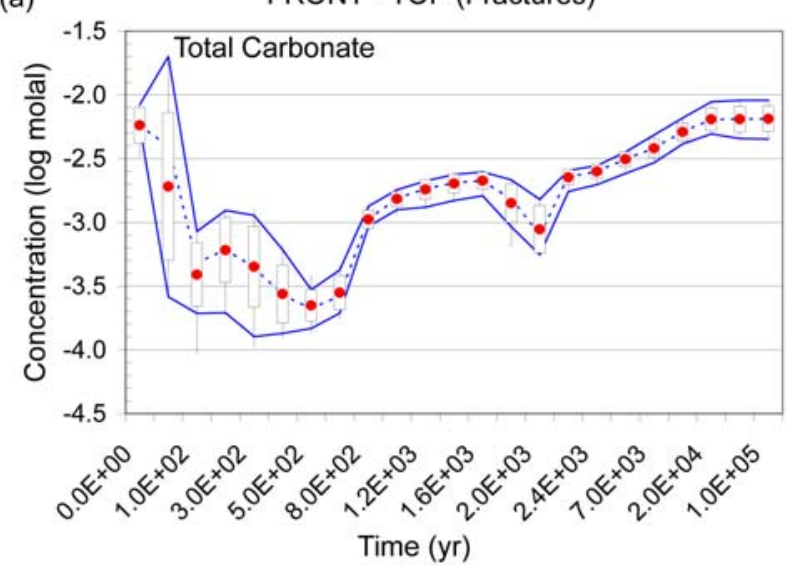

(c)

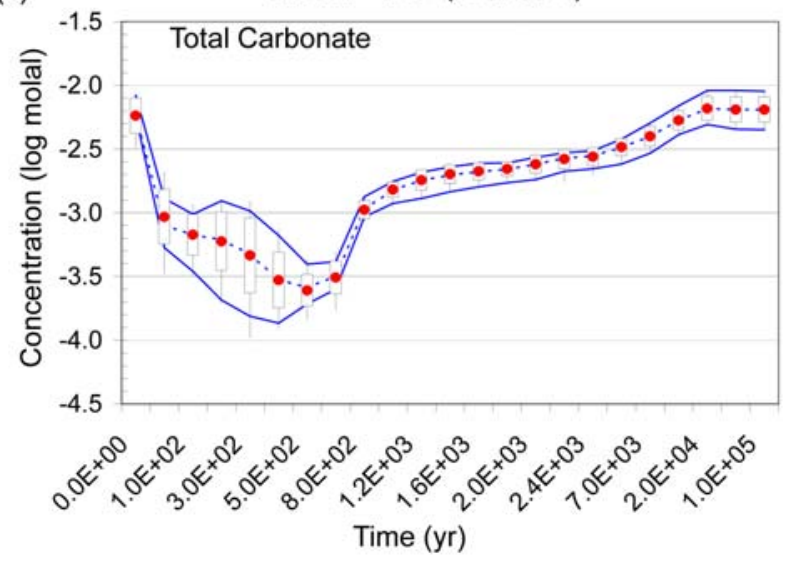

(b)

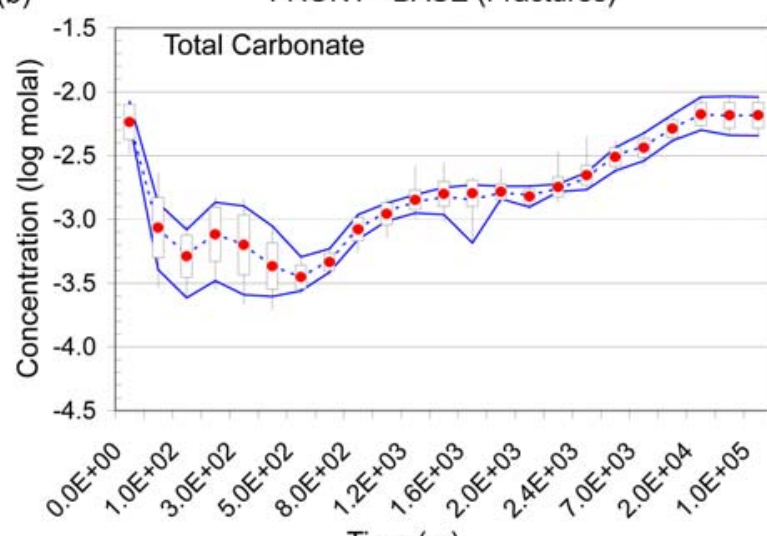

Time (yr)

(d)

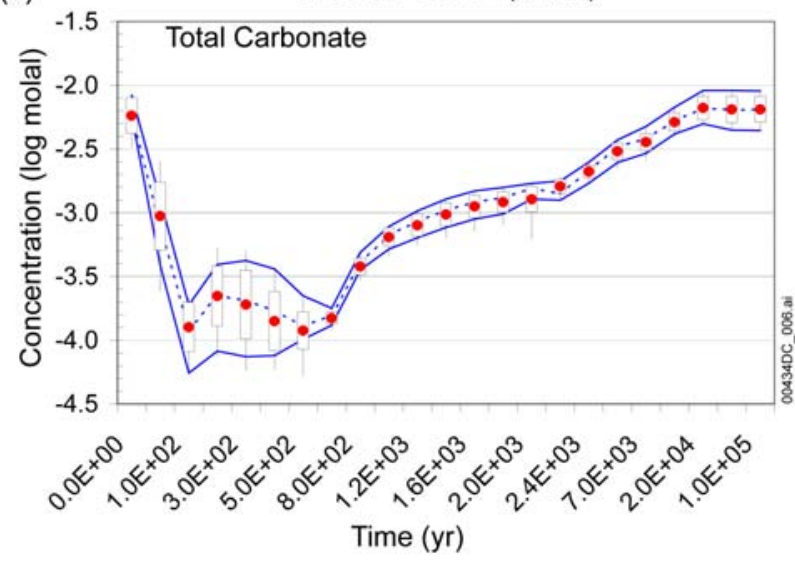

Input DTNs: $\quad$ LB0302DCSPTHCS.002 [DIRS 161976]; LB0307DSTTHCR2.002 [DIRS 165541].

Output DTN: LB0311ABSTHCR2.001 [DIRS 166714].

NOTE: Results for Group 1 simulations, log-transform data. Vertical lines define the spread between minimum and maximum values. Wide vertical bars define two times the standard deviation, centered around the mean (solid circles). Line profiles represent minimum and maximum values (solid lines) and mean (dashed lines) for subsets of data represented by INDX=4 for FRONT waters and INDX=5 for HISAT waters. See text (Section 6.2.3). The spacing of time values on the horizontal axis is not to scale.

Figure 6.2-6. Selection of Model Results around the Modeled Drift as a Function of Time: Total Aqueous Carbonate Concentration 
(a)

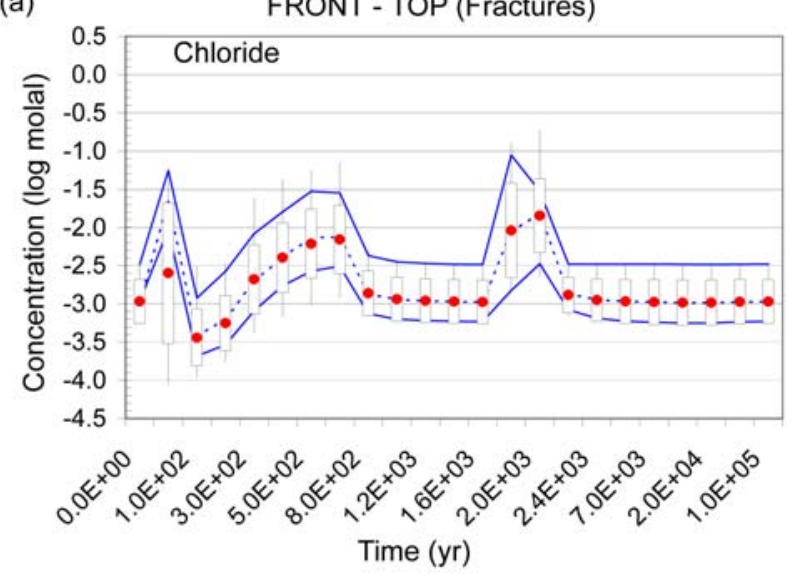

(c)

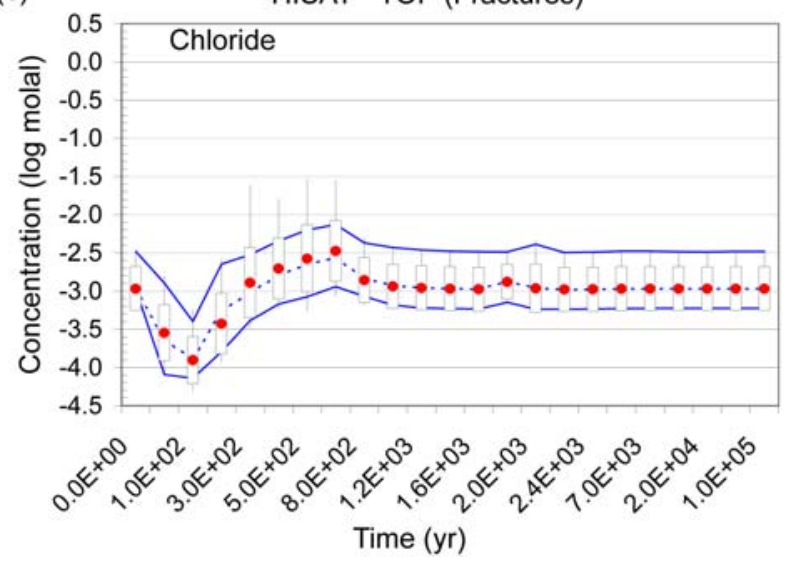

(b)

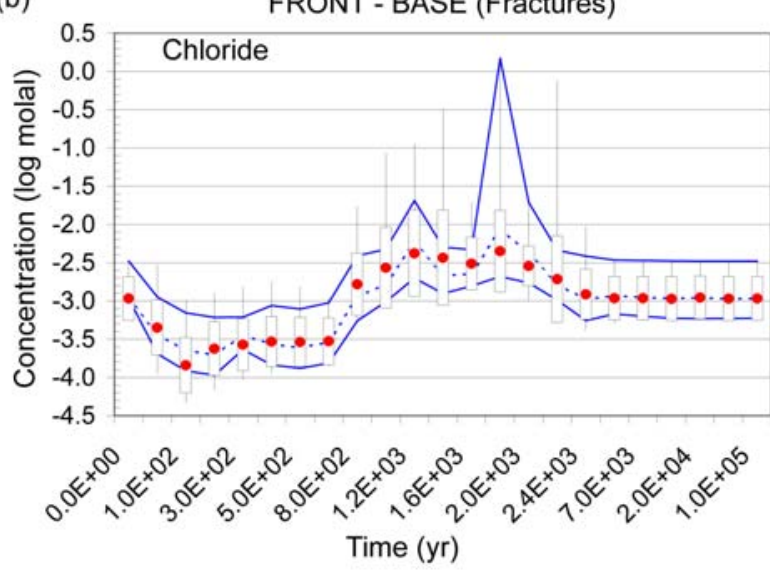

(d)

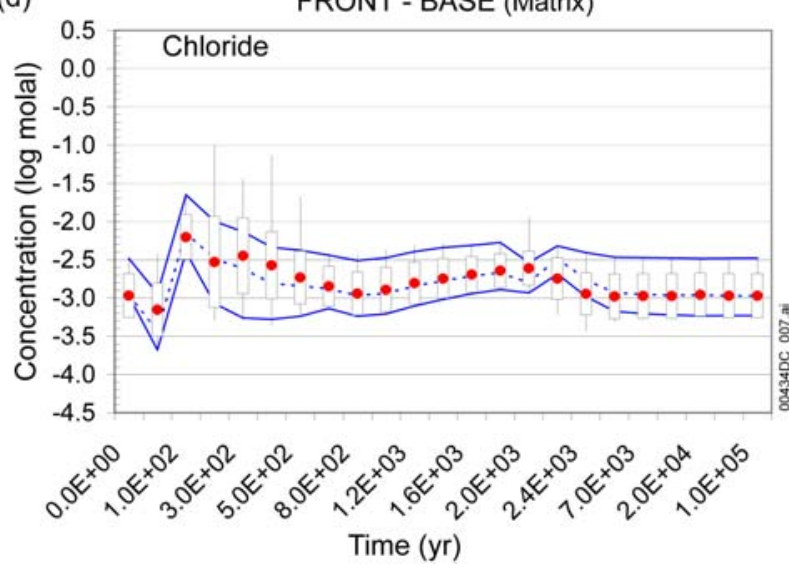

Input DTNs: $\quad$ LB0302DCSPTHCS.002 [DIRS 161976]; LB0307DSTTHCR2.002 [DIRS 165541].

Output DTN: LB0311ABSTHCR2.001 [DIRS 166714].

NOTE: Results for Group 1 simulations, log-transform data. Vertical lines define the spread between minimum and maximum values. Wide vertical bars define two times the standard deviation, centered around the mean (solid circles). Line profiles represent minimum and maximum values (solid lines) and mean (dashed lines) for subsets of data represented by INDX $=4$ for FRONT waters and INDX $=5$ for HISAT waters. See text (Section 6.2.3). The spacing of time values on the horizontal axis is not to scale.

Figure 6.2-7. Selection of Model Results around the Modeled Drift as a Function of Time: Total Aqueous Chloride Concentration 
(a)

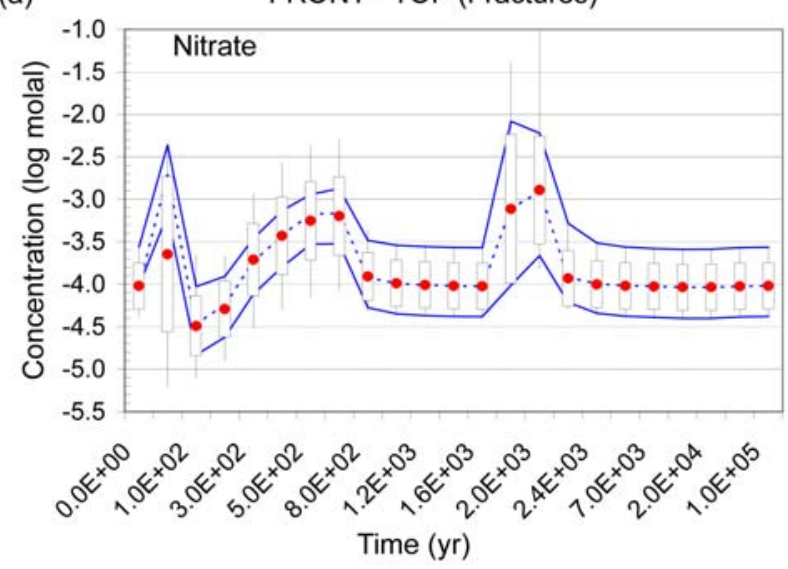

(c)

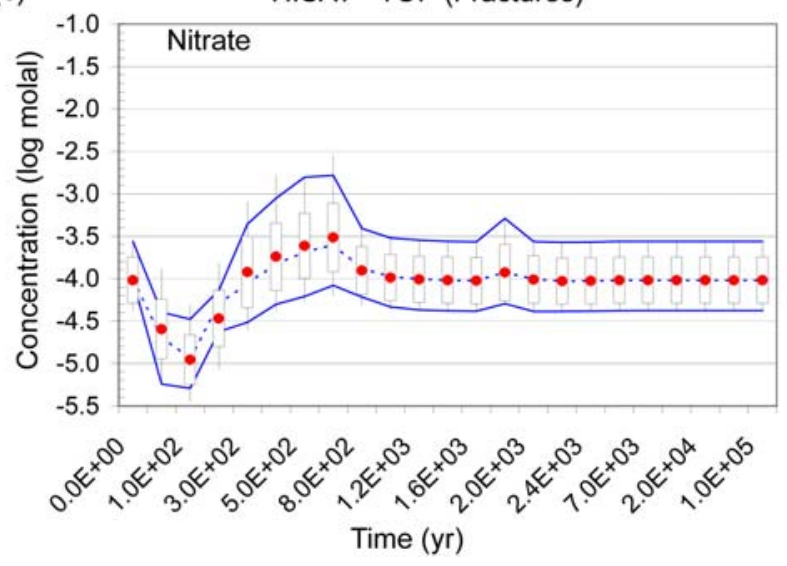

(b)

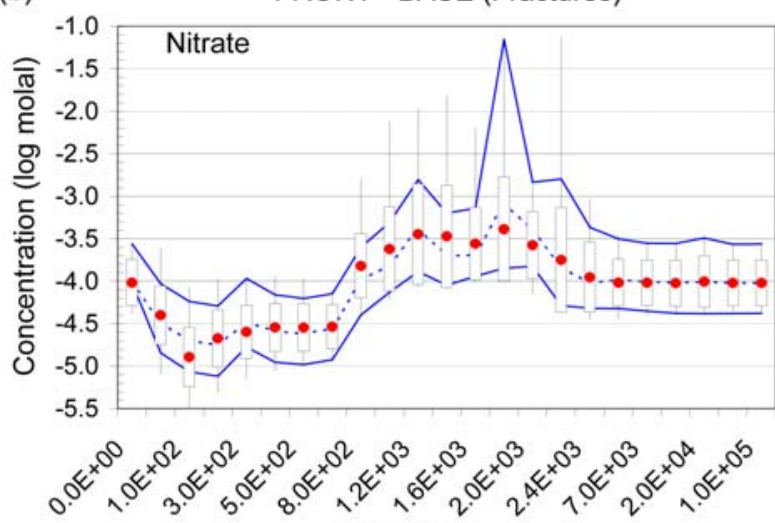

Time (yr)

(d)

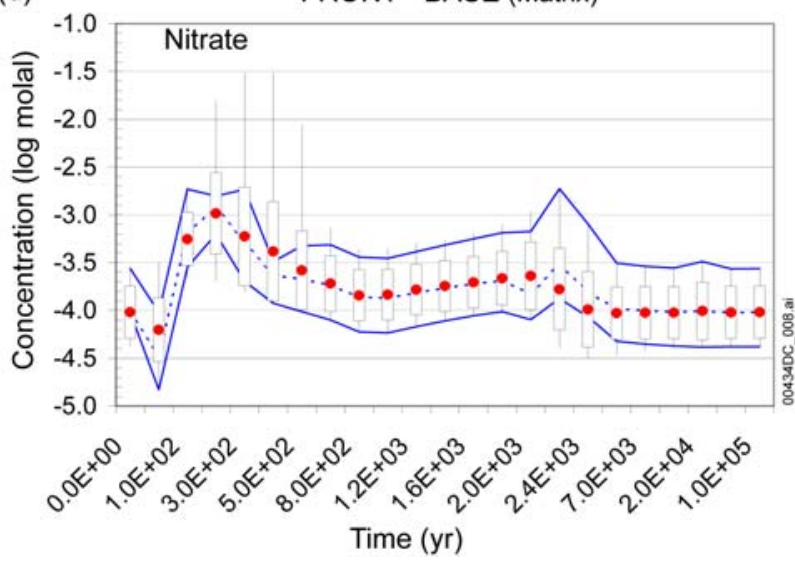

Input DTNs: $\quad$ LB0302DCSPTHCS.002 [DIRS 161976]; LB0307DSTTHCR2.002 [DIRS 165541].

Output DTN: LB0311ABSTHCR2.001 [DIRS 166714].

NOTE: Results for Group 1 simulations, log-transform data. Vertical lines define the spread between minimum and maximum values. Wide vertical bars define two times the standard deviation, centered around the mean (solid circles). Line profiles represent minimum and maximum values (solid lines) and mean (dashed lines) for subsets of data represented by INDX=4 for FRONT waters and INDX=5 for HISAT waters. See text (Section 6.2.3). The spacing of time values on the horizontal axis is not to scale.

Figure 6.2-8. Selection of Model Results around the Modeled Drift as a Function of Time: Total Aqueous Nitrate Concentration 
(a)

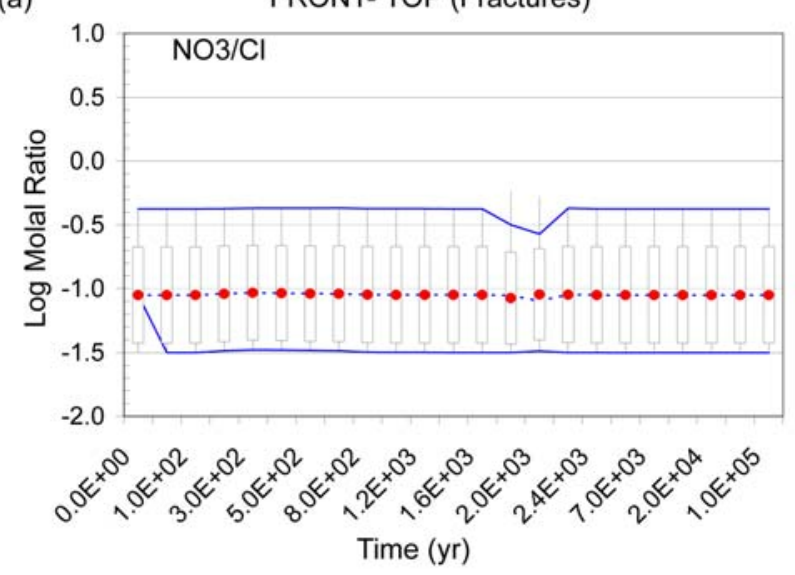

(c)

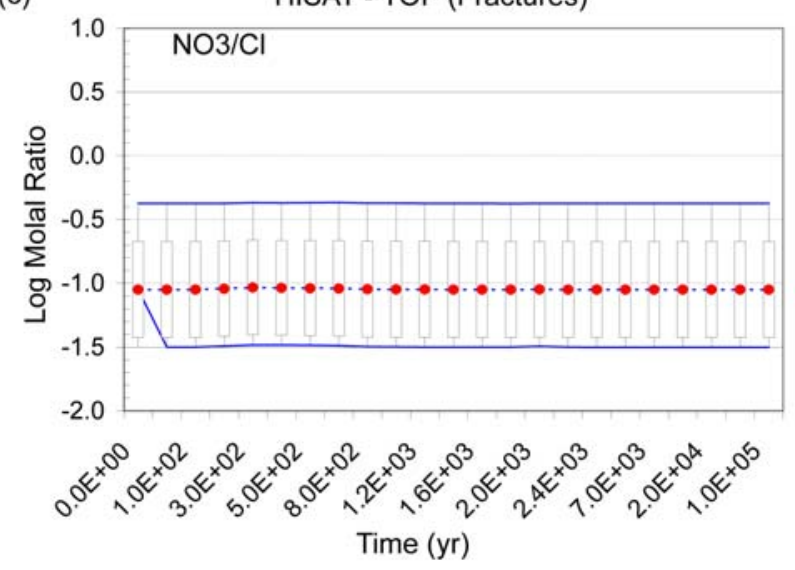

(b)

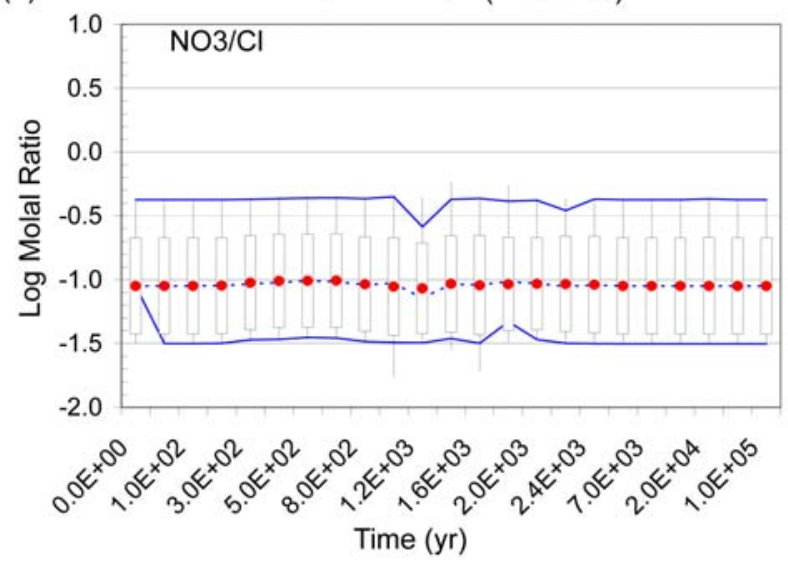

(d)

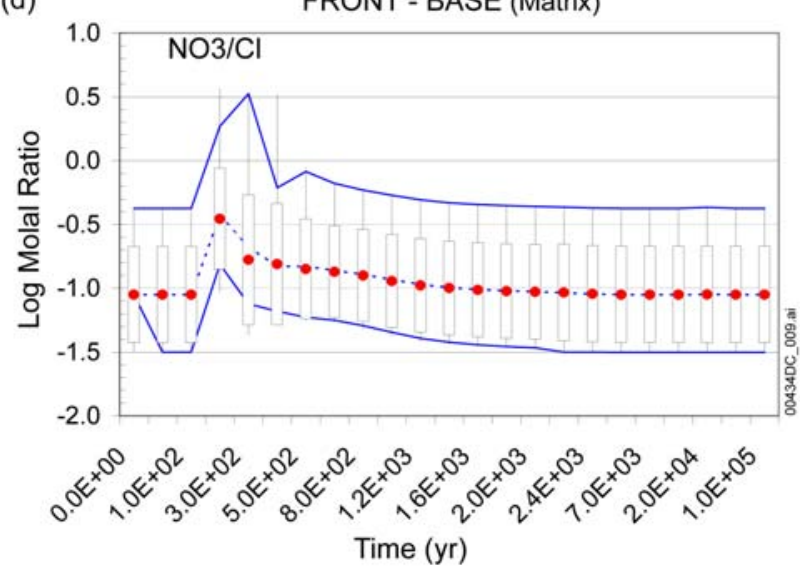

Input DTNs: $\quad$ LB0302DCSPTHCS.002 [DIRS 161976]; LB0307DSTTHCR2.002 [DIRS 165541].

Output DTN: LB0311ABSTHCR2.001 [DIRS 166714].

NOTE: $\quad$ Results for Group 1 simulations, log-transform data. Vertical lines define the spread between minimum and maximum values. Wide vertical bars define two times the standard deviation, centered around the mean (solid circles). Line profiles represent minimum and maximum values (solid lines) and mean (dashed lines) for subsets of data represented by INDX=4 for FRONT waters and INDX=5 for HISAT waters. See text (Section 6.2.3). The spacing of time values on the horizontal axis is not to scale.

Figure 6.2-9. Selection of Model Results around the Modeled Drift as a Function of Time: Ratio of Total Aqueous Nitrate to Total Aqueous Chloride Concentrations 
(a)

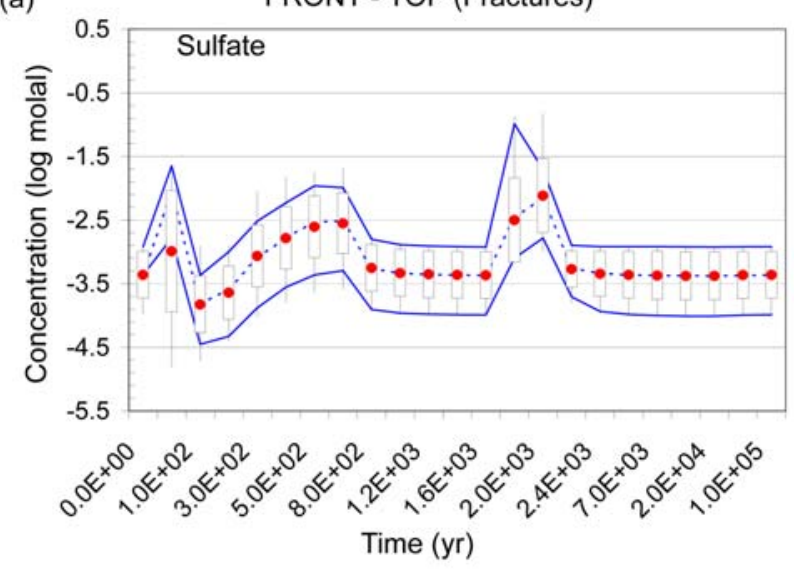

(c)

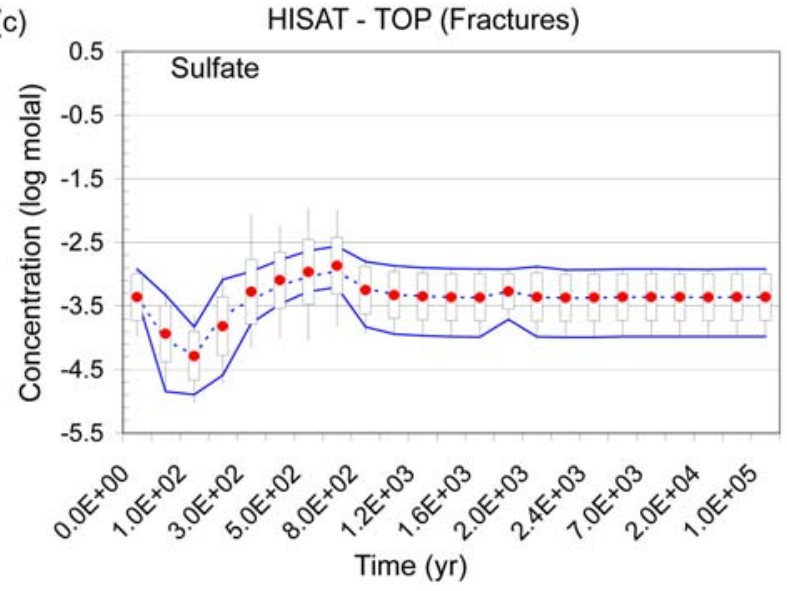

(b)

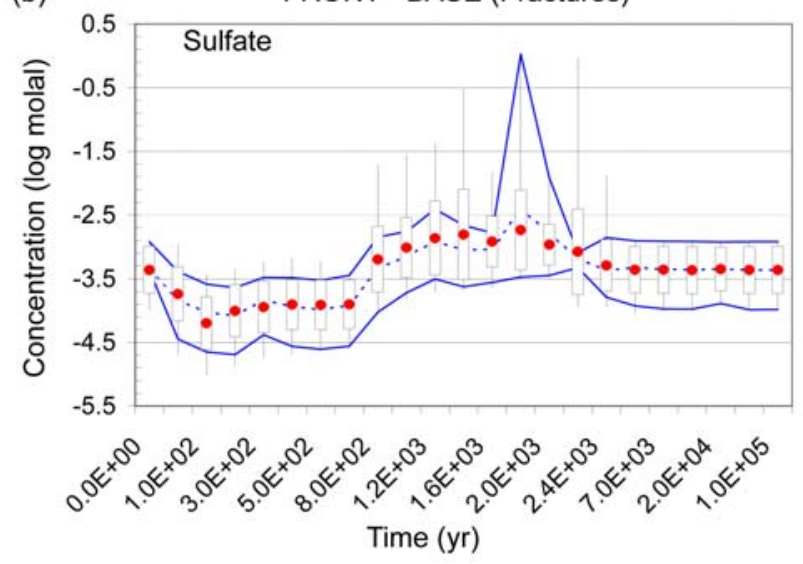

(d)

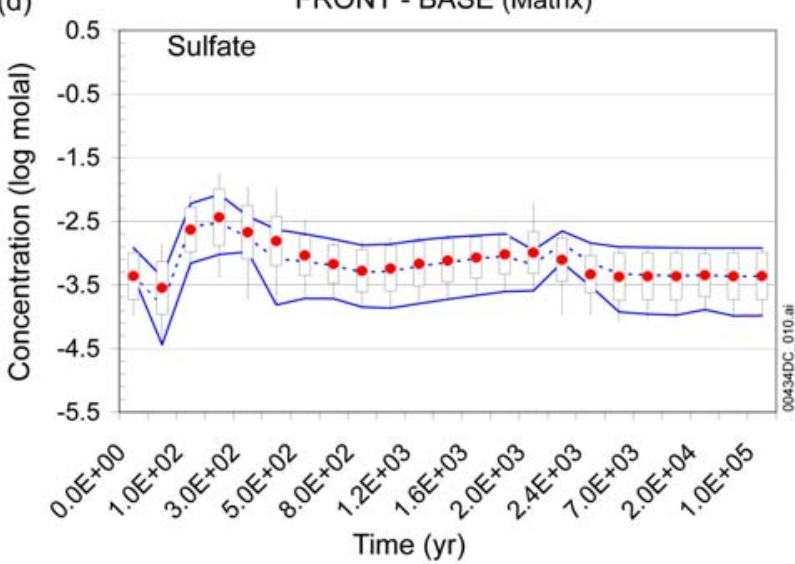

Input DTNs: $\quad$ LB0302DCSPTHCS.002 [DIRS 161976]; LB0307DSTTHCR2.002 [DIRS 165541].

Output DTN: LB0311ABSTHCR2.001 [DIRS 166714].

NOTE: $\quad$ Results for Group 1 simulations, log-transform data. Vertical lines define the spread between minimum and maximum values. Wide vertical bars define two times the standard deviation, centered around the mean (solid circles). Line profiles represent minimum and maximum values (solid lines) and mean (dashed lines) for subsets of data represented by INDX=4 for FRONT waters and INDX=5 for HISAT waters. See text (Section 6.2.3). The spacing of time values on the horizontal axis is not to scale.

Figure 6.2-10. Selection of Model Results around the Modeled Drift as a Function of Time: Total Aqueous Sulfate Concentration 
(a)

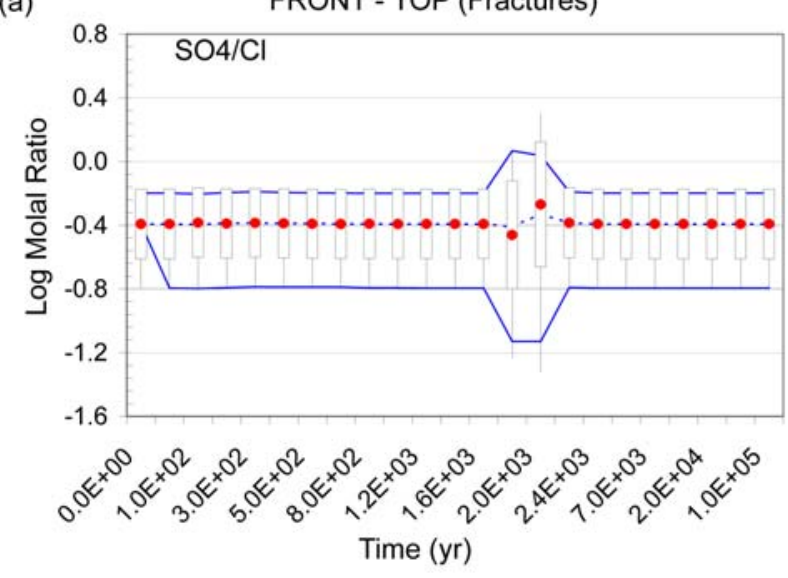

(c)

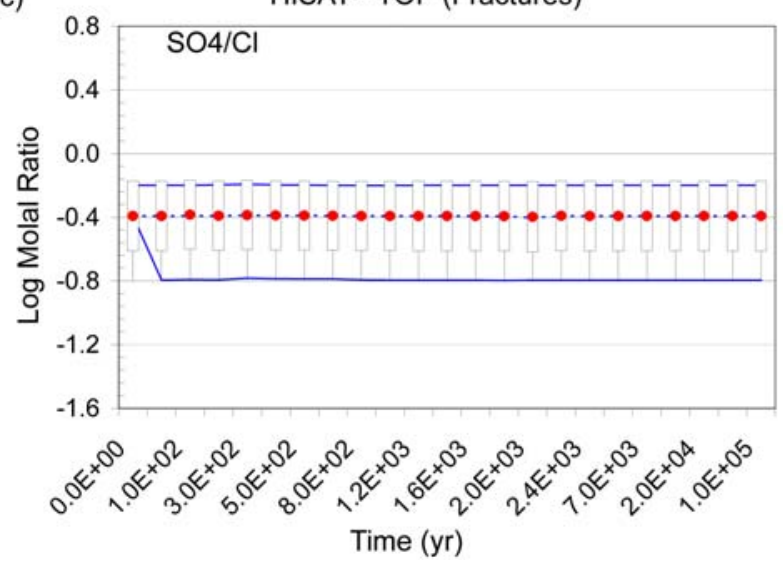

(b)

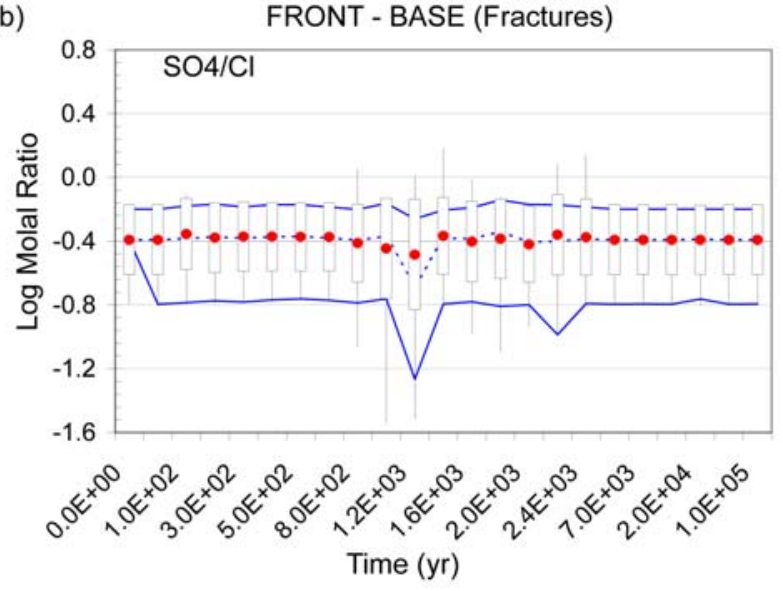

(d)

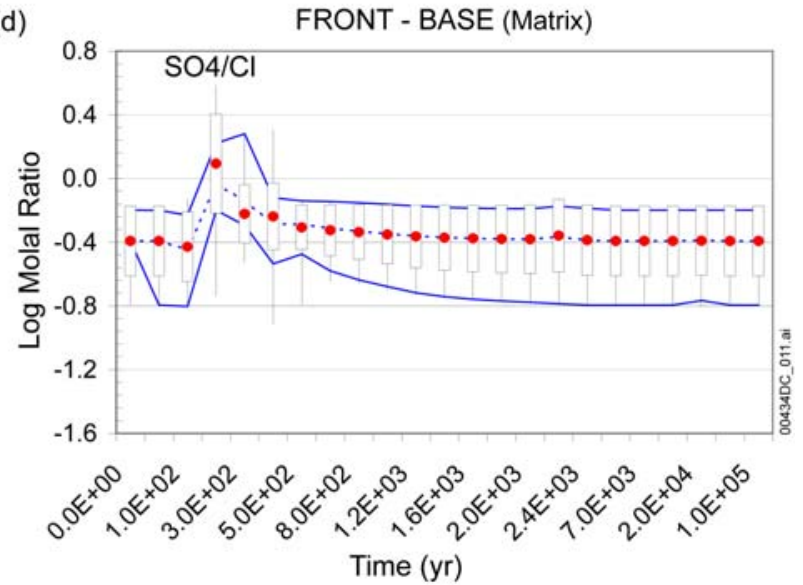

Input DTNS: $\quad$ LB0302DCSPTHCS.002 [DIRS 161976]; LB0307DSTTHCR2.002 [DIRS 165541].

Output DTN: LB0311ABSTHCR2.001 [DIRS 166714].

NOTE: $\quad$ Results for Group 1 simulations, log-transform data. Vertical lines define the spread between minimum and maximum values. Wide vertical bars define two times the standard deviation, centered around the mean (solid circles). Line profiles represent minimum and maximum values (solid lines) and mean (dashed lines) for subsets of data represented by INDX=4 for FRONT waters and INDX=5 for HISAT waters. See text (Section 6.2.3). The spacing of time values on the horizontal axis is not to scale.

Figure 6.2-11. Selection of Model Results around the Modeled Drift as a Function of Time: Ratio of Total Aqueous Sulfate to Total Aqueous Chloride Concentrations 
(a)

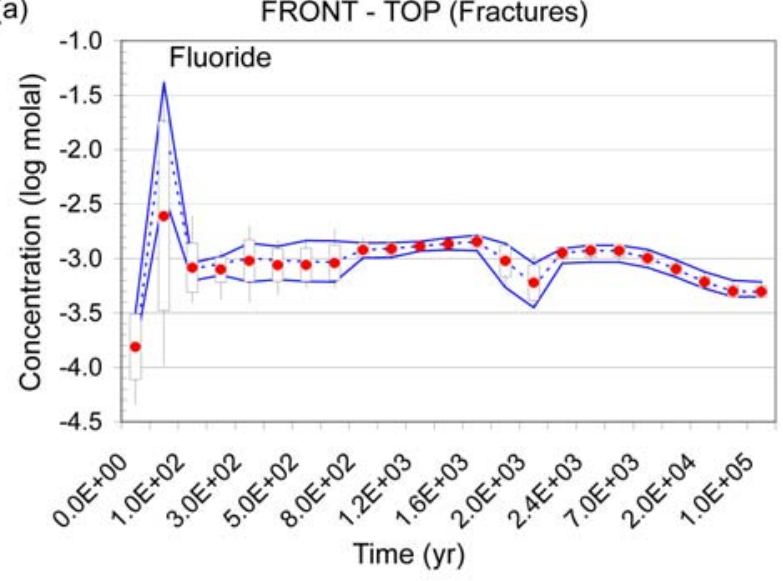

(c)

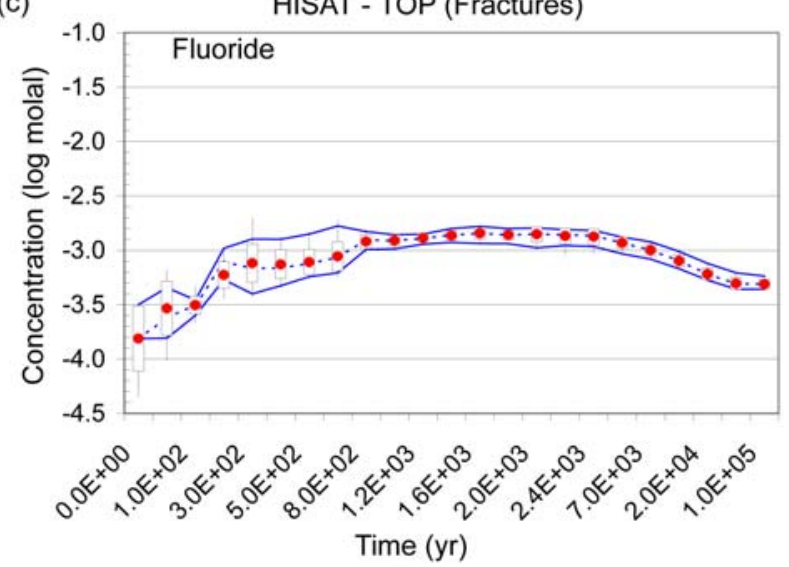

(b)

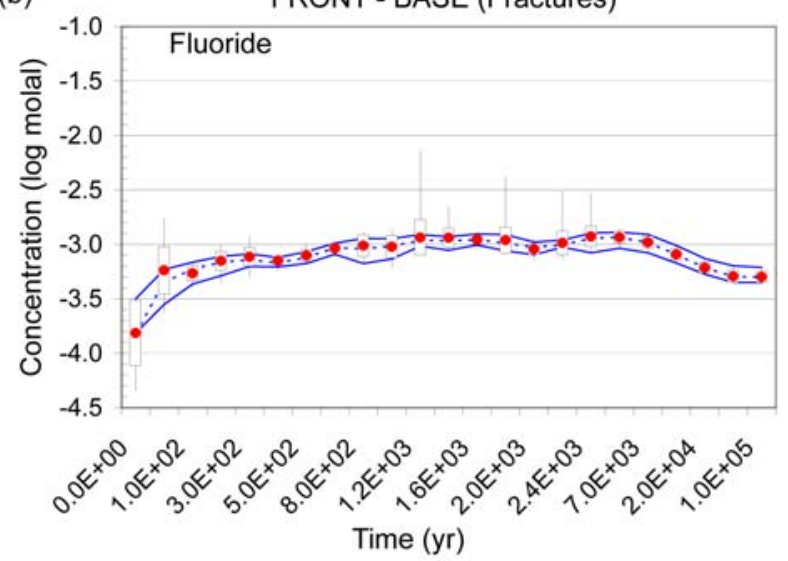

(d)

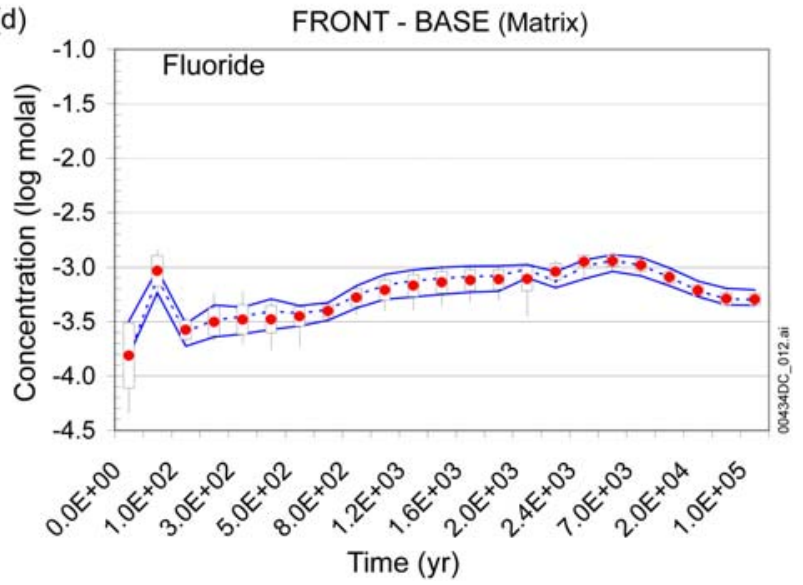

Input DTNs: $\quad$ LB0302DCSPTHCS.002 [DIRS 161976]; LB0307DSTTHCR2.002 [DIRS 165541].

Output DTN: $\quad$ LB0311ABSTHCR2.001 [DIRS 166714].

NOTE: $\quad$ Results for Group 1 simulations, log-transform data. Vertical lines define the spread between minimum and maximum values. Wide vertical bars define two times the standard deviation, centered around the mean (solid circles). Line profiles represent minimum and maximum values (solid lines) and mean (dashed lines) for subsets of data represented by INDX=4 for FRONT waters and INDX=5 for HISAT waters. See text (Section 6.2.3). The spacing of time values on the horizontal axis is not to scale.

Figure 6.2-12. Selection of Model Results around the Modeled Drift as a Function of Time: Total Aqueous Fluoride Concentration 
(a)

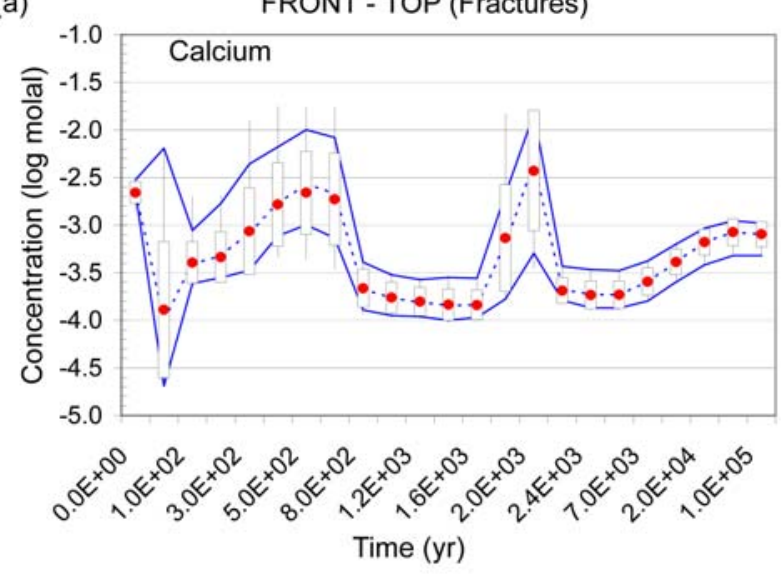

(c)

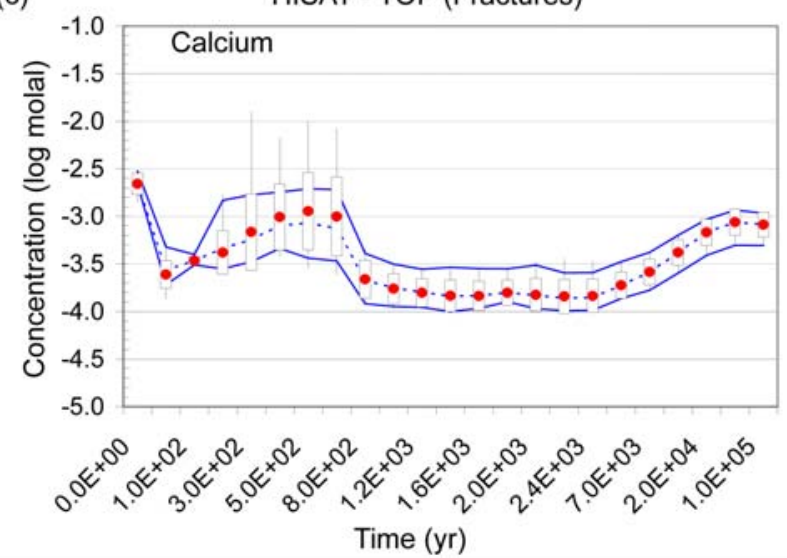

(b)

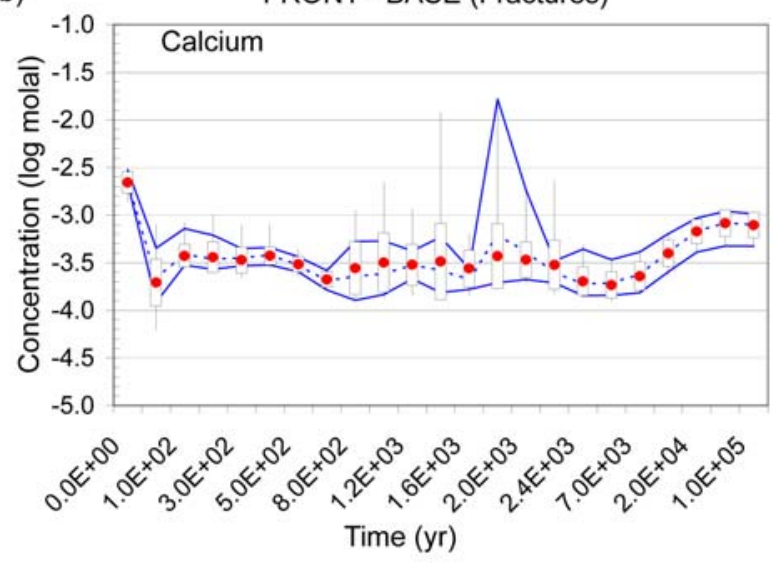

(d)

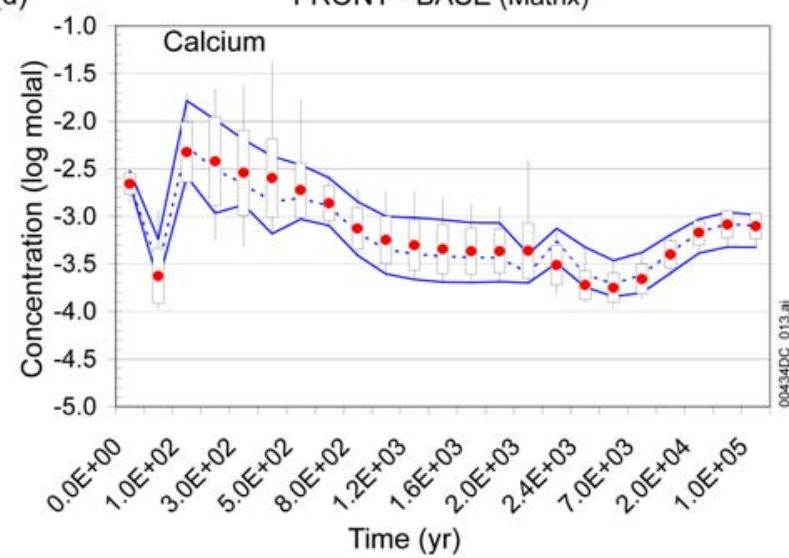

Input DTNs: $\quad$ LB0302DCSPTHCS.002 [DIRS 161976]; LB0307DSTTHCR2.002 [DIRS 165541].

Output DTN: LB0311ABSTHCR2.001 [DIRS 166714].

NOTE: $\quad$ Results for Group 1 simulations, log-transform data. Vertical lines define the spread between minimum and maximum values. Wide vertical bars define two times the standard deviation, centered around the mean (solid circles). Line profiles represent minimum and maximum values (solid lines) and mean (dashed lines) for subsets of data represented by INDX=4 for FRONT waters and INDX $=5$ for HISAT waters. See text (Section 6.2.3). The spacing of time values on the horizontal axis is not to scale.

Figure 6.2-13. Selection of Model Results around the Modeled Drift as a Function of Time: Total Aqueous Calcium Concentration 
(a)

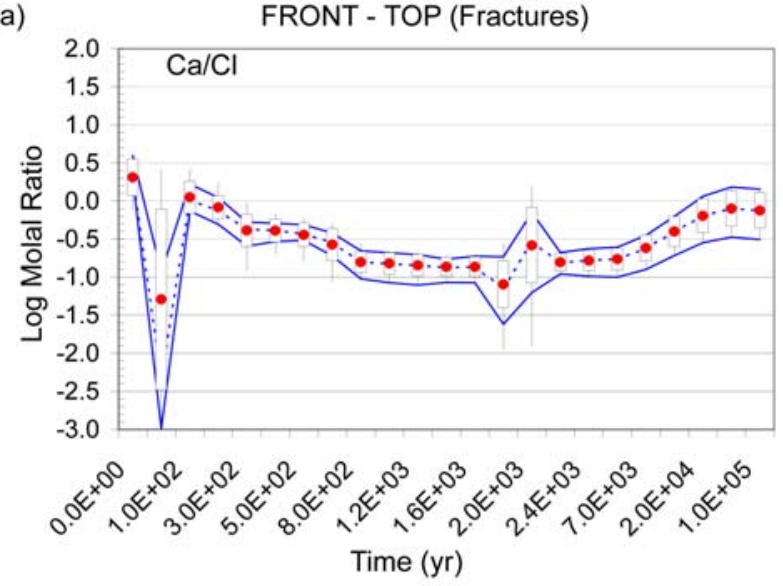

(c)

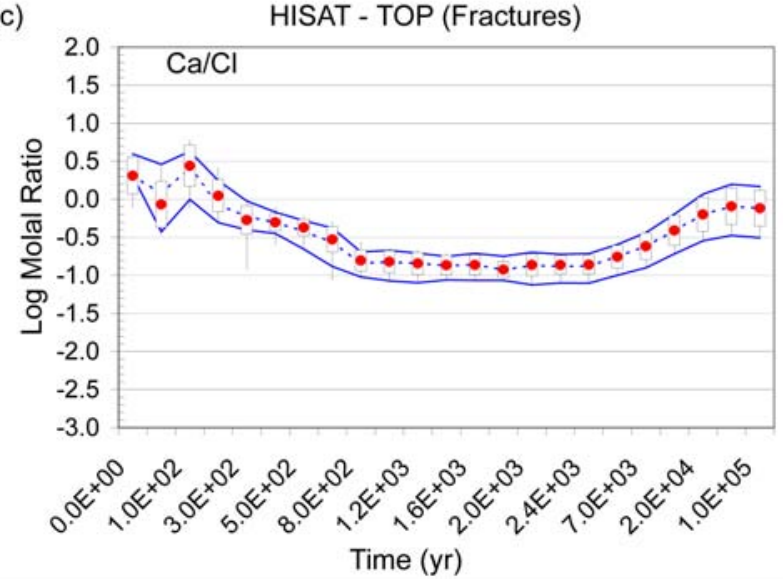

(b)

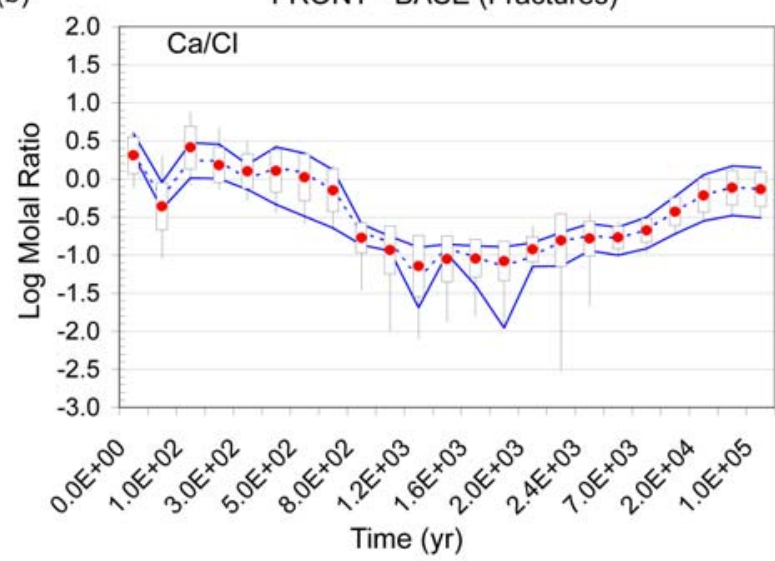

(d)

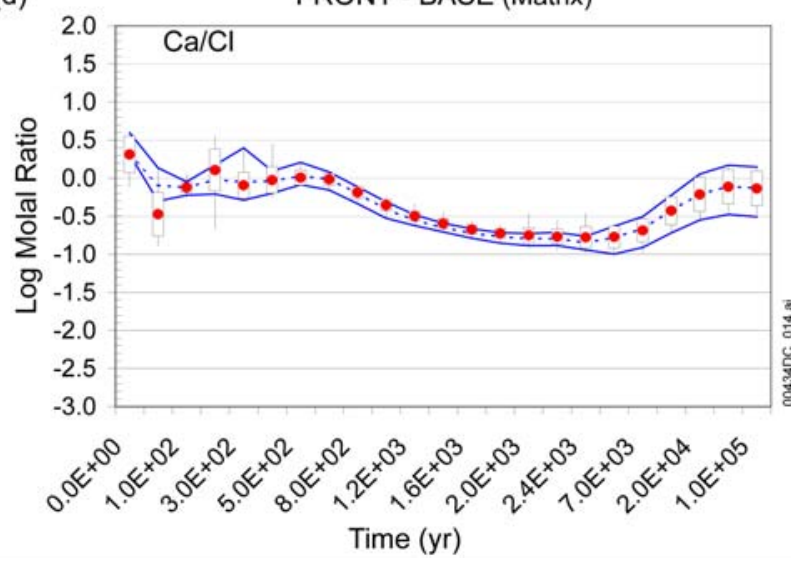

Input DTNs: $\quad$ LB0302DCSPTHCS.002 [DIRS 161976]; LB0307DSTTHCR2.002 [DIRS 165541].

Output DTN: LB0311ABSTHCR2.001 [DIRS 166714].

NOTE: $\quad$ Results for Group 1 simulations, log-transform data. Vertical lines define the spread between minimum and maximum values. Wide vertical bars define two times the standard deviation, centered around the mean (solid circles). Line profiles represent minimum and maximum values (solid lines) and mean (dashed lines) for subsets of data represented by INDX=4 for FRONT waters and INDX=5 for HISAT waters. See text (Section 6.2.3). The spacing of time values on the horizontal axis is not to scale.

Figure 6.2-14. Selection of Model Results around the Modeled Drift as a Function of Time: Ratio of Total Aqueous Calcium to Total Aqueous Chloride Concentrations 
(a)

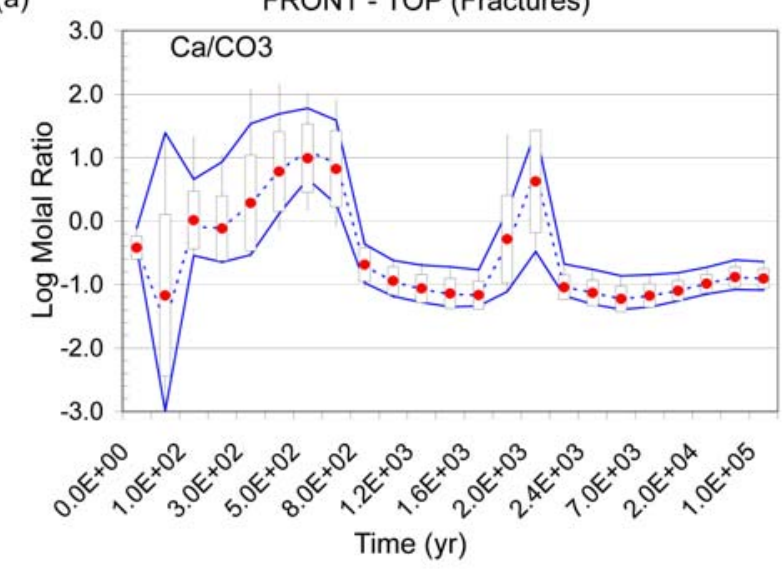

(c)

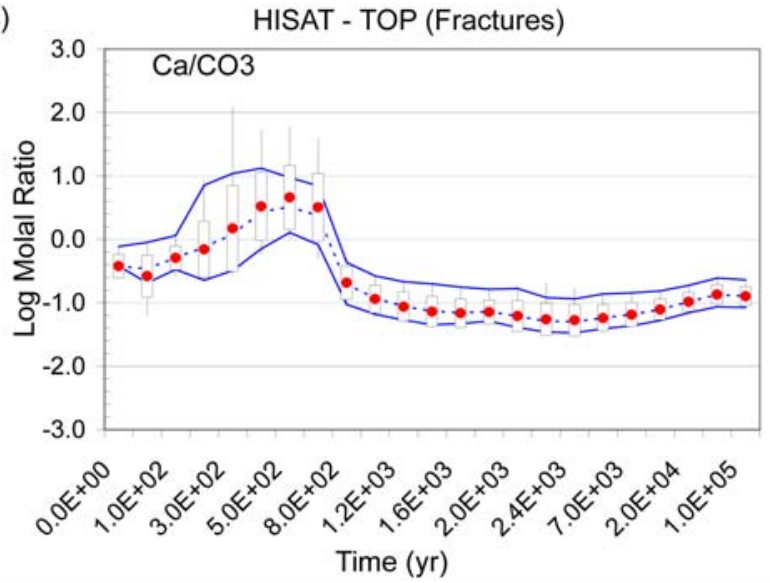

(b)

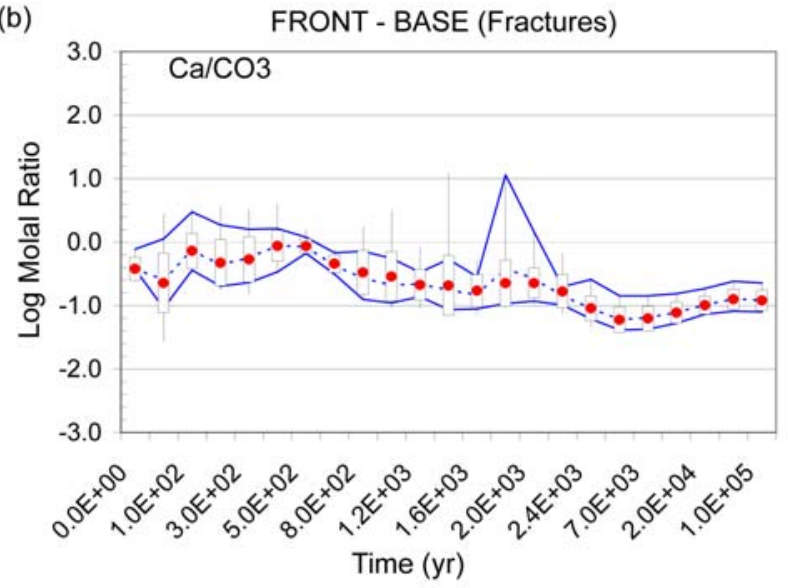

(d)

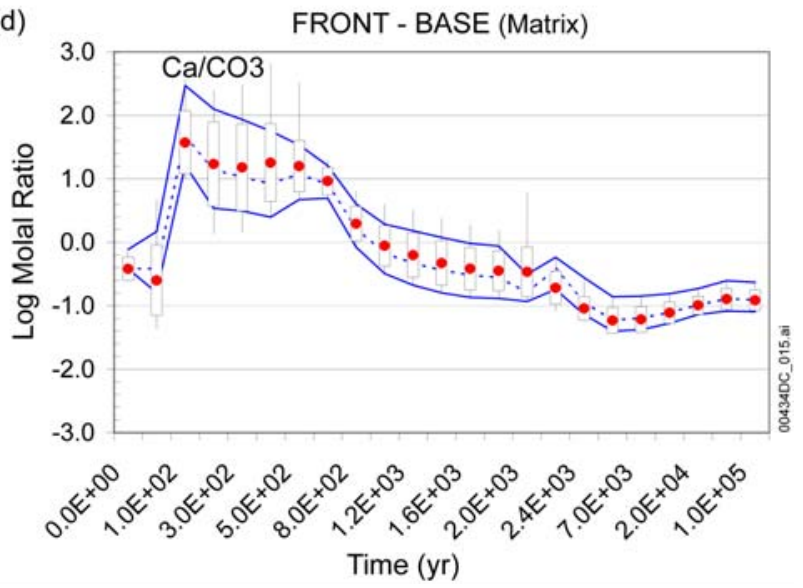

Input DTNs: $\quad$ LB0302DCSPTHCS.002 [DIRS 161976]; LB0307DSTTHCR2.002 [DIRS 165541].

Output DTN: LB0311ABSTHCR2.001 [DIRS 166714].

NOTE: $\quad$ Results for Group 1 simulations, log-transform data. Vertical lines define the spread between minimum and maximum values. Wide vertical bars define two times the standard deviation, centered around the mean (solid circles). Line profiles represent minimum and maximum values (solid lines) and mean (dashed lines) for subsets of data represented by INDX=4 for FRONT waters and INDX=5 for HISAT waters. See text (Section 6.2.3). The spacing of time values on the horizontal axis is not to scale.

Figure 6.2-15. Selection of Model Results around the Modeled Drift as a Function of Time: Ratio of Total Aqueous Calcium to Total Aqueous Carbonate Concentrations 
(a)

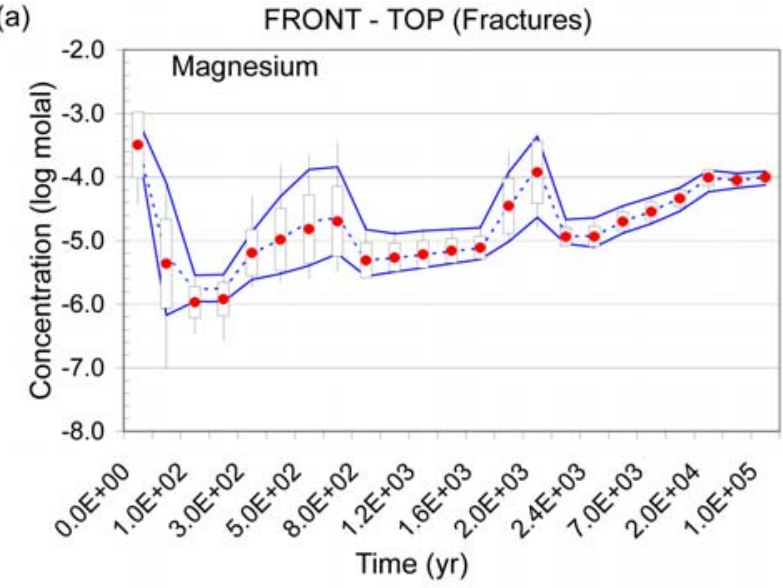

(c)

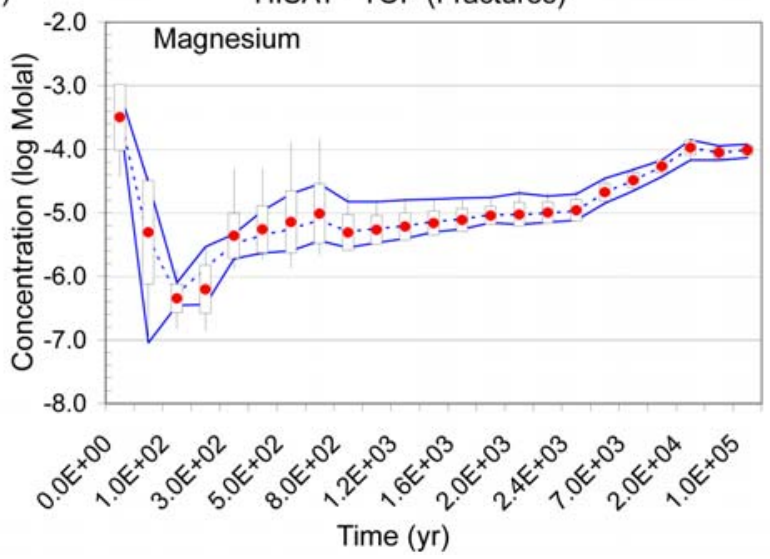

(b)

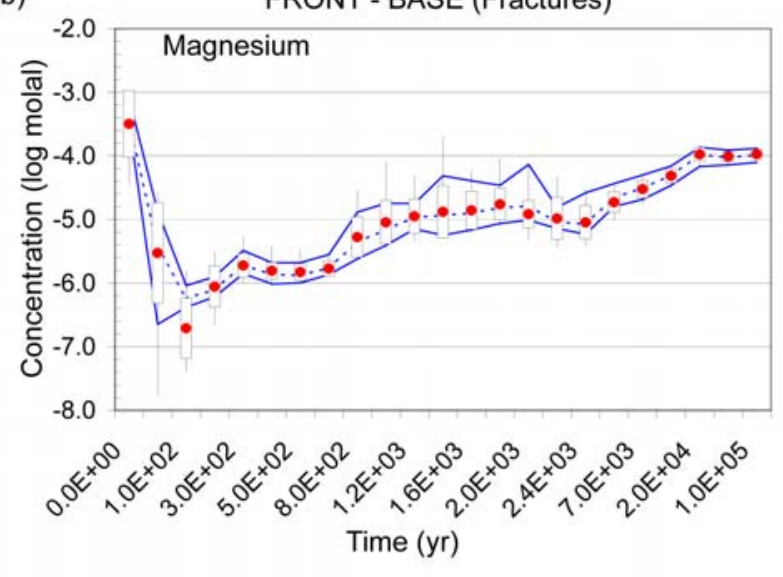

(d)

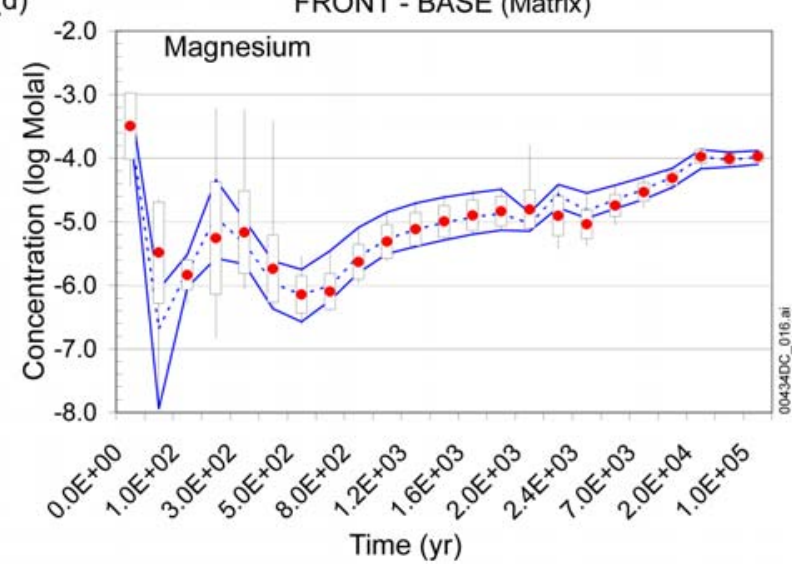

Input DTNs: $\quad$ LB0302DCSPTHCS.002 [DIRS 161976]; LB0307DSTTHCR2.002 [DIRS 165541].

Output DTN: LB0311ABSTHCR2.001 [DIRS 166714].

NOTE: $\quad$ Results for Group 1 simulations, log-transform data. Vertical lines define the spread between minimum and maximum values. Wide vertical bars define two times the standard deviation, centered around the mean (solid circles). Line profiles represent minimum and maximum values (solid lines) and mean (dashed lines) for subsets of data represented by INDX=4 for FRONT waters and INDX=5 for HISAT waters. See text (Section 6.2.3). The spacing of time values on the horizontal axis is not to scale.

Figure 6.2-16. Selection of Model Results around the Modeled Drift as a Function of Time: Total Aqueous Magnesium Concentration 
(a)

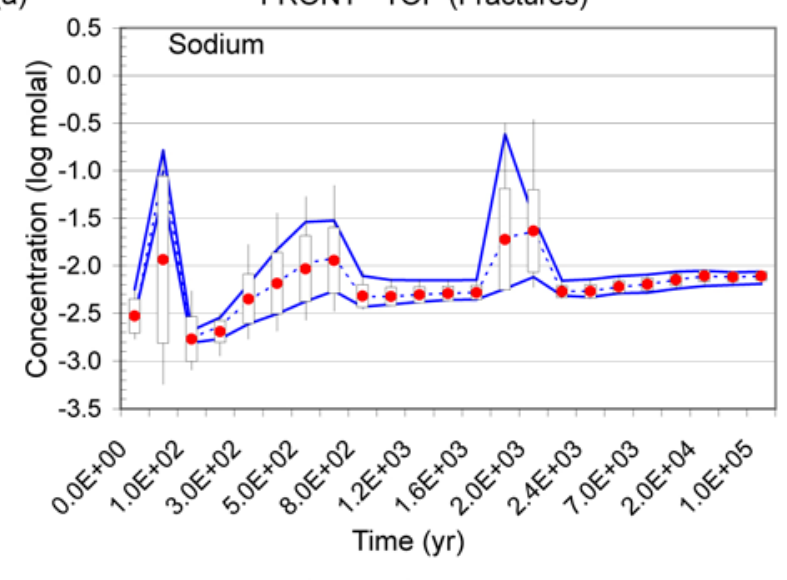

(c)

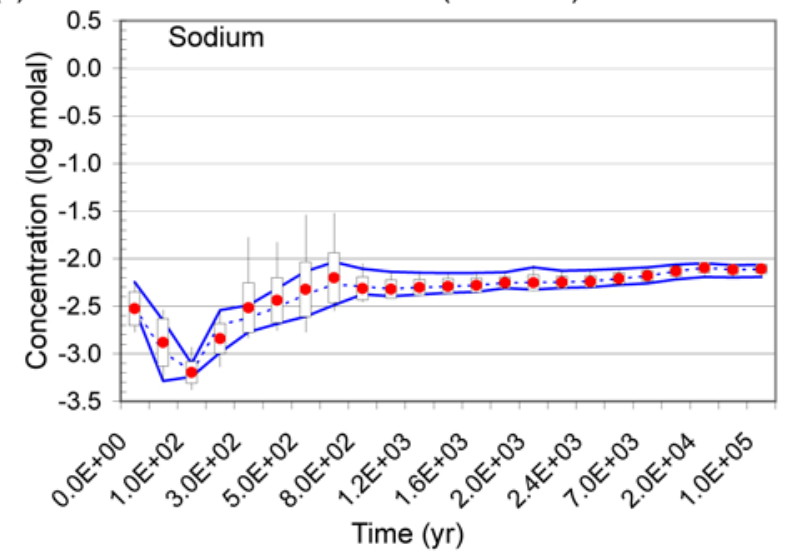

(b)

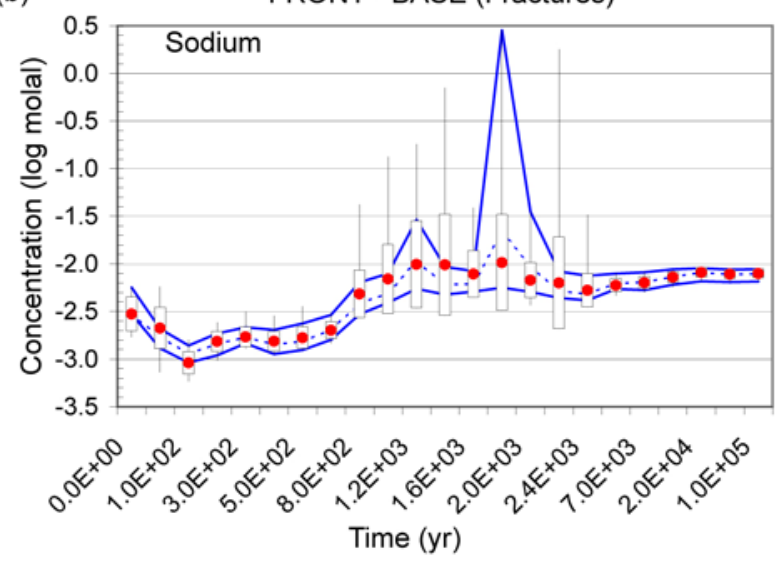

(d)

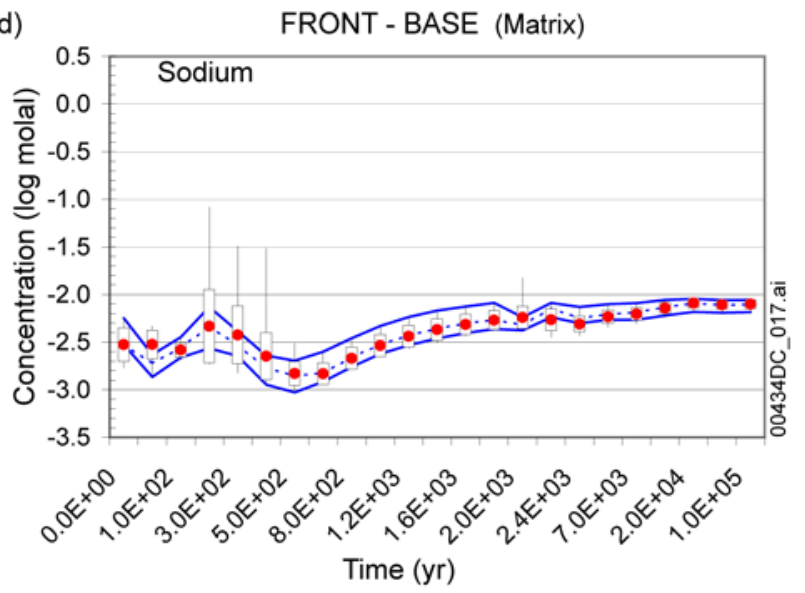

Input DTNs: $\quad$ LB0302DCSPTHCS.002 [DIRS 161976], LB0307DSTTHCR2.002 [DIRS 165541].

Output DTN: LB0311ABSTHCR2.001 [DIRS 166714].

NOTE: $\quad$ Results for Group 1 simulations, log-transform data. Vertical lines define the spread between minimum and maximum values. Wide vertical bars define two times the standard deviation, centered around the mean (solid circles). Line profiles represent minimum and maximum values (solid lines) and mean (dashed lines) for subsets of data represented by INDX=4 for FRONT waters and INDX=5 for HISAT waters. See text (Section 6.2.3). The spacing of time values on the horizontal axis is not to scale.

Figure 6.2-17. Selection of Model Results around the Modeled Drift as a Function of Time: Total Aqueous Sodium Concentration 
(a)

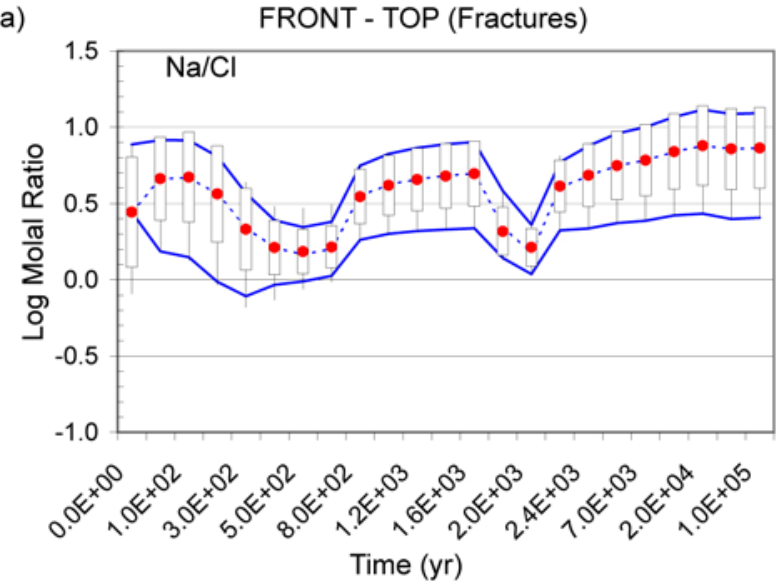

(c)

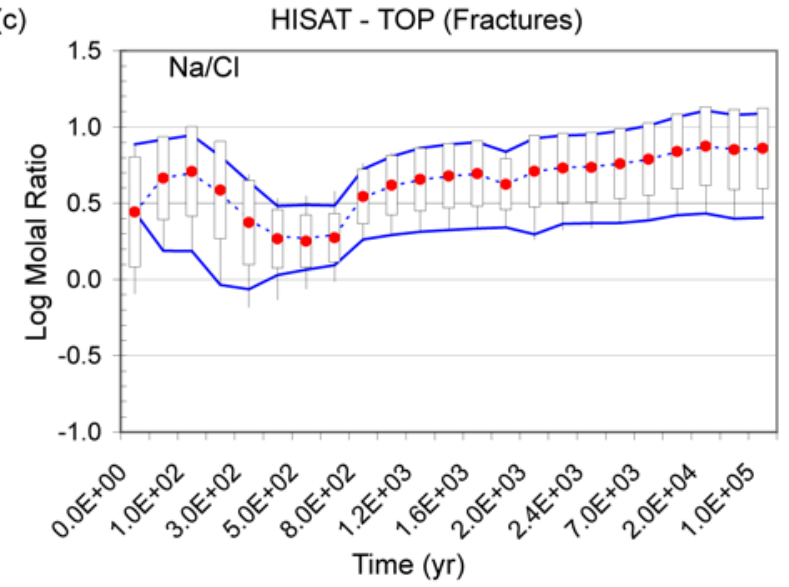

(b)

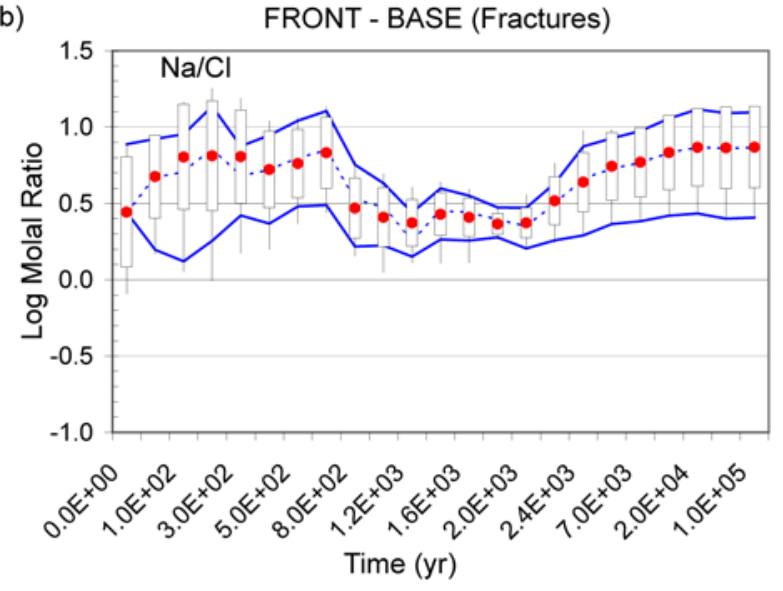

(d)

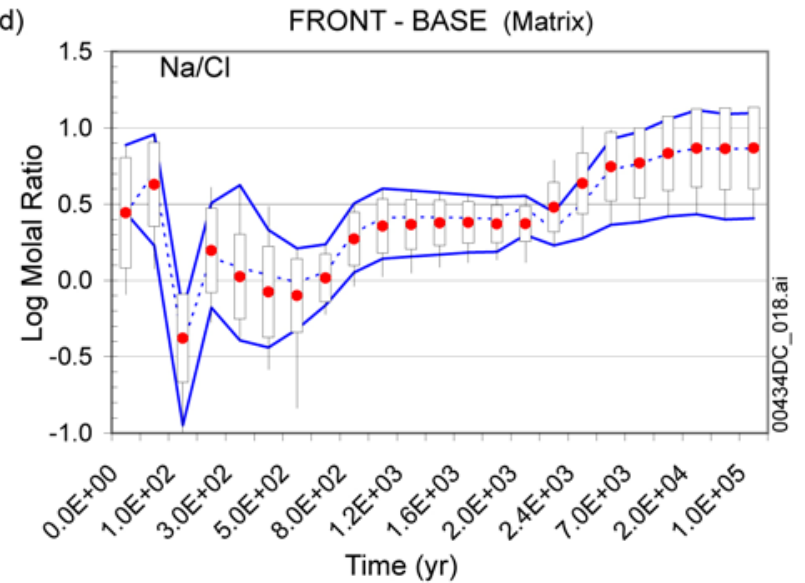

Input DTNs: $\quad$ LB0302DCSPTHCS.002 [DIRS 161976]; LB0307DSTTHCR2.002 [DIRS 165541].

Output DTN: LB0311ABSTHCR2.001 [DIRS 166714].

NOTE: $\quad$ Results for Group 1 simulations, log-transform data. Vertical lines define the spread between minimum and maximum values. Wide vertical bars define two times the standard deviation, centered around the mean (solid circles). Line profiles represent minimum and maximum values (solid lines) and mean (dashed lines) for subsets of data represented by INDX=4 for FRONT waters and INDX=5 for HISAT waters. See text (Section 6.2.3). The spacing of time values on the horizontal axis is not to scale.

Figure 6.2-18. Selection of Model Results around the Modeled Drift as a Function of Time: Ratio of Total Aqueous Sodium to Total Aqueous Chloride Concentrations 
(a)

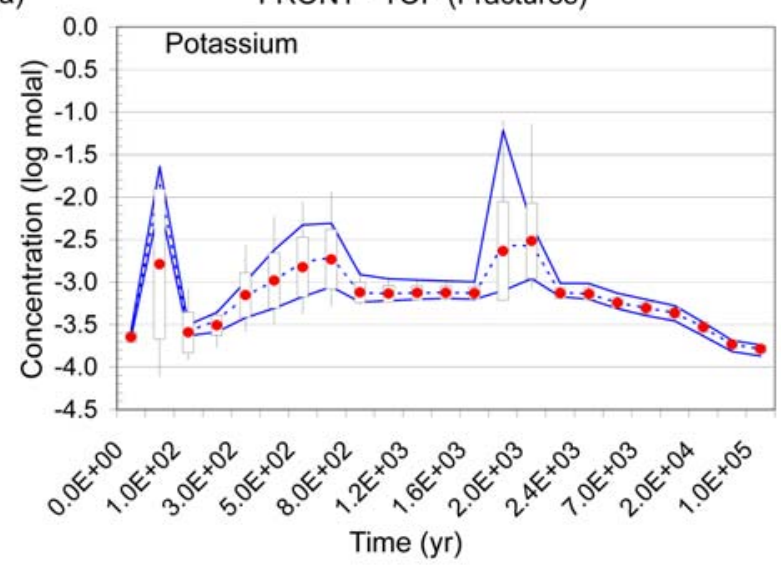

(c)

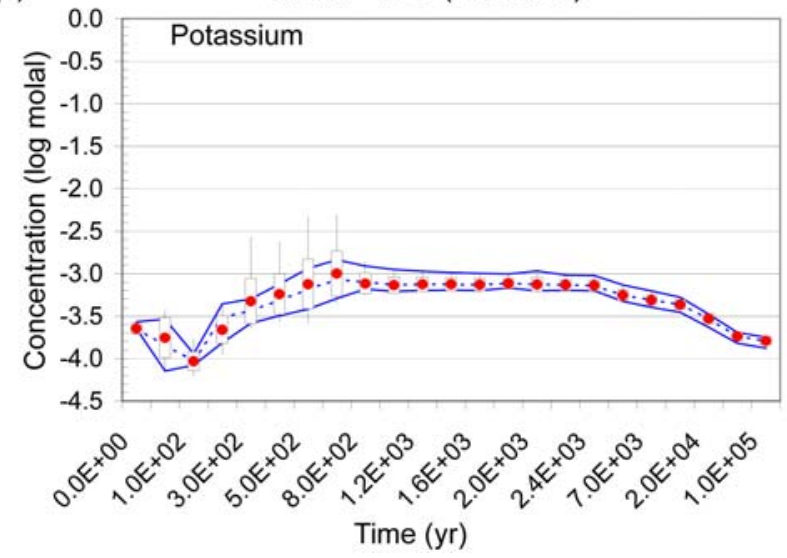

(b)

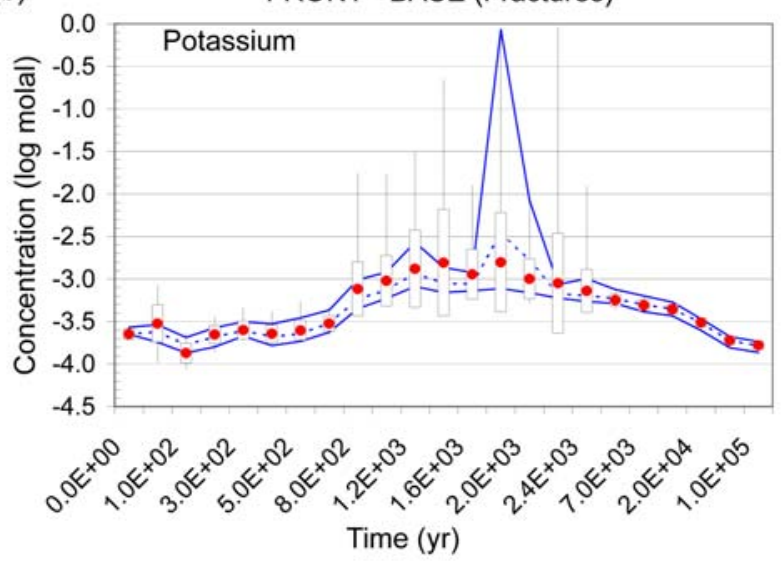

(d)

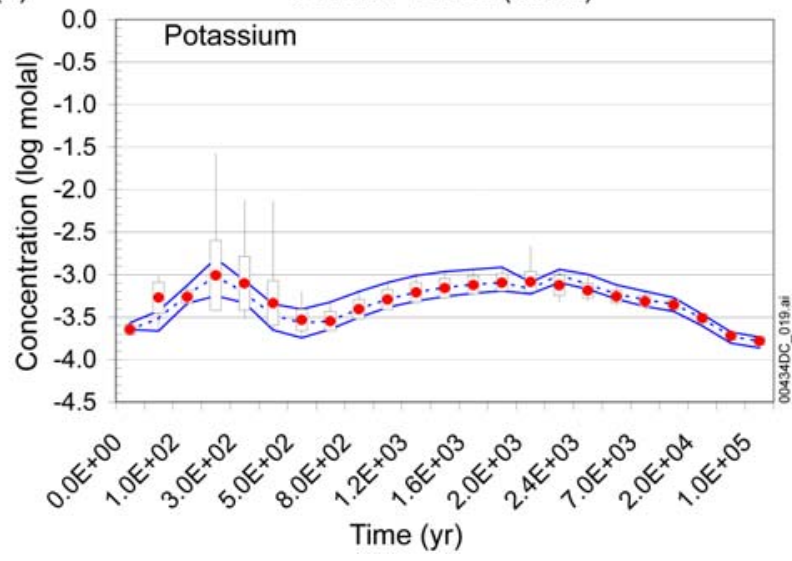

Input DTNs: $\quad$ LB0302DCSPTHCS.002 [DIRS 161976]; LB0307DSTTHCR2.002 [DIRS 165541].

Output DTN: LB0311ABSTHCR2.001 [DIRS 166714].

NOTE: $\quad$ Results for Group 1 simulations, log-transform data. Vertical lines define the spread between minimum and maximum values. Wide vertical bars define two times the standard deviation, centered around the mean (solid circles). Line profiles represent minimum and maximum values (solid lines) and mean (dashed lines) for subsets of data represented by INDX=4 for FRONT waters and INDX=5 for HISAT waters. See text (Section 6.2.3). The spacing of time values on the horizontal axis is not to scale.

Figure 6.2-19. Selection of Model Results around the Modeled Drift as a Function of Time: Total Aqueous Potassium Concentration 
(a)

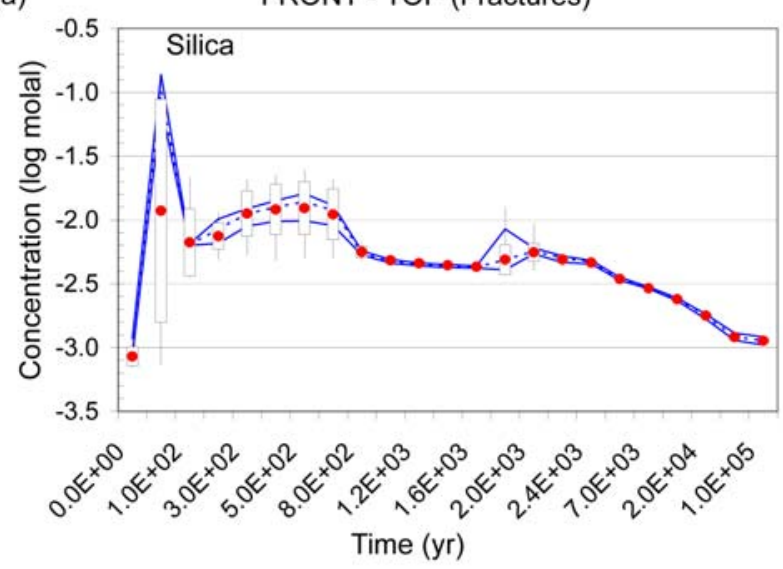

(c)

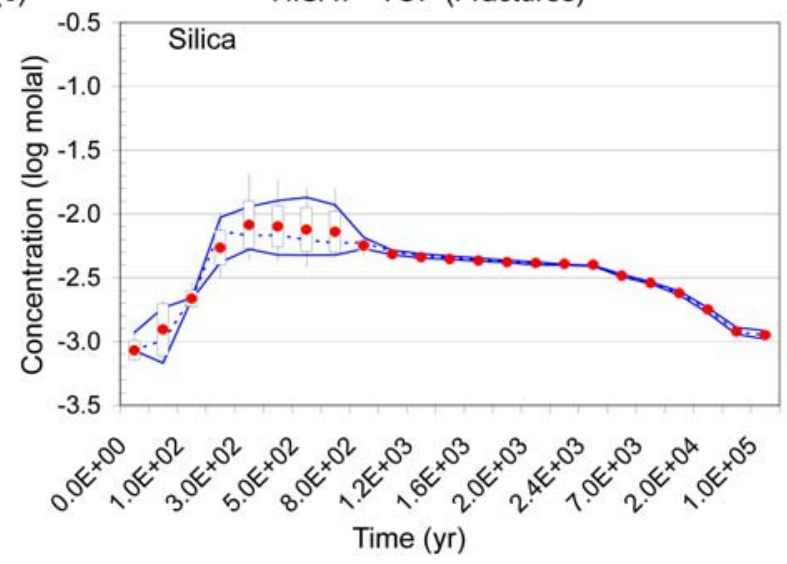

(b)

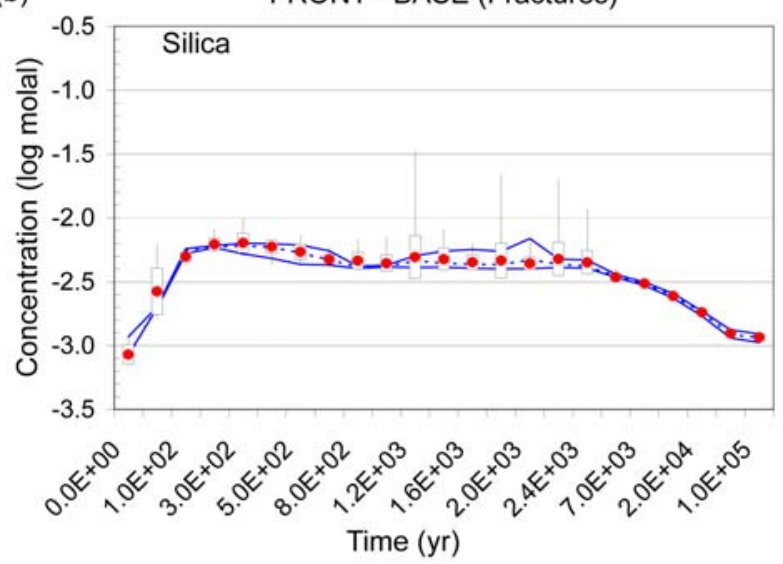

(d)

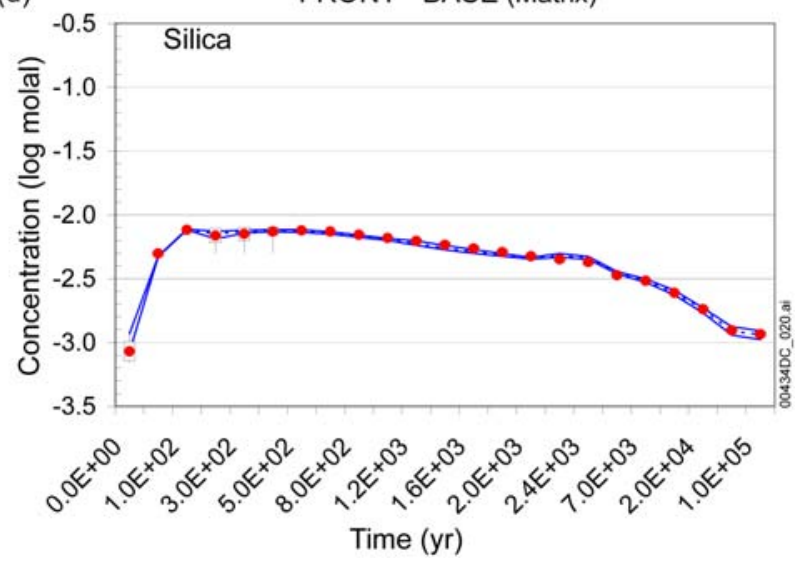

Input DTNs: $\quad$ LB0302DCSPTHCS.002 [DIRS 161976]; LB0307DSTTHCR2.002 [DIRS 165541].

Output DTN: LB0311ABSTHCR2.001 [DIRS 166714].

NOTE: $\quad$ Results for Group 1 simulations, log-transform data. Vertical lines define the spread between minimum and maximum values. Wide vertical bars define two times the standard deviation, centered around the mean (solid circles). Line profiles represent minimum and maximum values (solid lines) and mean (dashed lines) for subsets of data represented by INDX=4 for FRONT waters and INDX=5 for HISAT waters. See text (Section 6.2.3). The spacing of time values on the horizontal axis is not to scale.

Figure 6.2-20. Selection of Model Results around the Modeled Drift as a Function of Time: Total Aqueous Silica Concentration 


\subsubsection{Water Composition as a Function of Temperature and Liquid Saturation}

Scatter plots of predicted concentrations $\left(\mathrm{pH}, \mathrm{CO}_{2}\right.$ gas, and chloride) and concentration ratios (calcium over total aqueous carbonate) were generated for Group 1 results as functions of temperature, using the drift crown and base temperatures for waters from the TOP and BASE quadrants, respectively (Figures 6.2-21 through 6.2-24). Similar plots as a function of liquid saturation were also generated (Figures 6.2-25 through 6.2-28). For given temperature or saturation, those figures show the range of concentrations and concentration ratios. Compared to figures discussed earlier, these plots have the advantage of showing all data points (INDX=1 to 6 and 5 input waters). Because predicted temperatures are the same for all runs considered here (i.e., almost identical temperatures predicted for each run at each point in time), summary statistics presented earlier as a function of time essentially also apply to the data represented as a function of temperature. Therefore, the temperature plots can be viewed as a general rearrangement of the time-profile data (Figures 6.2-4 through 6.2-20), sorted in order of increasing temperature. This is not the case, however, for profiles as a function of liquid saturation.

As would be expected, the spread in model results typically increases with temperature, showing trend deviations related to the same processes as those discussed earlier for the time profiles. Values of $\mathrm{pH}$ above 8.5 in Figure 6.2-21b are artifacts (Section 6.2.3.1.2) and correspond to the points mentioned earlier for the time profiles at 5,000 and 7,000 years (Figure 6.2-4b). The increased spread of dissolved constituent concentrations after the collapse of the boiling front (FRONT waters) is evident in fractures when the drift crown has reached rewetting (below boiling) temperatures around 90 to $95^{\circ} \mathrm{C}$ (e.g., Figures 6.2-21a, 23a, and 24a). The effect is less evident in the matrix at the base of the drift, which is fully rewetted for drift-base temperatures approximately 105 to $120^{\circ} \mathrm{C}$ (e.g., Figure 6.2-24d). The higher rewetting temperatures in the matrix relative to the fractures result from greater capillary pressure in the matrix, causing more vapor pressure lowering than in fractures. The likelihood of in-drift seepage is essentially zero above these temperatures, because of vaporization around the drift (BSC 2004 [DIRS 170338], Section 6.2.1.1.2). Therefore, for representing in-drift seepage water compositions, the data above these temperatures can be ignored. For dissolved constituents, profiles in terms of liquid saturation are expected to show a general trend of increasing concentration, as well as spread, with decreasing liquid saturation, because of evaporative concentration. This is observed for chloride (Figure 6.2-27) and for $\mathrm{pH}$ (Figure 6.2-25). This inverse correlation is also evident for the profile of $\mathrm{Ca} / \mathrm{CO}_{3}$ ratios (Figure 6.2-28), because aqueous carbonate is being volatilized as $\mathrm{CO}_{2}$ gas when liquid saturations fall. Points below residual liquid saturation (typically around 0.1 for the matrix and 0.01 for the fractures) could not contribute to in-drift seepage because the movement of water at liquid saturation below the residual value is inhibited by low relative permeability. Therefore, excluding data points below residual liquid saturation is justified, to the extent that values of residual saturation themselves can be defended. Doing so would thus further narrow the spread and magnitude of the data that should be considered representative of potential in-drift seepage.

Similar to discussion in Section 6.2.3.1, the predicted concentrations (as well as concentration ratios) of water compositions, as functions of temperature and saturation, show more variability in FRONT-TOP water in fractures and FRONT-BASE water in matrix. It is further confirmed 
that only FRONT-TOP-fracture and FRONT-BASE-matrix waters are needed to represent the compositions of potential seepage water.

(a)

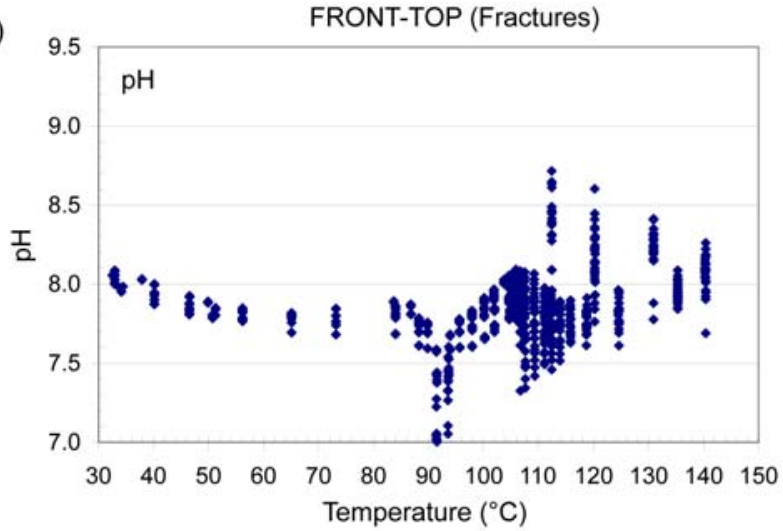

(c)

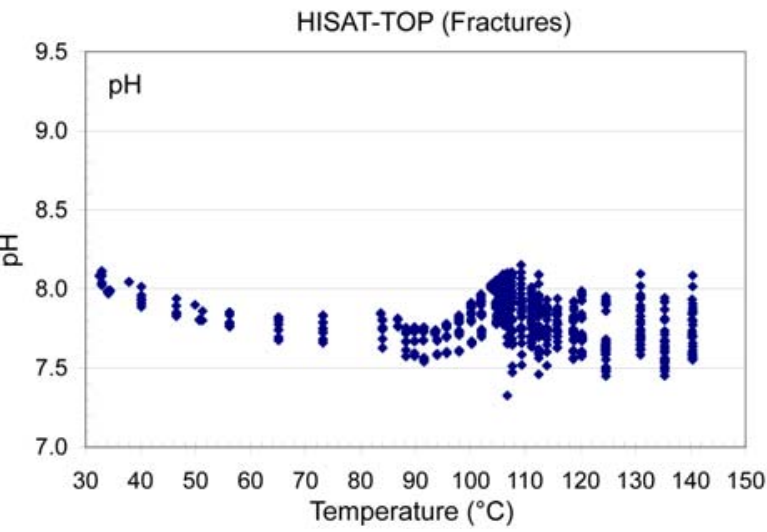

(b)

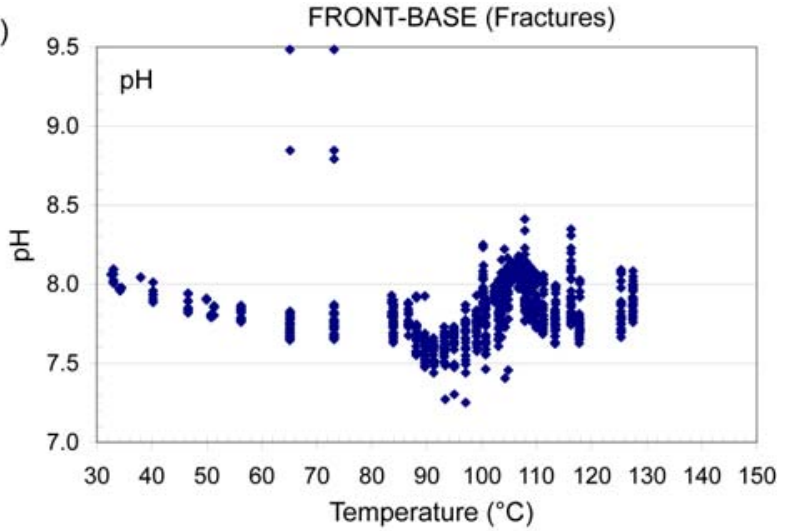

(d)

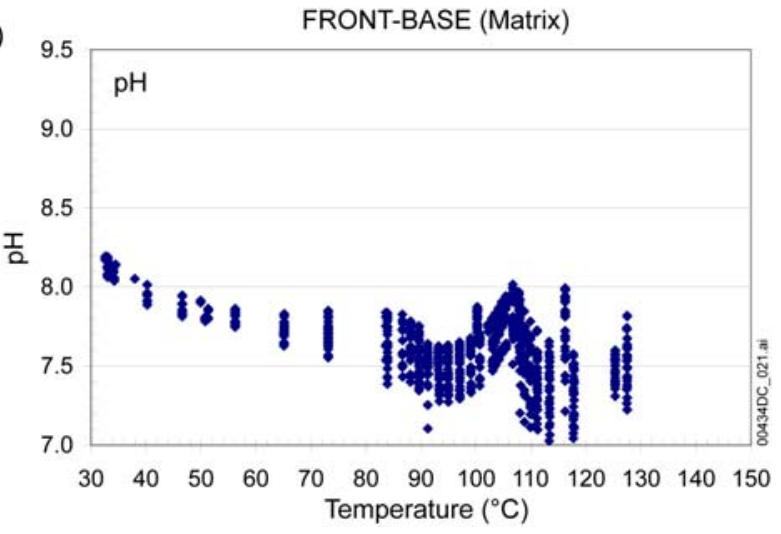

Input DTNs: $\quad$ LB0302DCSPTHCS.002 [DIRS 161976], LB0307DSTTHCR2.002 [DIRS 165541].

Output DTN: LB0311ABSTHCR2.001 [DIRS 166714].

NOTE: Results for Group 1 simulations. Horizontal axis represents predicted temperatures at the drift crown for data in the TOP quadrant, and at the drift base for data in the BASE quadrant. See text (Section 6.2.4.2).

Figure 6.2-21. Selection of Model Results around the Modeled Drift as a Function of Drift-Wall Temperature: $\mathrm{pH}$ 

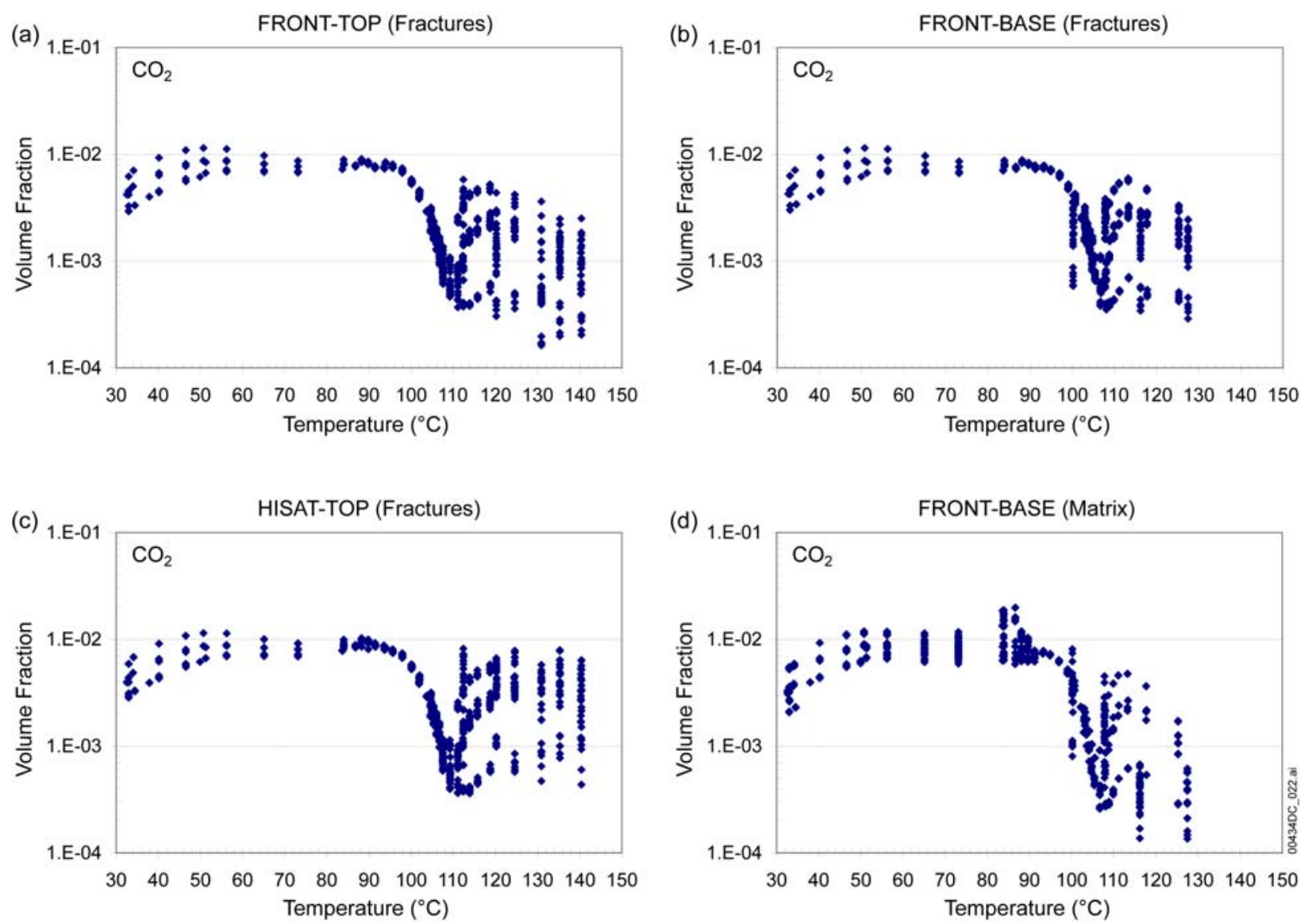

Input DTNs: $\quad$ LB0302DCSPTHCS.002 [DIRS 161976]; LB0307DSTTHCR2.002 [DIRS 165541].

Output DTN: LB0311ABSTHCR2.001 [DIRS 166714].

NOTE: Results for Group 1 simulations. Horizontal axis represents predicted temperatures at the drift crown for data in the TOP quadrant, and at the drift base for data in the BASE quadrant. See text (Section 6.2.4.2).

Figure 6.2-22. Selection of Model Results around the Modeled Drift as a Function of Drift-Wall Temperature: Volume Fraction of Carbon Dioxide Gas 

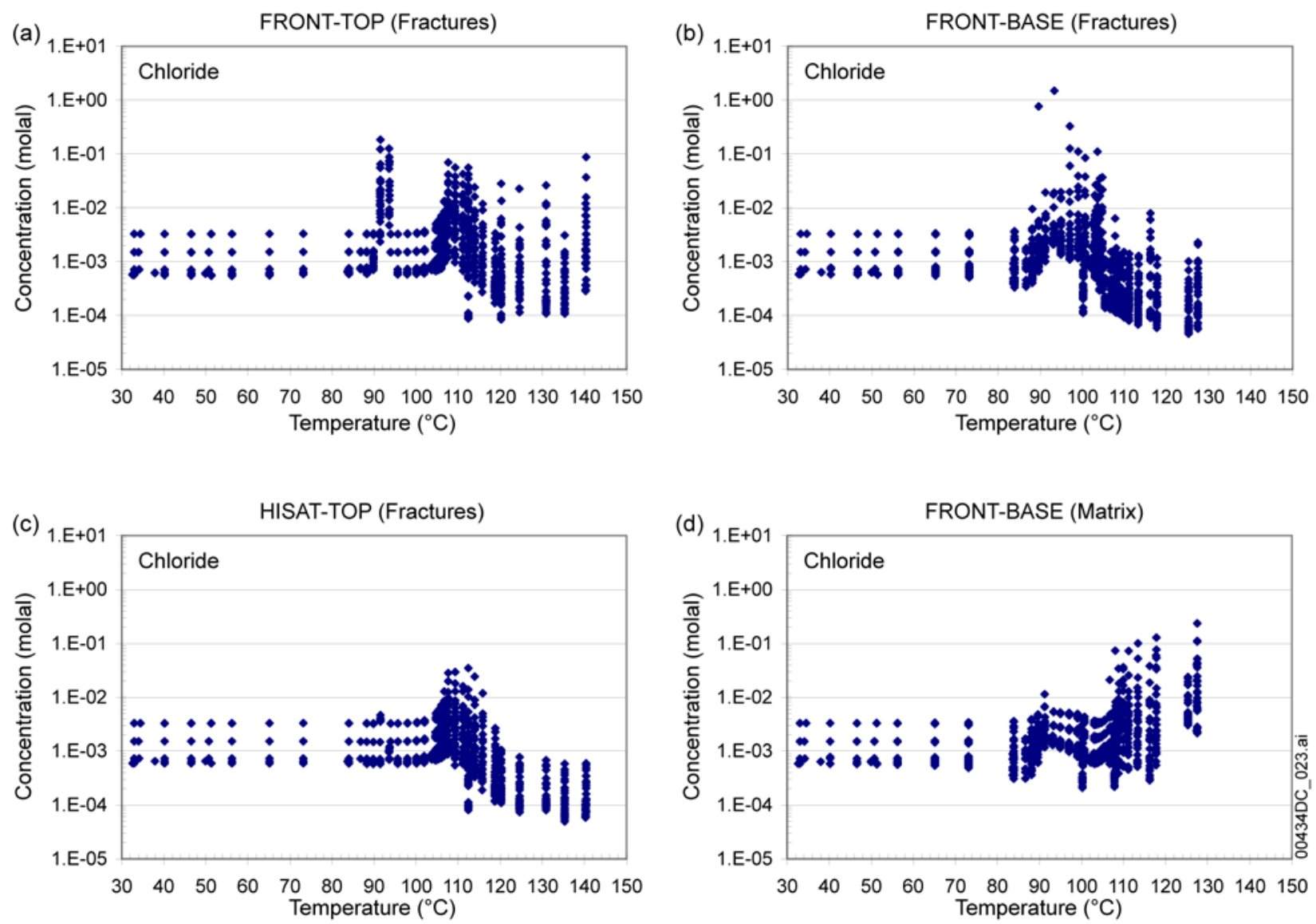

Input DTNs: $\quad$ LB0302DCSPTHCS.002 [DIRS 161976]; LB0307DSTTHCR2.002 [DIRS 165541].

Output DTN: $\quad$ LB0311ABSTHCR2.001 [DIRS 166714].

NOTE: Results for Group 1 simulations. Horizontal axis represents predicted temperatures at the drift crown for data in the TOP quadrant, and at the drift base for data in the BASE quadrant. See text (Section 6.2.4.2).

Figure 6.2-23. Selection of Model Results around the Modeled Drift as a Function of Drift-Wall Temperature: Total Aqueous Chloride Concentration 

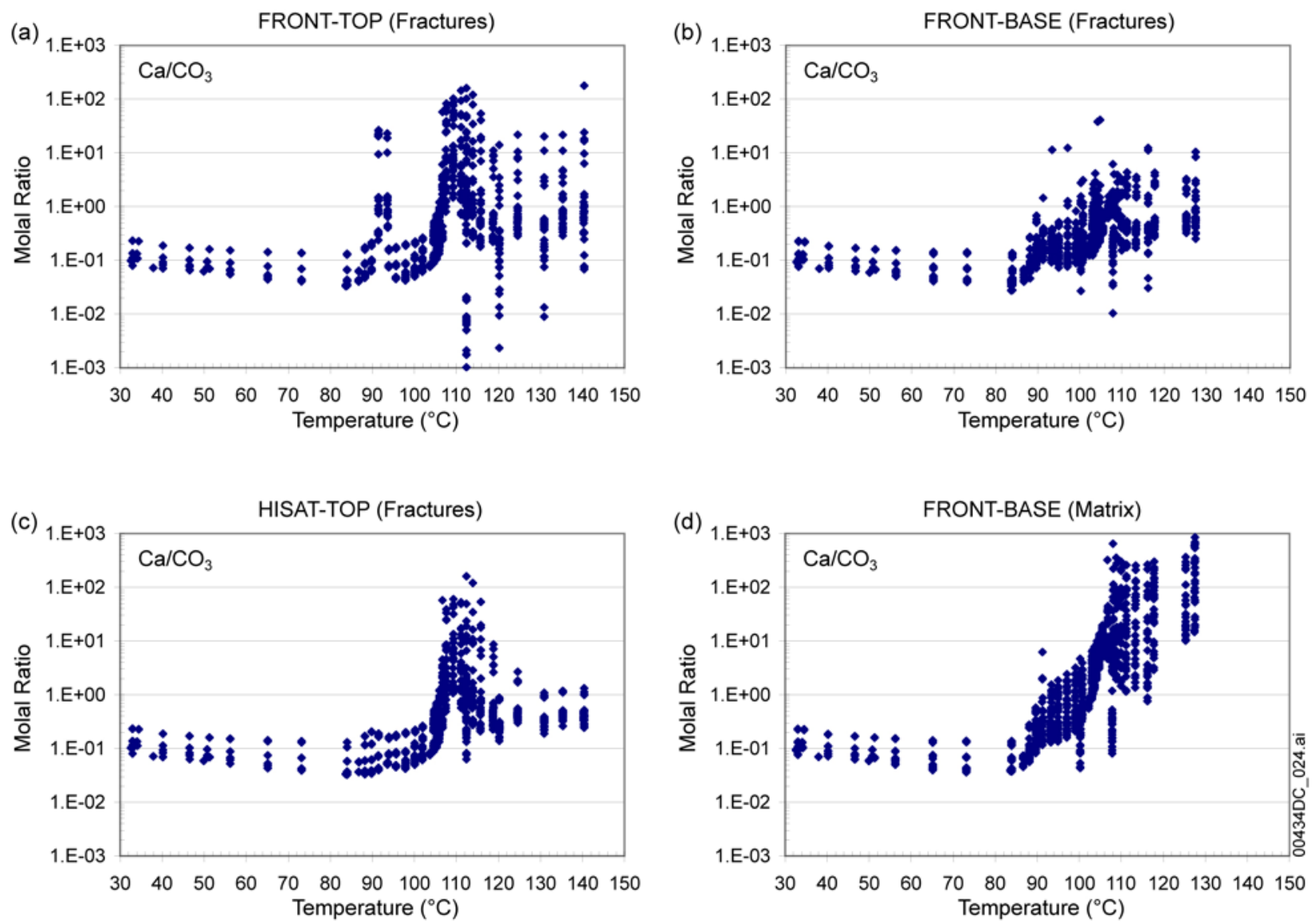

Input DTNs: $\quad$ LB0302DCSPTHCS.002 [DIRS 161976]; LB0307DSTTHCR2.002 [DIRS 165541].

Output DTN: LB0311ABSTHCR2.001 [DIRS 166714].

NOTE: Results for Group 1 simulations. Horizontal axis represents predicted temperatures at the drift crown for data in the TOP quadrant, and at the drift base for data in the BASE quadrant. See text (Section 6.2.4.2).

Figure 6.2-24. Selection of Model Results around the Modeled Drift as a Function of Drift-Wall Temperature: Ratio of Total Aqueous Calcium to Total Aqueous Carbonate Concentrations 

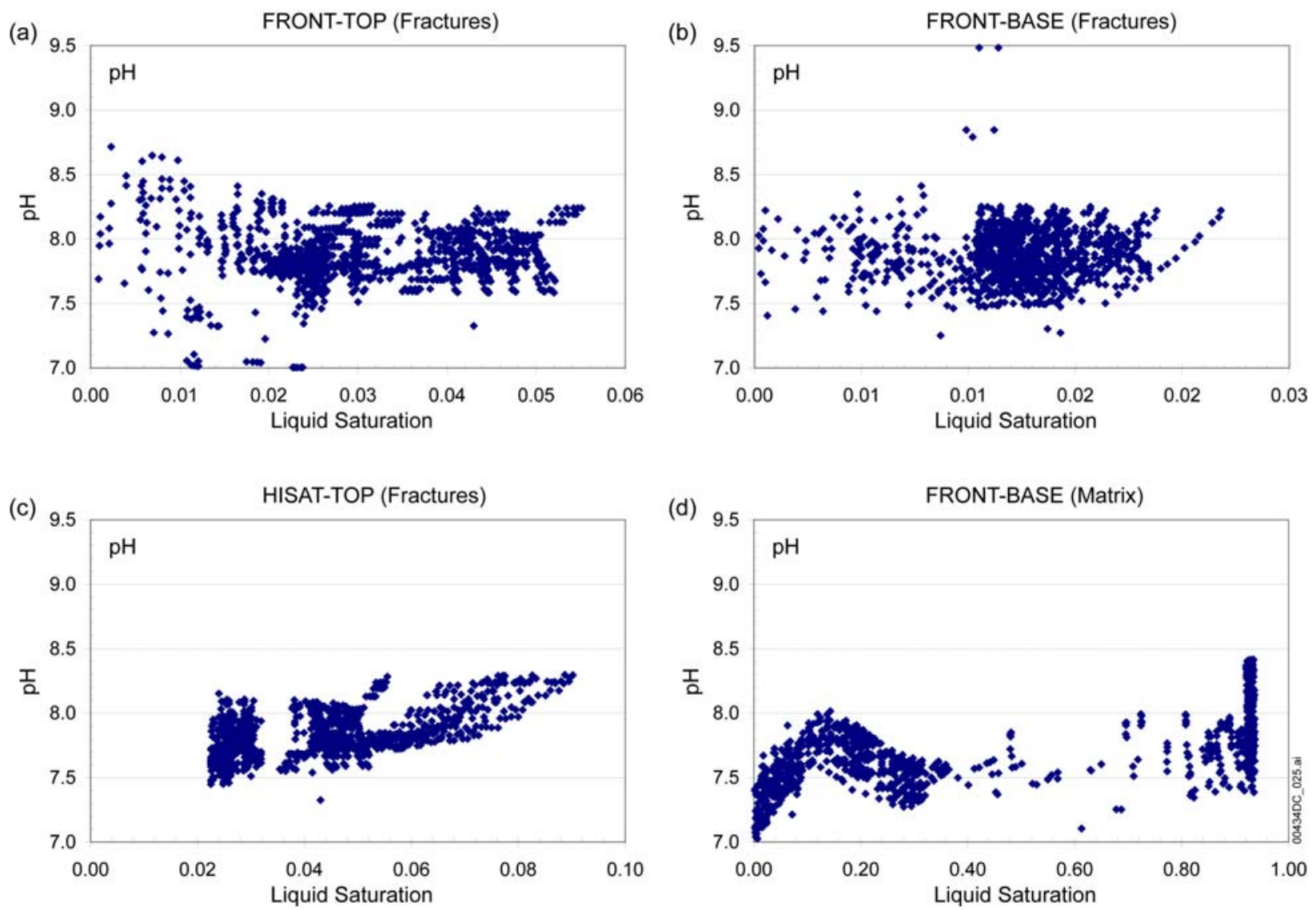

Input DTNs: $\quad$ LB0302DCSPTHCS.002 [DIRS 161976]; LB0307DSTTHCR2.002 [DIRS 165541]

Output DTN: $\quad$ LB0311ABSTHCR2.001 [DIRS 166714]

NOTE: $\quad$ Results for Group 1 simulations. See text (Section 6.2.4.2).

Figure 6.2-25. Selection of Model Results around the Modeled Drift as a Function of Liquid Saturation: $\mathrm{pH}$ 

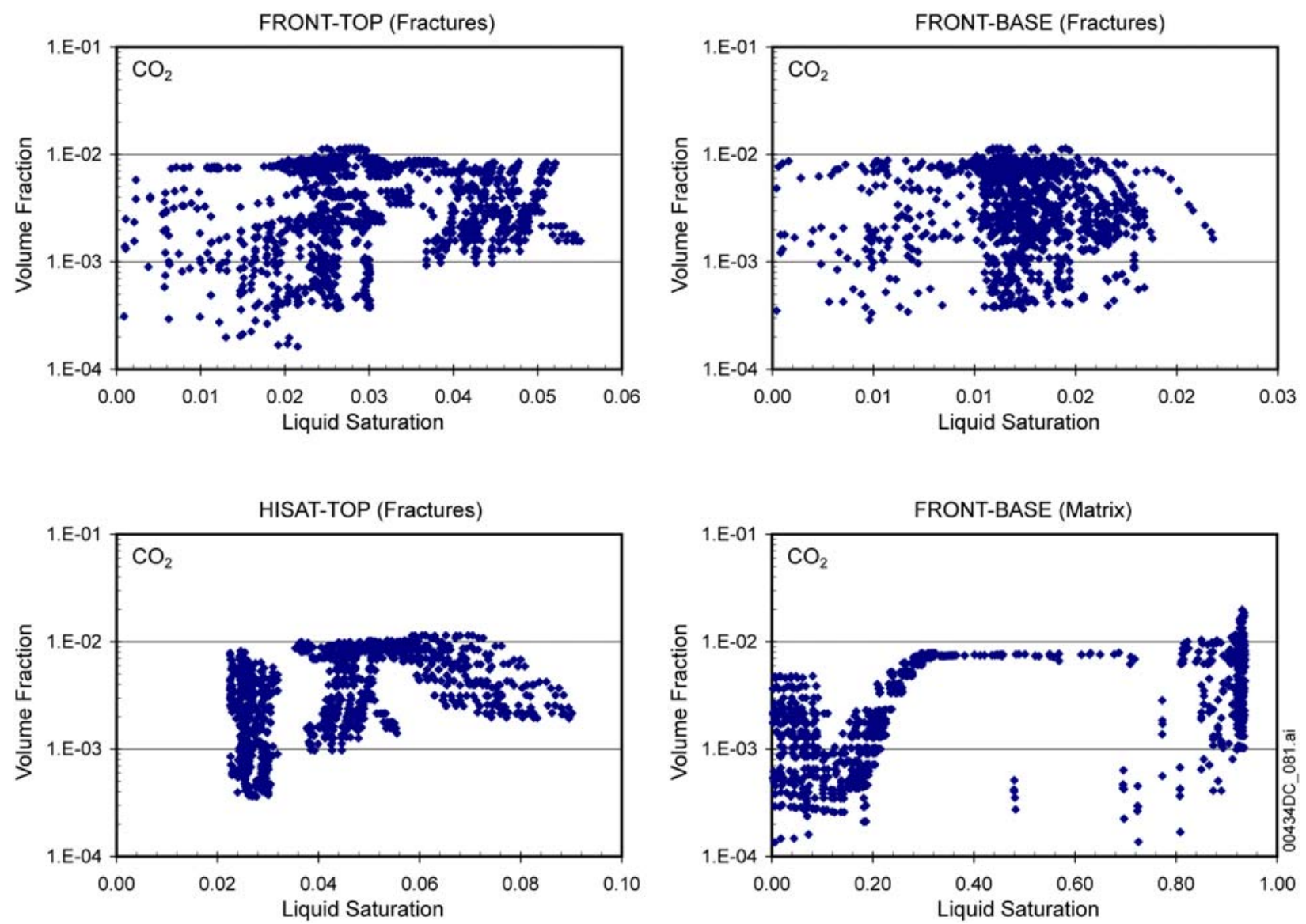

Input DTNs: $\quad$ LB0302DCSPTHCS.002 [DIRS 161976]; LB0307DSTTHCR2.002 [DIRS 165541].

Output DTN: LB0311ABSTHCR2.001 [DIRS 166714].

NOTE: $\quad$ Results for Group 1 simulations. See text (Section 6.2.4.2).

Figure 6.2-26. Selection of Model Results around the Modeled Drift as a Function of Liquid Saturation: Volume Fraction of Carbon Dioxide Gas 

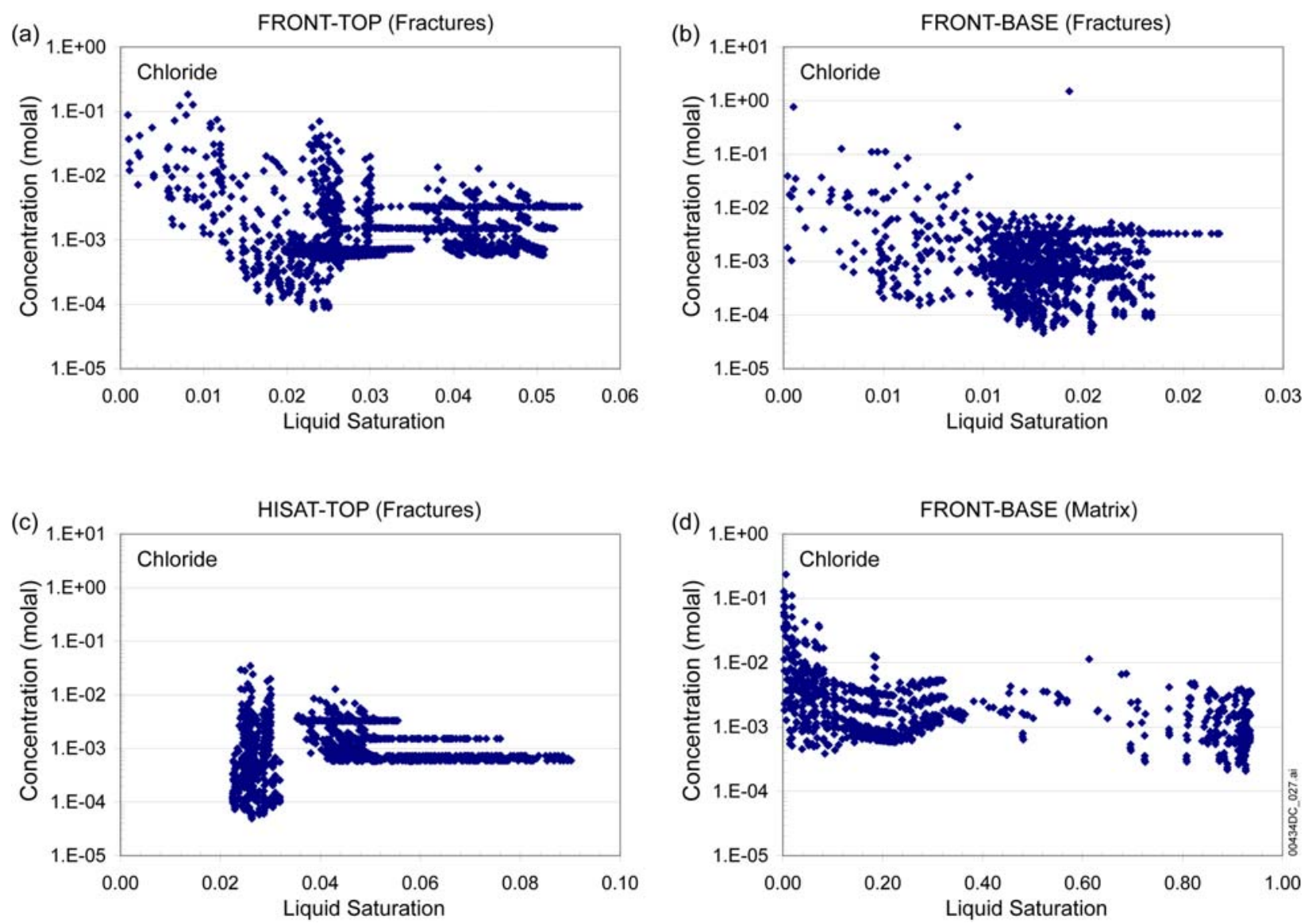

Input DTNs: $\quad$ LB0302DCSPTHCS.002 [DIRS 161976]; LB0307DSTTHCR2.002 [DIRS 165541].

Output DTN: LB0311ABSTHCR2.001 [DIRS 166714].

NOTE: $\quad$ Results for Group 1 simulations. See text (Section 6.2.4.2).

Figure 6.2-27. Selection of Model Results around the Modeled Drift as a Function of Liquid Saturation: Total Aqueous Chloride Concentration 

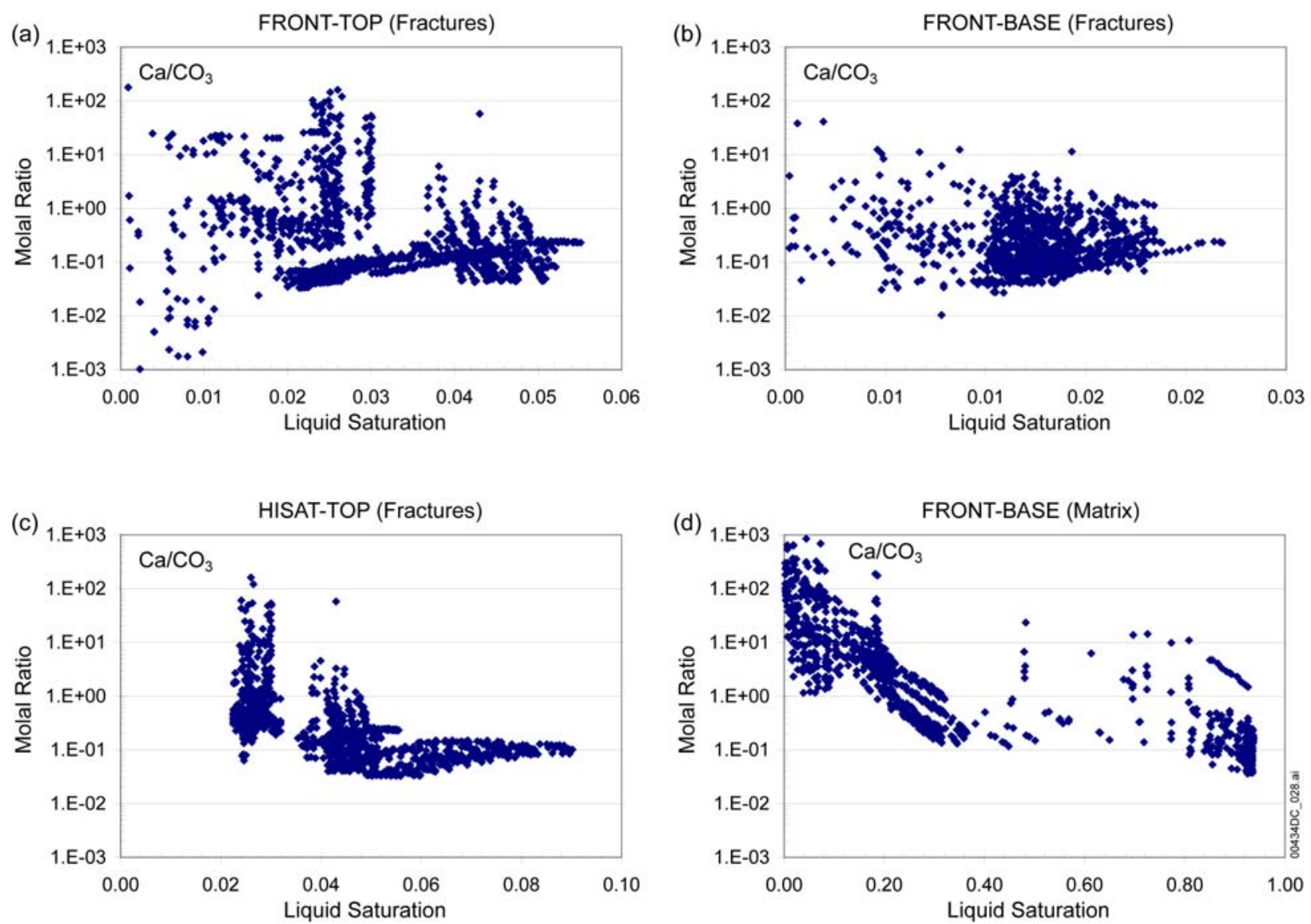

Input DTNs: $\quad$ LB0302DCSPTHCS.002 [DIRS 161976]; LB0307DSTTHCR2.002 [DIRS 165541].

Output DTN: $\quad$ LB0311ABSTHCR2.001 [DIRS 166714].

NOTE: $\quad$ Results for Group 1 simulations. See text (Section 6.2.4.2).

Figure 6.2-28. Selection of Model Results around the Modeled Drift as a Function of Liquid Saturation: Ratio of Total Aqueous Calcium to Total Aqueous Carbonate Concentrations

\subsubsection{Summary of Water Selection for P\&CE}

As discussed in Sections 6.2.2 and 6.2.3, several attributes are used to characterize the full data set of the drift-scale THC seepage model (BSC 2004 [DIRS 169856]). Those attributes include cross-sectional quadrants (TOP, SIDE, and BASE), media (fractures and matrix), saturation zones (HISAT and FRONT), and gridblock indices (INDX=1 to 6). FRONT-TOP-fracture and FRONT-BASE-matrix waters for INDX=4 appropriately represent the potential seepage water. Specific information of water compositions for those two waters can be obtained by selecting those attributes. For example, Figure 6.2.29 (from the "thc6_w4_r.xls" spreadsheet in DTN: LB0302DSCPTHCS.002 [DIRS 161976]) shows the movement of the wetting front as the temperature in the drift increases and decreases. As described Section 6.2.1, the following bulleted items summarize the selection of THC seepage model output for use in downstream reports (see Figure 1-1), such as Engineered Barrier System: Physical and Chemical Environment (BSC 2004 [DIRS 169860]): 
- Select Time Steps: Each THC seepage model output contains 50 time output points covering a period of 0 to 100,000 years. Thirty six (for W0) and thirty seven (for W4, W5, W6, W7) of the 50 time points are directly selected to cover the period of interest (51 through 20,013 years) for the TSPA-LA. Two other points are selected: the 0 to 50 -year preclosure response is represented by the year 10 results, and the post 20,000 year, or ambient response is represented by the 50,000 year case. The points for each of the five waters are coordinated so that water chemistries can be compared at equivalent times. (Note that in this report zero time represents emplacement and the times may need to be shifted 50 years if zero time is assigned to closure.)

- Select Quadrant: The THC seepage model provides water compositions the top (drift crown), the side, and the bottom (invert base). It is reasonable to neglect the data provided for the sides of the drift because the chemistry is similar to that in the crown and because gravity-driven seepage is more likely to occur above the drift opening. Therefore, the drift-crown and invert-base waters are selected.

- Select Fracture/Matrix: Potential seepage at the drift crown will come only from the fractures (CRWMS M\&O 2000 [DIRS 123916], Section 5.1.1). Water entering the invert will come only from the matrix where imbibition occurs via capillary suction from a higher saturated porous media into a porous media at a lower saturation (Jury et al. 1991 [DIRS 102010], pp. 87 to 110). Gravity and relatively low capillary pressure prohibit flow from the fractures into the invert. Therefore, the crown waters are selected from the THC seepage model output data worksheets labeled "fractures-ch" (DTN: LB0302DSCPTHCS.002 [DIRS 161976]) and the invert waters are selected from the data worksheets labeled "matrix-ch."

- Select Saturation Zone: The THC waters come from two zones: FRONT and HISAT. The FRONT zone waters come from the cells closest to the drift center with saturation levels greater than zero. The HISAT zone waters come from cells having the highest saturation within 25 meters of the drift springline (crown of drift). The FRONT waters are more concentrated and more variable with respect to location and time because of this variability. FRONT waters are more representative of potential seepage than HISAT water. The FRONT waters are shown in Figure 6.2-30 sorted by index and plotted against time.

- Select Index: Index selection is performed to reduce fluctuations in composition at the driest nodes, and to capture chemical composition representative of waters at the dry-out front. Index $4(\mathrm{INDX}=4)$ is chosen to moderate the numerical variation at the driest nodes, but capture the representative compositions.

The objective is to reflect the trends demonstrated by all front index waters, minimize any dry-out effects, and accommodate the simulations (BSC 2004 [DIRS 169860], Section 6.6), rather than using the THC model, to better control precipitation of selected waters. The dry-out effect is inherent to the discrete, numerical nature of the THC model, where a single cell may be at an arbitrary point approaching the dry-out cutoff, resulting in a wide range of relative concentration ratios as the THC model removes precipitates from the water. Figure 6.2-30 demonstrates this numerical fluctuation in the $\mathrm{Ca} / \mathrm{Cl}$ ratio for fracture 
water from FRONT-TOP (i.e., crown) (spreadsheet "thc6_w0_r.xls" in DTN: LB0302DSCPTHCS.002 [DIRS 161976]). Index 1 data, having a $\mathrm{Ca} / \mathrm{Cl}$ ratio of 1 at 650 years, show a large deviation from the other 5 Index waters having a $\mathrm{Ca} / \mathrm{Cl}$ ratio of around 0.2 (Table 6.2-3). One source of this fluctuation is demonstrated by the saturation level (SL in spreadsheet) plot in Figure 6.2-31 for TOP-FRONT water, in which both Index 1 and Index 2 saturation levels deviate towards 0.001 at a time near 100 years. These order of magnitude deviations in water content affect the relative chemical concentrations in those waters as the THC model precipitates minerals and possibly alters the results of the final EQ3/6 end-brine calculation (BSC 2004 [DIRS 169860]). The full set of THC seepage model results is represented by 368 data points as described in Table 6.2-3a. The number shows time steps for which water and gas concentrations are selected.

Table 6.2-3a. Selected Subset of THC Model Results for the Selected Five Water Compositions

\begin{tabular}{|c|c|c|c|c|c|c|c|c|c|c|c|c|}
\hline \multirow{3}{*}{$\begin{array}{c}\text { Location } \\
\text { Water }\end{array}$} & \multicolumn{4}{|c|}{ TOP } & \multicolumn{4}{|c|}{ BASE } & \multicolumn{4}{|c|}{ SIDE } \\
\hline & \multicolumn{2}{|c|}{ HISAT } & \multicolumn{2}{|c|}{ FRONT } & \multicolumn{2}{|c|}{ HISAT } & \multicolumn{2}{|c|}{ FRONT } & \multicolumn{2}{|c|}{ HISAT } & \multicolumn{2}{|c|}{ FRONT } \\
\hline & Frac & Matx & Frac & Matx & Frac & Matx & Frac & Matx & Frac & Matx & Frac & Matx \\
\hline Wo & - & - & 36 & - & - & - & - & 36 & - & - & - & - \\
\hline W4 & - & - & 37 & - & - & - & - & 37 & - & - & - & - \\
\hline W5 & - & - & 37 & - & - & - & - & 37 & - & - & - & - \\
\hline W6 & - & - & 37 & - & - & - & - & 37 & - & - & - & - \\
\hline W7 & - & - & 37 & - & - & - & - & 37 & - & - & - & - \\
\hline Total & - & - & 184 & - & - & - & - & 184 & - & - & - & - \\
\hline
\end{tabular}

NOTE: $\quad$ Dash $(-)=$ not used. The numbers show time steps. Data sources: DTNs: LB0302DCSPTHCS.002 [DIRS 161976]; LB0307DSTTHCR2.002 [DIRS 165541]. 


\section{Distance}

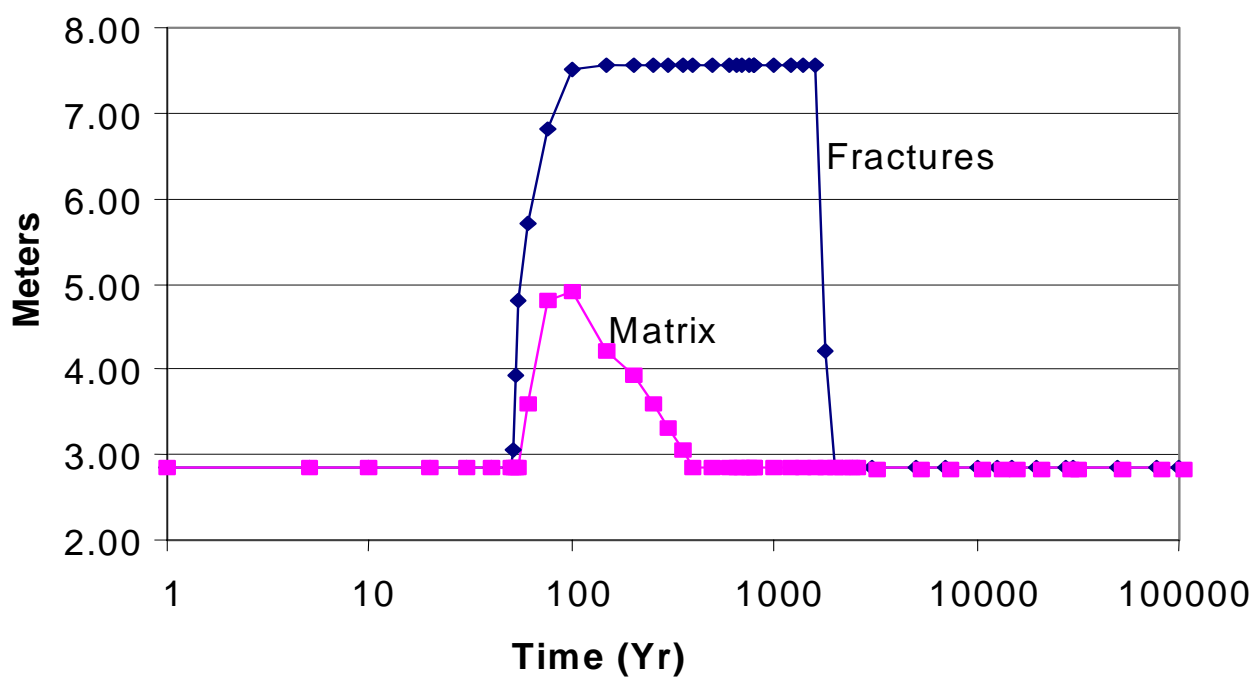

DTN: LB0302DSCPTHCS.002 [DIRS 161976].

Figure 6.2-29. Location of the Wetting Front in the Host Rock (Relative to Drift Center), as Calculated by the Thermal-Hydrological-Chemical- Seepage Model

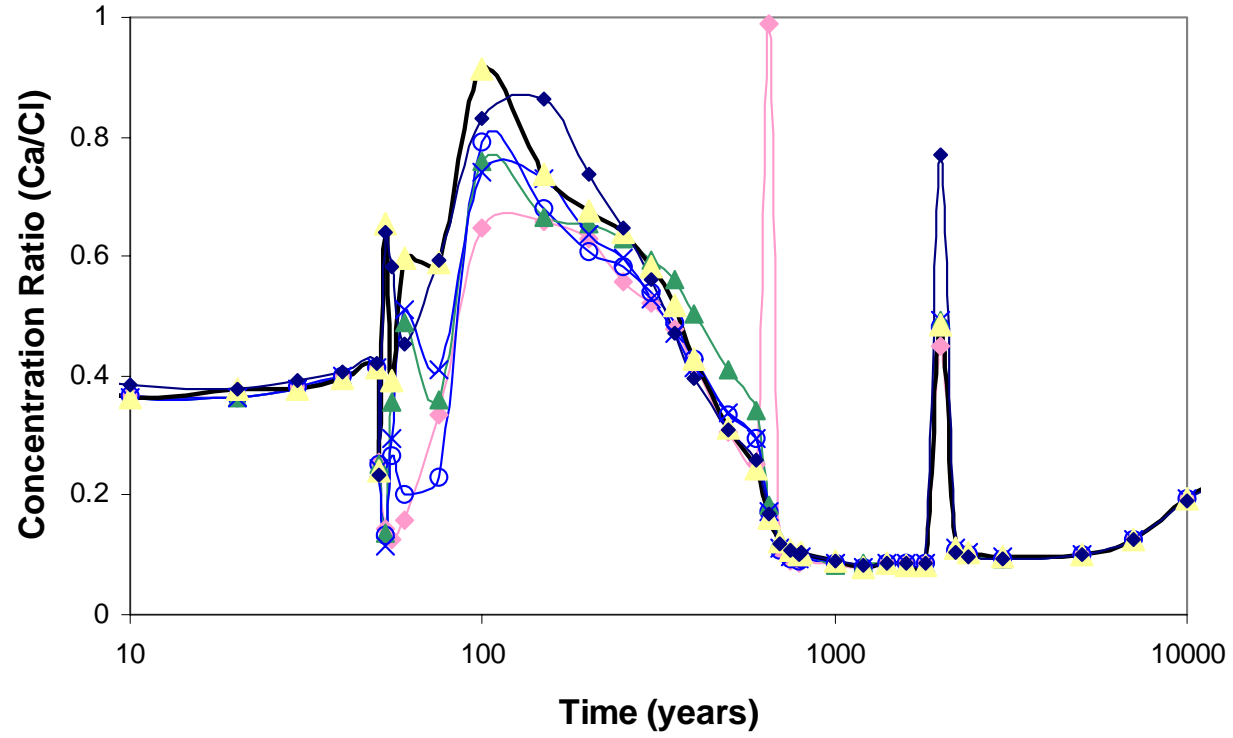

$\multimap$ Index $1 \multimap$ Index $2 \multimap$ Index $3 \multimap$ Index $4--$ Index $5 \multimap$ Index 6

DTN: LB0302DSCPTHCS.002 [DIRS 161976], Spreadsheet "thc6_w0_r.xls."

Figure 6.2-30. Ca to Cl Ratio in FRONT-TOP-Fracture Waters 


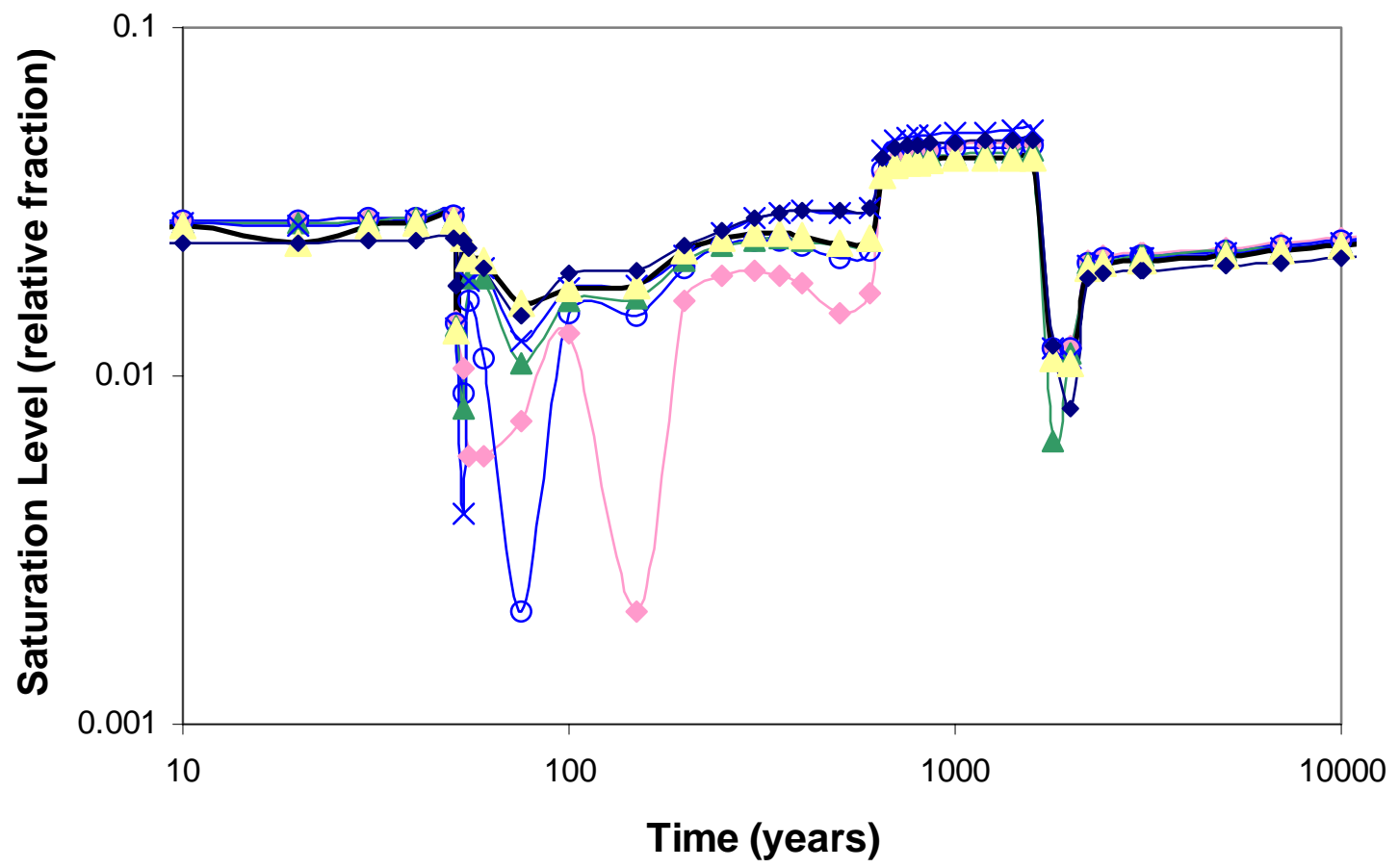

Index $1 \multimap$ Index $2 \multimap \operatorname{Index} 3 \rightarrow$ Index $4-$ Index $5 \multimap$ Index 6

DTN: LB0302DSCPTHCS.002 [DIRS 161976], spreadsheet "thc6_w6_r.xls."

Figure 6.2-31. Fracture Saturation Level in FRONT-TOP-Fracture Waters

\subsubsection{Uncertainties of Aqueous Species and $\mathrm{CO}_{2}$ Predicted Concentrations}

In this section, uncertainty associated with predicted water and gas concentrations is examined using Group 2 (Table 6.2-1) simulation runs. It is further confirmed that Group 1 simulations cover a wider range of concentration variability and that the selection of THC model results, from Group 1 simulation runs, better represents the compositions of potential seepage water. As mentioned in Section 6.2.3 (see Table 6.2-1), Group 2 THC simulations were also conducted for:

1. Three different infiltration scenarios (using water W0) (BSC 2004 [DIRS 169856], Table 6.5-3):

- Stepwise increase from 6 to $25 \mathrm{~mm} / \mathrm{yr}$,

- Constant $6 \mathrm{~mm} / \mathrm{yr}$, and

- Constant 25 mm/yr.

2. Two different water vapor-pressure options implemented in TOUGHREACT V3.0 (modules EOS4 and EOS3):

- With vapor-pressure lowering due to capillary pressure using water W0

- Without vapor-pressure lowering using water W0. 
3. Two values of $\mathrm{CO}_{2}$ gas diffusion coefficient

- Standard value of CO2 diffusion coefficient using water W0

- Six times of standard value of CO2 gas diffusion coefficient using water W0.

Summary statistics (minimum, maximum, mean, and standard deviation) of extracted data were calculated and compared at each specific time for Group 1 and Group 2 simulation results in Tables 6.2-4 and 6.2-5. The relative spread in model results is then evaluated as a function of time separately for Group 1 and Group 2 in Tables 6.2-4 and 6.2-5 respectively for HISAT-TOP and FRONT-TOP waters in fractures. This spread is generally larger for Group 1 than for Group 2. For this reason, further spread analyses were carried out using only Group 1.

The two-standard-deviation spread in predicted concentrations and concentration ratios for both Group 1 and Group 2 runs generally does not exceed one order of magnitude (Tables 6.2-4 and 6.2-5, Columns Grp 1 and Grp 2). If the spread in Group 2 compositions (run using only W0), representing uncertainties other than water composition, is applicable to each of the Group 1 runs (run using water compositions W0, W4, W5, W6, and W7), representing natural variability in water composition (See Table 6.2-1), then the combined standard deviation can be approximated by adding together the variances of both groups, then taking the square root of this sum to obtain the standard deviation (Tables 6.2-4 and 6.2-5, Column Grp 1+2). Thus, the combined standard deviation is calculated as $\mathrm{SD}_{1+2}=\left(\mathrm{SD}_{1}{ }^{2}+\mathrm{SD}_{2}{ }^{2}\right)^{0.5}$. The resulting combined spread also remains mostly within one order of magnitude. For HISAT and FRONT waters, the standard deviations for Group 1 on the average exceed those for Group 2 (Tables 6.2-4 and 6.2-5). For this reason, further analyses using FRONT waters from Group 2 runs are not necessary. It should be noted, though, that when standard deviation values are large, they are commonly and slightly larger for Group 2 than Group 1, although generally not by much (Table 6.2-5). In summary, Group 2 has little impact on concentration spreads. Group 1 simulations can represent the THC seepage model output for TSPA-LA. Similarly to Group 2 here, sensitivity analyses can be conducted for other waters (W4, W5, W6, and W7) with different $\mathrm{CO}_{2}$ diffusion coefficients and vapor-pressure lowering options. 
Table 6.2-4. Comparison of Standard Deviations in Water and Gas Compositions Between Group 1 and Group 2 Simulations Predicted in Zones of High Liquid Saturation above the Drift Crown (HISAT - TOP, Fractures)

\begin{tabular}{|c|c|c|c|c|c|c|c|c|c|c|c|c|c|c|c|}
\hline \multirow[b]{2}{*}{ Time (yr) } & \multicolumn{3}{|c|}{$\mathrm{pH}$} & \multicolumn{3}{|c|}{ Calcium } & \multicolumn{3}{|c|}{ Magnesium } & \multicolumn{3}{|c|}{ Sodium } & \multicolumn{3}{|c|}{ Chloride } \\
\hline & Grp 1 & Grp 2 & Grp 1+2 & Grp 1 & Grp 2 & $\begin{array}{l}\text { Grp } \\
1+2\end{array}$ & Grp 1 & Grp 2 & $\begin{array}{l}\text { Grp } \\
1+2\end{array}$ & Grp 1 & Grp 2 & $\begin{array}{l}\text { Grp } \\
1+2\end{array}$ & Grp 1 & Grp 2 & $\begin{array}{l}\text { Grp } \\
1+2\end{array}$ \\
\hline 0 & 0.11 & 0.00 & 0.11 & 0.11 & 0.00 & 0.11 & 0.52 & 0.00 & 0.52 & 0.18 & 0.00 & 0.18 & 0.29 & 0.00 & 0.29 \\
\hline 53 & 0.14 & 0.17 & 0.22 & 0.15 & 0.09 & 0.17 & 0.82 & 0.30 & 0.87 & 0.25 & 0.20 & 0.32 & 0.37 & 0.20 & 0.42 \\
\hline 100 & 0.13 & 0.18 & 0.23 & 0.04 & 0.04 & 0.06 & 0.23 & 0.27 & 0.36 & 0.11 & 0.12 & 0.17 & 0.31 & 0.12 & 0.33 \\
\hline 150 & 0.15 & 0.23 & 0.27 & 0.07 & 0.37 & 0.38 & 0.20 & 0.84 & 0.86 & 0.08 & 0.42 & 0.43 & 0.31 & 0.49 & 0.58 \\
\hline 200 & 0.09 & 0.21 & 0.23 & 0.23 & 0.29 & 0.37 & 0.38 & 0.62 & 0.73 & 0.16 & 0.30 & 0.34 & 0.40 & 0.36 & 0.54 \\
\hline 300 & 0.10 & 0.14 & 0.17 & 0.40 & 0.31 & 0.51 & 0.35 & 0.40 & 0.53 & 0.26 & 0.29 & 0.39 & 0.46 & 0.33 & 0.57 \\
\hline 400 & 0.11 & 0.12 & 0.16 & 0.35 & 0.31 & 0.47 & 0.38 & 0.40 & 0.55 & 0.24 & 0.27 & 0.36 & 0.40 & 0.31 & 0.51 \\
\hline 500 & 0.15 & 0.14 & 0.21 & 0.41 & 0.35 & 0.54 & 0.49 & 0.47 & 0.68 & 0.29 & 0.28 & 0.41 & 0.44 & 0.34 & 0.56 \\
\hline 600 & 0.17 & 0.14 & 0.22 & 0.42 & 0.36 & 0.55 & 0.47 & 0.48 & 0.67 & 0.26 & 0.28 & 0.38 & 0.40 & 0.33 & 0.52 \\
\hline 800 & 0.10 & 0.15 & 0.18 & 0.20 & 0.32 & 0.38 & 0.28 & 0.27 & 0.39 & 0.12 & 0.14 & 0.19 & 0.30 & 0.17 & 0.34 \\
\hline 1,000 & 0.09 & 0.09 & 0.12 & 0.16 & 0.08 & 0.18 & 0.23 & 0.12 & 0.26 & 0.10 & 0.06 & 0.11 & 0.29 & 0.07 & 0.30 \\
\hline 1.200 & 0.09 & 0.08 & 0.12 & 0.15 & 0.05 & 0.16 & 0.22 & 0.09 & 0.24 & 0.09 & 0.03 & 0.09 & 0.29 & 0.04 & 0.29 \\
\hline 1.400 & 0.08 & 0.06 & 0.10 & 0.17 & 0.03 & 0.17 & 0.19 & 0.06 & 0.20 & 0.08 & 0.01 & 0.08 & 0.29 & 0.02 & 0.29 \\
\hline 1.600 & 0.07 & 0.05 & 0.09 & 0.16 & 0.03 & 0.16 & 0.18 & 0.05 & 0.19 & 0.08 & 0.01 & 0.08 & 0.29 & 0.01 & 0.29 \\
\hline 1.800 & 0.06 & 0.04 & 0.07 & 0.13 & 0.07 & 0.15 & 0.15 & 0.07 & 0.16 & 0.06 & 0.01 & 0.06 & 0.23 & 0.00 & 0.23 \\
\hline 2.000 & 0.08 & 0.04 & 0.08 & 0.18 & 0.02 & 0.18 & 0.19 & 0.04 & 0.20 & 0.08 & 0.02 & 0.09 & 0.32 & 0.04 & 0.32 \\
\hline 2.200 & 0.06 & 0.07 & 0.09 & 0.18 & 0.09 & 0.20 & 0.17 & 0.12 & 0.21 & 0.06 & 0.03 & 0.07 & 0.29 & 0.05 & 0.29 \\
\hline 2.400 & 0.06 & 0.07 & 0.09 & 0.18 & 0.12 & 0.22 & 0.17 & 0.11 & 0.20 & 0.06 & 0.02 & 0.06 & 0.29 & 0.05 & 0.29 \\
\hline 5.000 & 0.05 & 0.06 & 0.08 & 0.14 & 0.08 & 0.16 & 0.14 & 0.07 & 0.16 & 0.06 & 0.02 & 0.06 & 0.29 & 0.01 & 0.29 \\
\hline 7.000 & 0.05 & 0.04 & 0.06 & 0.14 & 0.07 & 0.15 & 0.12 & 0.10 & 0.16 & 0.06 & 0.02 & 0.06 & 0.29 & 0.00 & 0.29 \\
\hline 10.000 & 0.03 & 0.03 & 0.05 & 0.14 & 0.09 & 0.16 & 0.10 & 0.12 & 0.16 & 0.06 & 0.03 & 0.06 & 0.29 & 0.00 & 0.29 \\
\hline 20.000 & 0.04 & 0.04 & 0.06 & 0.14 & 0.05 & 0.15 & 0.11 & 0.10 & 0.15 & 0.06 & 0.02 & 0.06 & 0.29 & 0.00 & 0.29 \\
\hline 50.000 & 0.05 & 0.09 & 0.10 & 0.14 & 0.02 & 0.14 & 0.09 & 0.12 & 0.15 & 0.05 & 0.03 & 0.06 & 0.29 & 0.00 & 0.29 \\
\hline 100.000 & 0.03 & 0.13 & 0.14 & 0.13 & 0.01 & 0.13 & 0.08 & 0.18 & 0.20 & 0.05 & 0.04 & 0.06 & 0.29 & 0.00 & 0.29 \\
\hline Interval (yr) & Grp 1 & Grp 2 & Grp 1+2 & Grp 1 & Grp 2 & Grp 1+2 & Grp 1 & Grp 2 & Grp 1+2 & Grp 1 & Grp 2 & Grp 1+2 & Grp 1 & Grp 2 & Grp 1+2 \\
\hline $0-100,000$ & 0.09 & 0.10 & 0.14 & 0.19 & 0.14 & 0.24 & 0.26 & 0.23 & 0.37 & 0.12 & 0.11 & 0.17 & 0.32 & 0.12 & 0.36 \\
\hline $150-600$ & 0.13 & 0.16 & 0.21 & 0.31 & 0.33 & 0.47 & 0.38 & 0.53 & 0.67 & 0.22 & 0.31 & 0.39 & 0.40 & 0.36 & 0.54 \\
\hline $600-2,000$ & 0.09 & 0.08 & 0.12 & 0.20 & 0.12 & 0.24 & 0.24 & 0.15 & 0.29 & 0.11 & 0.07 & 0.13 & 0.30 & 0.09 & 0.32 \\
\hline $2,000-100,000$ & 0.05 & 0.06 & 0.08 & 0.15 & 0.06 & 0.17 & 0.13 & 0.11 & 0.18 & 0.06 & 0.03 & 0.07 & 0.29 & 0.02 & 0.29 \\
\hline Maximum & 0.17 & 0.23 & 0.27 & 0.42 & 0.37 & 0.55 & 0.82 & 0.84 & 0.87 & 0.29 & 0.42 & 0.43 & 0.46 & 0.49 & 0.58 \\
\hline
\end{tabular}


Table 6.2-4. Comparison of Standard Deviations in Water and Gas Compositions Between Group 1 and Group 2 Simulations Predicted in Zones of High Liquid Saturation above the Drift Crown (HISAT - TOP, Fractures) (Continued)

\begin{tabular}{|c|c|c|c|c|c|c|c|c|c|c|c|c|c|c|c|}
\hline \multirow[b]{2}{*}{ Time (yr) } & \multicolumn{3}{|c|}{ Silica } & \multicolumn{3}{|c|}{ Carbonate } & \multicolumn{3}{|c|}{ Sulfate } & \multicolumn{3}{|c|}{ Potassium } & \multicolumn{3}{|c|}{ Fluoride } \\
\hline & Grp 1 & Grp 2 & $\begin{array}{l}\text { Grp } \\
1+2 \\
\end{array}$ & Grp 1 & Grp 2 & $\begin{array}{l}\text { Grp } \\
1+2 \\
\end{array}$ & Grp 1 & Grp 2 & $\begin{array}{l}\text { Grp } \\
1+2 \\
\end{array}$ & Grp 1 & Grp 2 & $\begin{array}{l}\text { Grp } \\
1+2 \\
\end{array}$ & Grp 1 & Grp 2 & $\begin{array}{l}\text { Grp } \\
1+2 \\
\end{array}$ \\
\hline 0 & 0.08 & 0.00 & 0.08 & 0.14 & 0.00 & 0.14 & 0.37 & 0.00 & 0.37 & 0.06 & 0.00 & 0.06 & 0.30 & 0.00 & 0.30 \\
\hline 53 & 0.20 & 0.18 & 0.27 & 0.22 & 0.15 & 0.26 & 0.44 & 0.20 & 0.49 & 0.24 & 0.19 & 0.31 & 0.25 & 0.19 & 0.31 \\
\hline 100 & 0.06 & 0.05 & 0.08 & 0.16 & 0.20 & 0.26 & 0.39 & 0.12 & 0.40 & 0.11 & 0.12 & 0.17 & 0.08 & 0.05 & 0.10 \\
\hline 150 & 0.05 & 0.21 & 0.22 & 0.20 & 0.23 & 0.31 & 0.38 & 0.48 & 0.62 & 0.08 & 0.43 & 0.44 & 0.07 & 0.11 & 0.13 \\
\hline 200 & 0.14 & 0.16 & 0.21 & 0.23 & 0.23 & 0.32 & 0.46 & 0.36 & 0.58 & 0.16 & 0.31 & 0.35 & 0.12 & 0.10 & 0.16 \\
\hline 300 & 0.19 & 0.20 & 0.28 & 0.30 & 0.11 & 0.32 & 0.51 & 0.33 & 0.61 & 0.27 & 0.30 & 0.40 & 0.18 & 0.07 & 0.19 \\
\hline 400 & 0.16 & 0.18 & 0.24 & 0.22 & 0.09 & 0.24 & 0.44 & 0.30 & 0.54 & 0.24 & 0.28 & 0.37 & 0.13 & 0.08 & 0.15 \\
\hline 500 & 0.17 & 0.15 & 0.23 & 0.13 & 0.07 & 0.15 & 0.51 & 0.35 & 0.62 & 0.29 & 0.29 & 0.41 & 0.12 & 0.06 & 0.13 \\
\hline 600 & 0.16 & 0.14 & 0.21 & 0.13 & 0.11 & 0.17 & 0.45 & 0.35 & 0.57 & 0.27 & 0.29 & 0.39 & 0.13 & 0.06 & 0.14 \\
\hline 800 & 0.04 & 0.10 & 0.10 & 0.07 & 0.12 & 0.14 & 0.37 & 0.24 & 0.45 & 0.12 & 0.15 & 0.19 & 0.07 & 0.10 & 0.12 \\
\hline 1,000 & 0.02 & 0.05 & 0.06 & 0.06 & 0.11 & 0.12 & 0.37 & 0.08 & 0.38 & 0.10 & 0.06 & 0.12 & 0.05 & 0.05 & 0.07 \\
\hline 1,200 & 0.02 & 0.04 & 0.05 & 0.08 & 0.09 & 0.12 & 0.37 & 0.04 & 0.37 & 0.09 & 0.03 & 0.09 & 0.04 & 0.05 & 0.06 \\
\hline 1,400 & 0.02 & 0.04 & 0.04 & 0.07 & 0.08 & 0.11 & 0.37 & 0.02 & 0.37 & 0.08 & 0.02 & 0.08 & 0.05 & 0.04 & 0.06 \\
\hline 1,600 & 0.01 & 0.04 & 0.04 & 0.07 & 0.06 & 0.09 & 0.37 & 0.01 & 0.37 & 0.08 & 0.01 & 0.08 & 0.06 & 0.03 & 0.06 \\
\hline 1,800 & 0.01 & 0.03 & 0.03 & 0.06 & 0.04 & 0.07 & 0.28 & 0.05 & 0.28 & 0.06 & 0.01 & 0.06 & 0.05 & 0.06 & 0.08 \\
\hline 2,000 & 0.01 & 0.03 & 0.03 & 0.07 & 0.04 & 0.08 & 0.38 & 0.02 & 0.38 & 0.08 & 0.02 & 0.09 & 0.07 & 0.04 & 0.08 \\
\hline 2,200 & 0.02 & 0.07 & 0.07 & 0.08 & 0.07 & 0.10 & 0.37 & 0.05 & 0.38 & 0.07 & 0.04 & 0.08 & 0.07 & 0.05 & 0.09 \\
\hline 2,400 & 0.02 & 0.06 & 0.07 & 0.07 & 0.06 & 0.09 & 0.37 & 0.05 & 0.37 & 0.07 & 0.02 & 0.07 & 0.07 & 0.06 & 0.09 \\
\hline 5,000 & 0.01 & 0.02 & 0.02 & 0.07 & 0.04 & 0.08 & 0.37 & 0.01 & 0.37 & 0.07 & 0.02 & 0.07 & 0.06 & 0.04 & 0.07 \\
\hline 7,000 & 0.01 & 0.02 & 0.02 & 0.08 & 0.08 & 0.11 & 0.37 & 0.00 & 0.37 & 0.06 & 0.02 & 0.07 & 0.05 & 0.03 & 0.06 \\
\hline 10,000 & 0.01 & 0.02 & 0.02 & 0.08 & 0.13 & 0.15 & 0.37 & 0.00 & 0.37 & 0.06 & 0.01 & 0.06 & 0.05 & 0.04 & 0.07 \\
\hline 20,000 & 0.01 & 0.02 & 0.02 & 0.09 & 0.07 & 0.12 & 0.37 & 0.00 & 0.37 & 0.06 & 0.02 & 0.06 & 0.06 & 0.02 & 0.06 \\
\hline 50,000 & 0.02 & 0.04 & 0.04 & 0.10 & 0.07 & 0.12 & 0.37 & 0.00 & 0.37 & 0.05 & 0.05 & 0.07 & 0.06 & 0.01 & 0.06 \\
\hline 100,000 & 0.02 & 0.05 & 0.06 & 0.10 & 0.08 & 0.13 & 0.37 & 0.00 & 0.37 & 0.05 & 0.05 & 0.07 & 0.05 & 0.01 & 0.05 \\
\hline Interval (yr) & Grp 1 & Grp 2 & Grp 1+2 & Grp 1 & Grp 2 & Grp 1+2 & Grp 1 & Grp 2 & Grp 1+2 & Grp 1 & Grp 2 & Grp 1+2 & Grp 1 & Grp 2 & Grp 1+2 \\
\hline $0-100,000$ & 0.06 & 0.08 & 0.10 & 0.12 & 0.10 & 0.16 & 0.39 & 0.13 & 0.43 & 0.12 & 0.11 & 0.17 & 0.09 & 0.06 & 0.11 \\
\hline $150-600$ & 0.15 & 0.18 & 0.23 & 0.20 & 0.14 & 0.25 & 0.46 & 0.36 & 0.59 & 0.22 & 0.32 & 0.39 & 0.13 & 0.08 & 0.15 \\
\hline $600-2,000$ & 0.04 & 0.06 & 0.07 & 0.08 & 0.08 & 0.11 & 0.37 & 0.10 & 0.40 & 0.11 & 0.07 & 0.14 & 0.06 & 0.05 & 0.09 \\
\hline $2,000-100,000$ & 0.01 & 0.04 & 0.04 & 0.08 & 0.07 & 0.11 & 0.37 & 0.02 & 0.37 & 0.06 & 0.03 & 0.07 & 0.06 & 0.03 & 0.07 \\
\hline Maximum & 0.20 & 0.21 & 0.28 & 0.30 & 0.23 & 0.32 & 0.51 & 0.48 & 0.62 & 0.29 & 0.43 & 0.44 & 0.30 & 0.19 & 0.31 \\
\hline
\end{tabular}


Table 6.2-4. Comparison of Standard Deviations in Water and Gas Compositions Between Group 1 and Group 2 Simulations Predicted in Zones of High Liquid Saturation above the Drift Crown (HISAT - TOP, Fractures) (Continued)

\begin{tabular}{|c|c|c|c|c|c|c|c|c|c|c|c|c|c|c|c|}
\hline \multirow[b]{2}{*}{ Time (yr) } & \multicolumn{3}{|c|}{ Nitrate } & \multicolumn{3}{|c|}{$\mathrm{CO}_{2}$ (gas) } & \multicolumn{3}{|c|}{$\mathrm{Ca} / \mathrm{Na}$} & \multicolumn{3}{|c|}{$\mathrm{NO}_{3} / \mathrm{Cl}$} & \multicolumn{3}{|c|}{$\mathrm{HCO}_{3} / \mathrm{Cl}$} \\
\hline & Grp 1 & Grp 2 & $\begin{array}{l}\text { Grp } \\
1+2 \\
\end{array}$ & Grp 1 & Grp 2 & $\begin{array}{l}\text { Grp } \\
1+2 \\
\end{array}$ & Grp 1 & Grp 2 & $\begin{array}{l}\text { Grp } \\
1+2 \\
\end{array}$ & Grp 1 & Grp 2 & $\begin{array}{l}\text { Grp } \\
1+2 \\
\end{array}$ & Grp 1 & Grp 2 & $\begin{array}{l}\text { Grp } \\
1+2\end{array}$ \\
\hline 0 & 0.27 & 0.00 & 0.27 & 0.23 & 0.00 & 0.23 & 0.25 & 0.00 & 0.25 & 0.38 & 0.00 & 0.38 & 0.40 & 0.00 & 0.40 \\
\hline 53 & 0.35 & 0.20 & 0.41 & 0.32 & 0.30 & 0.44 & 0.30 & 0.12 & 0.32 & 0.38 & 0.00 & 0.38 & 0.44 & 0.15 & 0.46 \\
\hline 100 & 0.30 & 0.12 & 0.32 & 0.29 & 0.39 & 0.49 & 0.11 & 0.12 & 0.16 & 0.38 & 0.00 & 0.38 & 0.43 & 0.21 & 0.48 \\
\hline 150 & 0.28 & 0.49 & 0.57 & 0.35 & 0.42 & 0.55 & 0.11 & 0.13 & 0.17 & 0.38 & 0.00 & 0.38 & 0.48 & 0.57 & 0.75 \\
\hline 200 & 0.33 & 0.36 & 0.49 & 0.32 & 0.42 & 0.53 & 0.23 & 0.09 & 0.24 & 0.38 & 0.00 & 0.38 & 0.58 & 0.45 & 0.74 \\
\hline 300 & 0.42 & 0.33 & 0.54 & 0.34 & 0.19 & 0.39 & 0.31 & 0.10 & 0.33 & 0.37 & 0.01 & 0.37 & 0.70 & 0.39 & 0.80 \\
\hline 400 & 0.40 & 0.31 & 0.51 & 0.25 & 0.14 & 0.29 & 0.18 & 0.16 & 0.24 & 0.37 & 0.01 & 0.37 & 0.58 & 0.36 & 0.68 \\
\hline 500 & 0.39 & 0.34 & 0.52 & 0.13 & 0.11 & 0.17 & 0.18 & 0.12 & 0.21 & 0.37 & 0.01 & 0.37 & 0.54 & 0.39 & 0.67 \\
\hline 600 & 0.41 & 0.33 & 0.52 & 0.08 & 0.13 & 0.15 & 0.25 & 0.10 & 0.27 & 0.38 & 0.01 & 0.38 & 0.50 & 0.41 & 0.65 \\
\hline 800 & 0.28 & 0.18 & 0.33 & 0.07 & 0.16 & 0.17 & 0.12 & 0.24 & 0.27 & 0.38 & 0.00 & 0.38 & 0.35 & 0.26 & 0.44 \\
\hline 1,000 & 0.27 & 0.08 & 0.29 & 0.03 & 0.18 & 0.18 & 0.08 & 0.06 & 0.10 & 0.38 & 0.00 & 0.38 & 0.35 & 0.13 & 0.37 \\
\hline 1,200 & 0.27 & 0.04 & 0.28 & 0.01 & 0.16 & 0.16 & 0.07 & 0.04 & 0.08 & 0.38 & 0.00 & 0.38 & 0.37 & 0.10 & 0.38 \\
\hline 1,400 & 0.27 & 0.02 & 0.27 & 0.01 & 0.13 & 0.13 & 0.09 & 0.03 & 0.10 & 0.38 & 0.00 & 0.38 & 0.36 & 0.08 & 0.37 \\
\hline 1,600 & 0.27 & 0.01 & 0.27 & 0.01 & 0.10 & 0.10 & 0.08 & 0.03 & 0.09 & 0.38 & 0.00 & 0.38 & 0.35 & 0.06 & 0.36 \\
\hline 1,800 & 0.33 & 0.00 & 0.33 & 0.01 & 0.07 & 0.07 & 0.08 & 0.07 & 0.10 & 0.38 & 0.00 & 0.38 & 0.28 & 0.04 & 0.28 \\
\hline 2,000 & 0.28 & 0.05 & 0.28 & 0.01 & 0.06 & 0.06 & 0.09 & 0.04 & 0.10 & 0.38 & 0.00 & 0.38 & 0.39 & 0.06 & 0.39 \\
\hline 2,200 & 0.27 & 0.05 & 0.28 & 0.03 & 0.11 & 0.12 & 0.12 & 0.07 & 0.14 & 0.38 & 0.00 & 0.38 & 0.36 & 0.09 & 0.38 \\
\hline 2,400 & 0.27 & 0.05 & 0.28 & 0.02 & 0.09 & 0.09 & 0.12 & 0.11 & 0.16 & 0.38 & 0.00 & 0.38 & 0.36 & 0.09 & 0.37 \\
\hline 5,000 & 0.27 & 0.01 & 0.27 & 0.04 & 0.05 & 0.06 & 0.08 & 0.10 & 0.12 & 0.38 & 0.00 & 0.38 & 0.36 & 0.04 & 0.36 \\
\hline 7,000 & 0.27 & 0.00 & 0.27 & 0.06 & 0.08 & 0.10 & 0.08 & 0.06 & 0.10 & 0.38 & 0.00 & 0.38 & 0.36 & 0.08 & 0.37 \\
\hline 10,000 & 0.27 & 0.00 & 0.27 & 0.08 & 0.15 & 0.17 & 0.08 & 0.06 & 0.10 & 0.38 & 0.00 & 0.38 & 0.35 & 0.13 & 0.37 \\
\hline 20,000 & 0.27 & 0.00 & 0.27 & 0.12 & 0.10 & 0.15 & 0.08 & 0.03 & 0.09 & 0.38 & 0.00 & 0.38 & 0.35 & 0.07 & 0.36 \\
\hline 50,000 & 0.27 & 0.00 & 0.27 & 0.12 & 0.16 & 0.20 & 0.09 & 0.04 & 0.10 & 0.38 & 0.00 & 0.38 & 0.36 & 0.07 & 0.37 \\
\hline 100,000 & 0.27 & 0.00 & 0.27 & 0.11 & 0.22 & 0.24 & 0.08 & 0.04 & 0.09 & 0.38 & 0.00 & 0.38 & 0.37 & 0.08 & 0.37 \\
\hline Interval (yr) & Grp 1 & Grp 2 & Grp 1+2 & Grp 1 & Grp 2 & Grp 1+2 & Grp 1 & Grp 2 & Grp 1+2 & Grp 1 & Grp 2 & Grp 1+2 & Grp 1 & Grp 2 & Grp 1+2 \\
\hline $0-100,000$ & 0.31 & 0.12 & 0.35 & 0.13 & 0.16 & 0.22 & 0.14 & 0.08 & 0.16 & 0.38 & 0.00 & 0.38 & 0.42 & 0.18 & 0.47 \\
\hline $150-600$ & 0.37 & 0.36 & 0.52 & 0.24 & 0.24 & 0.35 & 0.21 & 0.12 & 0.24 & 0.37 & 0.01 & 0.37 & 0.56 & 0.43 & 0.71 \\
\hline $600-2,000$ & 0.30 & 0.09 & 0.32 & 0.03 & 0.12 & 0.13 & 0.11 & 0.08 & 0.14 & 0.38 & 0.00 & 0.38 & 0.37 & 0.14 & 0.41 \\
\hline $2,000-100,000$ & 0.27 & 0.02 & 0.28 & 0.07 & 0.11 & 0.13 & 0.09 & 0.06 & 0.11 & 0.38 & 0.00 & 0.38 & 0.36 & 0.08 & 0.37 \\
\hline Maximum & 0.42 & 0.49 & 0.57 & 0.35 & 0.42 & 0.55 & 0.31 & 0.24 & 0.33 & 0.38 & 0.01 & 0.38 & 0.70 & 0.57 & 0.80 \\
\hline
\end{tabular}


Table 6.2-4. Comparison of Standard Deviations in Water and Gas Compositions Between Group 1 and Group 2 Simulations Predicted in Zones of High Liquid Saturation above the Drift Crown (HISAT - TOP, Fractures) (Continued)

\begin{tabular}{|c|c|c|c|c|c|c|c|c|c|c|c|c|}
\hline \multirow[b]{2}{*}{ Time (yr) } & \multicolumn{3}{|c|}{$\mathrm{SO}_{4} / \mathrm{Cl}$} & \multicolumn{3}{|c|}{$\mathrm{Na} / \mathrm{Cl}$} & \multicolumn{3}{|c|}{$\mathrm{Ca} / \mathrm{CO}_{3}$} & \multicolumn{3}{|c|}{$\mathrm{Ca} / \mathrm{Cl}$} \\
\hline & Grp 1 & Grp 2 & $\begin{array}{c}\text { Grp } \\
1+2\end{array}$ & Grp 1 & Grp 2 & $\begin{array}{l}\text { Grp } \\
1+2\end{array}$ & Grp 1 & Grp 2 & $\begin{array}{l}\text { Grp } \\
1+2\end{array}$ & Grp 1 & Grp 2 & $\begin{array}{l}\text { Grp } \\
1+2\end{array}$ \\
\hline 0 & 0.22 & 0.00 & 0.22 & 0.36 & 0.00 & 0.36 & 0.19 & 0.00 & 0.19 & 0.24 & 0.00 & 0.24 \\
\hline 53 & 0.22 & 0.00 & 0.22 & 0.27 & 0.01 & 0.27 & 0.33 & 0.08 & 0.34 & 0.31 & 0.12 & 0.33 \\
\hline 100 & 0.22 & 0.02 & 0.22 & 0.29 & 0.03 & 0.29 & 0.19 & 0.23 & 0.30 & 0.27 & 0.11 & 0.29 \\
\hline 150 & 0.22 & 0.01 & 0.22 & 0.30 & 0.09 & 0.32 & 0.27 & 0.49 & 0.56 & 0.24 & 0.15 & 0.28 \\
\hline 200 & 0.22 & 0.01 & 0.22 & 0.32 & 0.08 & 0.33 & 0.45 & 0.41 & 0.60 & 0.21 & 0.10 & 0.23 \\
\hline 300 & 0.22 & 0.00 & 0.22 & 0.28 & 0.07 & 0.29 & 0.68 & 0.36 & 0.77 & 0.19 & 0.06 & 0.20 \\
\hline 400 & 0.22 & 0.03 & 0.22 & 0.19 & 0.08 & 0.21 & 0.53 & 0.36 & 0.64 & 0.12 & 0.09 & 0.15 \\
\hline 500 & 0.22 & 0.03 & 0.22 & 0.17 & 0.07 & 0.19 & 0.51 & 0.41 & 0.65 & 0.11 & 0.07 & 0.13 \\
\hline 600 & 0.22 & 0.06 & 0.22 & 0.16 & 0.06 & 0.17 & 0.54 & 0.45 & 0.70 & 0.17 & 0.05 & 0.18 \\
\hline 800 & 0.22 & 0.13 & 0.25 & 0.18 & 0.04 & 0.18 & 0.27 & 0.41 & 0.49 & 0.14 & 0.22 & 0.26 \\
\hline 1.000 & 0.22 & 0.01 & 0.22 & 0.20 & 0.02 & 0.20 & 0.22 & 0.11 & 0.25 & 0.15 & 0.06 & 0.16 \\
\hline 1.200 & 0.22 & 0.01 & 0.22 & 0.21 & 0.01 & 0.21 & 0.23 & 0.10 & 0.25 & 0.15 & 0.04 & 0.15 \\
\hline 1.400 & 0.22 & 0.00 & 0.22 & 0.21 & 0.01 & 0.21 & 0.24 & 0.09 & 0.26 & 0.13 & 0.02 & 0.13 \\
\hline 1.600 & 0.22 & 0.00 & 0.22 & 0.22 & 0.01 & 0.22 & 0.23 & 0.08 & 0.24 & 0.13 & 0.03 & 0.14 \\
\hline 1.800 & 0.22 & 0.04 & 0.22 & 0.17 & 0.01 & 0.17 & 0.19 & 0.09 & 0.21 & 0.11 & 0.07 & 0.13 \\
\hline 2.000 & 0.22 & 0.03 & 0.22 & 0.23 & 0.02 & 0.24 & 0.25 & 0.04 & 0.25 & 0.15 & 0.05 & 0.16 \\
\hline 2.200 & 0.22 & 0.01 & 0.22 & 0.23 & 0.03 & 0.23 & 0.26 & 0.14 & 0.29 & 0.12 & 0.05 & 0.13 \\
\hline 2.400 & 0.22 & 0.00 & 0.22 & 0.23 & 0.04 & 0.23 & 0.25 & 0.16 & 0.30 & 0.12 & 0.08 & 0.15 \\
\hline 5.000 & 0.22 & 0.00 & 0.22 & 0.23 & 0.02 & 0.23 & 0.21 & 0.10 & 0.23 & 0.15 & 0.08 & 0.17 \\
\hline 7.000 & 0.22 & 0.00 & 0.22 & 0.24 & 0.02 & 0.24 & 0.19 & 0.05 & 0.20 & 0.18 & 0.07 & 0.19 \\
\hline 10.000 & 0.22 & 0.00 & 0.22 & 0.25 & 0.03 & 0.25 & 0.17 & 0.05 & 0.17 & 0.20 & 0.09 & 0.22 \\
\hline 20.000 & 0.22 & 0.00 & 0.22 & 0.26 & 0.02 & 0.26 & 0.15 & 0.03 & 0.15 & 0.22 & 0.05 & 0.23 \\
\hline 50.000 & 0.22 & 0.00 & 0.22 & 0.26 & 0.03 & 0.27 & 0.15 & 0.07 & 0.17 & 0.24 & 0.02 & 0.24 \\
\hline 100.000 & 0.22 & 0.00 & 0.22 & 0.26 & 0.04 & 0.27 & 0.15 & 0.08 & 0.17 & 0.24 & 0.01 & 0.24 \\
\hline
\end{tabular}


Table 6.2-4. Comparison of Standard Deviations in Water and Gas Compositions Between Group 1 and Group 2 Simulations Predicted in Zones of High Liquid Saturation above the Drift Crown (HISAT - TOP, Fractures) (Continued)

\begin{tabular}{|c|c|c|c|c|c|c|c|c|c|c|c|c|}
\hline \multirow[b]{2}{*}{ Interval (yr) } & \multicolumn{3}{|c|}{$\mathrm{SO}_{4} / \mathrm{Cl}$} & \multicolumn{3}{|c|}{$\mathrm{Na} / \mathrm{Cl}$} & \multicolumn{3}{|c|}{$\mathrm{Ca} / \mathrm{CO}_{3}$} & \multicolumn{3}{|c|}{$\mathrm{Ca} / \mathrm{Cl}$} \\
\hline & Grp 1 & Grp 2 & $\begin{array}{c}\text { Grp } \\
1+2\end{array}$ & Grp 1 & Grp 2 & $\begin{array}{l}\text { Grp } \\
1+2\end{array}$ & Grp 1 & Grp 2 & $\begin{array}{l}\text { Grp } \\
1+2\end{array}$ & Grp 1 & Grp 2 & $\begin{array}{l}\text { Grp } \\
1+2\end{array}$ \\
\hline $0-100,000$ & 0.22 & 0.02 & 0.22 & 0.24 & 0.03 & 0.24 & 0.28 & 0.18 & 0.35 & 0.18 & 0.07 & 0.20 \\
\hline $150-600$ & 0.22 & 0.02 & 0.22 & 0.24 & 0.08 & 0.25 & 0.49 & 0.41 & 0.65 & 0.17 & 0.09 & 0.19 \\
\hline $600-2,000$ & 0.22 & 0.03 & 0.23 & 0.20 & 0.02 & 0.20 & 0.27 & 0.17 & 0.33 & 0.14 & 0.07 & 0.16 \\
\hline $2,000-100,000$ & 0.22 & 0.01 & 0.22 & 0.24 & 0.03 & 0.25 & 0.20 & 0.08 & 0.21 & 0.18 & 0.05 & 0.19 \\
\hline Maximum & 0.22 & 0.13 & 0.25 & 0.36 & 0.09 & 0.36 & 0.68 & 0.49 & 0.77 & 0.31 & 0.22 & 0.33 \\
\hline
\end{tabular}

Input DTNS: LB0302DSCPTHCS.002 [DIRS 161976]; LB0307DSTTHCR2.002 [DIRS 165541].

Output DTN: LB0311ABSTHCR2.001 [DIRS 166714].

NOTES: Standard deviation values are shown for two sets of simulation results (Grp 1 and Grp 2) and their combined effect (Grp 1+2):

(1) Runs using input water compositions W0, W4, W5, W6, and W7 (Grp 1 column).

(2) Runs using input water composition (W0) and different conceptualization and ranges of input data (Grp 2 column) (stepped up infiltration rate 6-16-25 mm/yr, constant $6 \mathrm{~mm} / \mathrm{year}$, constant $25 \mathrm{~mm} / \mathrm{yr}$, with and without vapor pressure lowering, and with 6-times difference in $\mathrm{CO}_{2}$ diffusion coefficient (see BSC 2004 [DIRS 169856] Section 6.5.3)

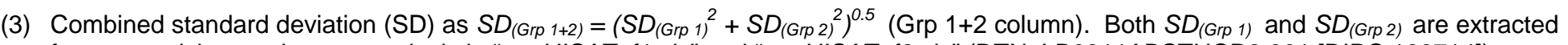
from spreadsheet stdev, respectively in "top-HISAT_f1.xls" and "top-HISAT_f2.xIs" (DTN: LB0311ABSTHCR2.001 [DIRS 166714]). $S D_{(G r p ~ 1+2)}$ is not a part of output in the DTN and calculated here for comparison purposes.

Standard deviation values and units are as follows:

(1) For $\mathrm{pH}$, standard deviation in $( \pm) \mathrm{pH}$ units.

(2) For other data, standard deviation of logarithmic values of total molality for aqueous species, volume fraction for $\mathrm{CO}_{2}$, and unitless mola ratios, thus representing a $( \pm$ ) change in $\log 10$ values of concentrations and concentration ratios around the mean of $\log 10$ values (e.g., 0.5 corresponds to total spread of one order of magnitude).

The bottom of the table shows averages of individual standard deviations over the time intervals shown. See Appendix B for details. 
Table 6.2-5. Comparison of Standard Deviations in Water and Gas Compositions Between Group 1 and Group 2 Simulations Predicted at the Boiling/Wetting Front in Fractures above the Drift Crown (FRONT - TOP, Fractures)

\begin{tabular}{|c|c|c|c|c|c|c|c|c|c|c|c|c|c|c|c|}
\hline \multirow[b]{2}{*}{ Time (yr) } & \multicolumn{3}{|c|}{$\mathrm{pH}$} & \multicolumn{3}{|c|}{ Calcium } & \multicolumn{3}{|c|}{ Magnesium } & \multicolumn{3}{|c|}{ Sodium } & \multicolumn{3}{|c|}{ Chloride } \\
\hline & Grp 1 & Grp 2 & $\begin{array}{l}\text { Grp } \\
1+2\end{array}$ & Grp 1 & Grp 2 & $\begin{array}{l}\text { Grp } \\
1+2\end{array}$ & Grp 1 & Grp 2 & $\begin{array}{l}\text { Grp } \\
1+2\end{array}$ & Grp 1 & Grp 2 & $\begin{array}{l}\text { Grp } \\
1+2\end{array}$ & Grp 1 & Grp 2 & $\begin{array}{l}\text { Grp } \\
1+2 \\
\end{array}$ \\
\hline 0 & 0.11 & 0.00 & 0.11 & 0.11 & 0.00 & 0.11 & 0.52 & 0.00 & 0.52 & 0.18 & 0.00 & 0.18 & 0.29 & 0.00 & 0.29 \\
\hline 100 & 0.06 & 0.14 & 0.15 & 0.22 & 0.26 & 0.34 & 0.25 & 0.36 & 0.44 & 0.24 & 0.34 & 0.42 & 0.37 & 0.36 & 0.52 \\
\hline 150 & 0.08 & 0.26 & 0.27 & 0.26 & 0.43 & 0.50 & 0.34 & 0.90 & 0.96 & 0.33 & 0.49 & 0.59 & 0.48 & 0.54 & 0.73 \\
\hline 200 & 0.06 & 0.20 & 0.21 & 0.27 & 0.22 & 0.35 & 0.26 & 0.50 & 0.56 & 0.12 & 0.25 & 0.27 & 0.37 & 0.28 & 0.46 \\
\hline 400 & 0.14 & 0.14 & 0.19 & 0.44 & 0.40 & 0.60 & 0.49 & 0.49 & 0.70 & 0.32 & 0.39 & 0.51 & 0.46 & 0.42 & 0.62 \\
\hline 500 & 0.17 & 0.16 & 0.24 & 0.44 & 0.46 & 0.63 & 0.54 & 0.53 & 0.76 & 0.35 & 0.44 & 0.56 & 0.45 & 0.48 & 0.66 \\
\hline 600 & 0.20 & 0.19 & 0.27 & 0.48 & 0.50 & 0.70 & 0.55 & 0.59 & 0.81 & 0.35 & 0.45 & 0.57 & 0.45 & 0.51 & 0.68 \\
\hline 800 & 0.10 & 0.16 & 0.19 & 0.20 & 0.34 & 0.40 & 0.28 & 0.33 & 0.43 & 0.12 & 0.17 & 0.21 & 0.30 & 0.21 & 0.36 \\
\hline 1,000 & 0.08 & 0.08 & 0.12 & 0.16 & 0.08 & 0.18 & 0.22 & 0.12 & 0.26 & 0.10 & 0.06 & 0.11 & 0.29 & 0.07 & 0.30 \\
\hline 1,200 & 0.09 & 0.08 & 0.12 & 0.15 & 0.05 & 0.16 & 0.21 & 0.09 & 0.23 & 0.08 & 0.03 & 0.09 & 0.29 & 0.03 & 0.29 \\
\hline 1,400 & 0.08 & 0.06 & 0.10 & 0.17 & 0.03 & 0.17 & 0.19 & 0.06 & 0.20 & 0.08 & 0.01 & 0.08 & 0.29 & 0.02 & 0.29 \\
\hline 1,800 & 0.17 & 0.04 & 0.17 & 0.56 & 0.07 & 0.57 & 0.44 & 0.07 & 0.44 & 0.53 & 0.01 & 0.53 & 0.62 & 0.01 & 0.62 \\
\hline 2,000 & 0.24 & 0.28 & 0.37 & 0.63 & 0.80 & 1.02 & 0.49 & 0.68 & 0.84 & 0.43 & 0.51 & 0.67 & 0.48 & 0.61 & 0.78 \\
\hline 2,200 & 0.06 & 0.08 & 0.10 & 0.13 & 0.09 & 0.16 & 0.15 & 0.14 & 0.20 & 0.06 & 0.04 & 0.07 & 0.23 & 0.06 & 0.24 \\
\hline 2,400 & 0.06 & 0.13 & 0.14 & 0.15 & 0.34 & 0.37 & 0.17 & 0.12 & 0.20 & 0.07 & 0.27 & 0.28 & 0.28 & 0.32 & 0.42 \\
\hline 5,000 & 0.06 & 0.06 & 0.08 & 0.15 & 0.08 & 0.17 & 0.15 & 0.07 & 0.17 & 0.07 & 0.02 & 0.07 & 0.29 & 0.01 & 0.29 \\
\hline 7,000 & 0.04 & 0.10 & 0.11 & 0.14 & 0.07 & 0.16 & 0.15 & 0.10 & 0.18 & 0.07 & 0.02 & 0.07 & 0.30 & 0.00 & 0.30 \\
\hline 10,000 & 0.03 & 0.11 & 0.11 & 0.14 & 0.09 & 0.16 & 0.14 & 0.13 & 0.19 & 0.06 & 0.03 & 0.07 & 0.30 & 0.00 & 0.30 \\
\hline 20,000 & 0.04 & 0.24 & 0.24 & 0.14 & 0.05 & 0.15 & 0.13 & 0.11 & 0.17 & 0.06 & 0.02 & 0.06 & 0.30 & 0.00 & 0.30 \\
\hline 50,000 & 0.04 & 0.21 & 0.21 & 0.14 & 0.02 & 0.15 & 0.09 & 0.12 & 0.15 & 0.05 & 0.03 & 0.06 & 0.29 & 0.00 & 0.29 \\
\hline 100,000 & 0.02 & 0.21 & 0.21 & 0.13 & 0.01 & 0.13 & 0.08 & 0.18 & 0.20 & 0.05 & 0.04 & 0.06 & 0.29 & 0.00 & 0.29 \\
\hline Interval (yr) & Grp 1 & Grp 2 & $\begin{array}{l}\text { Grp } \\
1+2\end{array}$ & Grp 1 & Grp 2 & $\begin{array}{l}\text { Grp } \\
1+2\end{array}$ & Grp 1 & Grp 2 & $\begin{array}{l}\text { Grp } \\
1+2\end{array}$ & Grp 1 & Grp 2 & $\begin{array}{l}\text { Grp } \\
1+2 \\
\end{array}$ & Grp 1 & Grp 2 & $\begin{array}{l}\text { Grp } \\
1+2\end{array}$ \\
\hline $0-100,000$ & 0.10 & 0.14 & 0.18 & 0.27 & 0.23 & 0.37 & 0.30 & 0.28 & 0.42 & 0.21 & 0.21 & 0.31 & 0.38 & 0.23 & 0.47 \\
\hline $150-600$ & 0.12 & 0.18 & 0.22 & 0.39 & 0.39 & 0.56 & 0.42 & 0.56 & 0.72 & 0.29 & 0.39 & 0.48 & 0.44 & 0.43 & 0.62 \\
\hline $600-2,000$ & 0.13 & 0.13 & 0.19 & 0.31 & 0.28 & 0.45 & 0.32 & 0.25 & 0.43 & 0.22 & 0.19 & 0.32 & 0.38 & 0.23 & 0.47 \\
\hline
\end{tabular}


Table 6.2-5. Comparison of Standard Deviations in Water and Gas Compositions Between Group 1 and Group 2 Simulations Predicted at the Boiling/Wetting Front in Fractures above the Drift Crown (FRONT-TOP, Fractures) (Continued)

\begin{tabular}{|c|c|c|c|c|c|c|c|c|c|c|c|c|c|c|c|}
\hline \multirow[b]{2}{*}{ Time (yr) } & \multicolumn{3}{|c|}{ Silica } & \multicolumn{3}{|c|}{ Carbonate } & \multicolumn{3}{|c|}{ Sulfate } & \multicolumn{3}{|c|}{ Potassium } & \multicolumn{3}{|c|}{ Fluoride } \\
\hline & Grp 1 & Grp 2 & $\begin{array}{l}\text { Grp } \\
1+2\end{array}$ & Grp 1 & Grp 2 & $\begin{array}{l}\text { Grp } \\
1+2\end{array}$ & Grp 1 & Grp 2 & $\begin{array}{l}\text { Grp } \\
1+2 \\
\end{array}$ & Grp 1 & Grp 2 & $\begin{array}{l}\text { Grp } \\
1+2\end{array}$ & Grp 1 & Grp 2 & $\begin{array}{l}\text { Grp } \\
1+2 \\
\end{array}$ \\
\hline 0 & 0.08 & 0.00 & 0.08 & 0.14 & 0.00 & 0.14 & 0.37 & 0.00 & 0.37 & 0.06 & 0.00 & 0.06 & 0.30 & 0.00 & 0.30 \\
\hline 100 & 0.26 & 0.32 & 0.42 & 0.25 & 0.18 & 0.31 & 0.45 & 0.36 & 0.57 & 0.24 & 0.35 & 0.42 & 0.23 & 0.20 & 0.30 \\
\hline 150 & 0.27 & 0.27 & 0.38 & 0.26 & 0.24 & 0.35 & 0.51 & 0.51 & 0.72 & 0.39 & 0.50 & 0.63 & 0.26 & 0.15 & 0.30 \\
\hline 200 & 0.10 & 0.15 & 0.18 & 0.25 & 0.21 & 0.33 & 0.42 & 0.28 & 0.50 & 0.12 & 0.25 & 0.28 & 0.11 & 0.11 & 0.16 \\
\hline 400 & 0.20 & 0.27 & 0.34 & 0.23 & 0.12 & 0.26 & 0.49 & 0.40 & 0.63 & 0.33 & 0.40 & 0.52 & 0.15 & 0.06 & 0.16 \\
\hline 500 & 0.21 & 0.31 & 0.37 & 0.12 & 0.09 & 0.16 & 0.49 & 0.44 & 0.66 & 0.35 & 0.45 & 0.57 & 0.15 & 0.06 & 0.17 \\
\hline 600 & 0.20 & 0.31 & 0.37 & 0.14 & 0.11 & 0.18 & 0.48 & 0.46 & 0.67 & 0.35 & 0.46 & 0.58 & 0.16 & 0.05 & 0.17 \\
\hline 800 & 0.04 & 0.11 & 0.12 & 0.07 & 0.12 & 0.14 & 0.37 & 0.27 & 0.46 & 0.12 & 0.18 & 0.22 & 0.07 & 0.10 & 0.12 \\
\hline 1,000 & 0.02 & 0.05 & 0.06 & 0.06 & 0.11 & 0.12 & 0.37 & 0.08 & 0.38 & 0.10 & 0.06 & 0.12 & 0.05 & 0.05 & 0.07 \\
\hline 1,200 & 0.02 & 0.04 & 0.05 & 0.08 & 0.09 & 0.12 & 0.37 & 0.04 & 0.37 & 0.08 & 0.03 & 0.09 & 0.04 & 0.05 & 0.06 \\
\hline 1,400 & 0.02 & 0.04 & 0.04 & 0.07 & 0.08 & 0.11 & 0.37 & 0.02 & 0.37 & 0.08 & 0.02 & 0.08 & 0.05 & 0.04 & 0.06 \\
\hline 1,600 & 0.01 & 0.04 & 0.04 & 0.07 & 0.08 & 0.11 & 0.37 & 0.28 & 0.46 & 0.08 & 0.27 & 0.28 & 0.06 & 0.05 & 0.07 \\
\hline 2,000 & 0.07 & 0.29 & 0.30 & 0.19 & 0.26 & 0.32 & 0.58 & 0.65 & 0.87 & 0.45 & 0.50 & 0.67 & 0.16 & 0.22 & 0.27 \\
\hline 2,200 & 0.02 & 0.07 & 0.08 & 0.06 & 0.07 & 0.09 & 0.29 & 0.06 & 0.29 & 0.06 & 0.04 & 0.07 & 0.05 & 0.05 & 0.07 \\
\hline 2,400 & 0.02 & 0.06 & 0.06 & 0.06 & 0.08 & 0.10 & 0.36 & 0.28 & 0.45 & 0.07 & 0.26 & 0.27 & 0.06 & 0.06 & 0.08 \\
\hline 5,000 & 0.01 & 0.02 & 0.02 & 0.06 & 0.04 & 0.07 & 0.37 & 0.00 & 0.37 & 0.07 & 0.02 & 0.07 & 0.06 & 0.04 & 0.07 \\
\hline 7,000 & 0.00 & 0.02 & 0.02 & 0.07 & 0.08 & 0.11 & 0.38 & 0.00 & 0.38 & 0.07 & 0.02 & 0.07 & 0.06 & 0.03 & 0.07 \\
\hline 10,000 & 0.01 & 0.02 & 0.02 & 0.07 & 0.13 & 0.15 & 0.38 & 0.00 & 0.38 & 0.06 & 0.01 & 0.07 & 0.05 & 0.04 & 0.07 \\
\hline 20,000 & 0.01 & 0.02 & 0.02 & 0.09 & 0.07 & 0.11 & 0.38 & 0.00 & 0.38 & 0.06 & 0.02 & 0.06 & 0.05 & 0.03 & 0.06 \\
\hline 50,000 & 0.02 & 0.03 & 0.04 & 0.10 & 0.07 & 0.12 & 0.37 & 0.00 & 0.37 & 0.05 & 0.05 & 0.07 & 0.06 & 0.01 & 0.06 \\
\hline 100,000 & 0.02 & 0.05 & 0.06 & 0.10 & 0.08 & 0.13 & 0.37 & 0.00 & 0.37 & 0.05 & 0.05 & 0.07 & 0.05 & 0.01 & 0.05 \\
\hline Interval (yr) & Grp 1 & Grp 2 & $\begin{array}{l}\text { Grp } \\
1+2\end{array}$ & Grp 1 & Grp 2 & $\begin{array}{l}\text { Grp } \\
1+2 \\
\end{array}$ & Grp 1 & Grp 2 & $\begin{array}{l}\text { Grp } \\
1+2 \\
\end{array}$ & Grp 1 & Grp 2 & $\begin{array}{l}\text { Grp } \\
1+2 \\
\end{array}$ & Grp 1 & Grp 2 & $\begin{array}{l}\text { Grp } \\
1+2 \\
\end{array}$ \\
\hline $0-100,000$ & 0.12 & 0.15 & 0.19 & 0.15 & 0.11 & 0.19 & 0.44 & 0.22 & 0.52 & 0.21 & 0.21 & 0.31 & 0.14 & 0.09 & 0.17 \\
\hline $150-600$ & 0.19 & 0.26 & 0.32 & 0.22 & 0.15 & 0.27 & 0.48 & 0.41 & 0.63 & 0.30 & 0.40 & 0.50 & 0.17 & 0.08 & 0.19 \\
\hline $600-2,000$ & 0.06 & 0.11 & 0.14 & 0.10 & 0.11 & 0.16 & 0.45 & 0.23 & 0.53 & 0.23 & 0.19 & 0.33 & 0.09 & 0.08 & 0.12 \\
\hline $2,000-100,000$ & 0.02 & 0.06 & 0.07 & 0.09 & 0.10 & 0.13 & 0.39 & 0.11 & 0.43 & 0.10 & 0.11 & 0.16 & 0.07 & 0.05 & 0.09 \\
\hline
\end{tabular}


Table 6.2-5. Comparison of Standard Deviations in Water and Gas Compositions Between Group 1 and Group 2 Simulations Predicted at the Boiling/Wetting Front in Fractures above the Drift Crown (FRONT-TOP, Fractures) (Continued)

\begin{tabular}{|c|c|c|c|c|c|c|c|c|c|c|c|c|c|c|c|}
\hline \multirow[b]{2}{*}{ Time (yr) } & \multicolumn{3}{|c|}{ Nitrate } & \multicolumn{3}{|c|}{$\mathrm{CO}_{2}$ (gas) } & \multicolumn{3}{|c|}{$\mathrm{Ca} / \mathrm{Na}$} & \multicolumn{3}{|c|}{$\mathrm{NO}_{3} / \mathrm{Cl}$} & \multicolumn{3}{|c|}{$\mathrm{HCO}_{3} / \mathrm{Cl}$} \\
\hline & Grp 1 & Grp 2 & $\begin{array}{l}\text { Grp } \\
1+2\end{array}$ & Grp 1 & Grp 2 & $\begin{array}{l}\text { Grp } \\
1+2 \\
\end{array}$ & Grp 1 & Grp 2 & $\begin{array}{l}\text { Grp } \\
1+2 \\
\end{array}$ & Grp 1 & Grp 2 & $\begin{array}{l}\text { Grp } \\
1+2 \\
\end{array}$ & Grp 1 & Grp 2 & $\begin{array}{l}\text { Grp } \\
1+2 \\
\end{array}$ \\
\hline 0 & 0.27 & 0.00 & 0.27 & 0.23 & 0.00 & 0.23 & 0.25 & 0.00 & 0.25 & 0.38 & 0.00 & 0.38 & 0.40 & 0.00 & 0.40 \\
\hline 100 & 0.35 & 0.36 & 0.50 & 0.30 & 0.28 & 0.41 & 0.26 & 0.14 & 0.30 & 0.38 & 0.00 & 0.38 & 0.58 & 0.44 & 0.73 \\
\hline 150 & 0.57 & 0.54 & 0.79 & 0.32 & 0.46 & 0.56 & 0.38 & 0.17 & 0.42 & 0.39 & 0.00 & 0.39 & 0.64 & 0.61 & 0.88 \\
\hline 200 & 0.33 & 0.28 & 0.43 & 0.31 & 0.41 & 0.51 & 0.26 & 0.10 & 0.28 & 0.37 & 0.01 & 0.37 & 0.59 & 0.35 & 0.69 \\
\hline 400 & 0.46 & 0.43 & 0.62 & 0.25 & 0.16 & 0.29 & 0.24 & 0.14 & 0.28 & 0.37 & 0.01 & 0.37 & 0.63 & 0.51 & 0.81 \\
\hline 500 & 0.46 & 0.48 & 0.67 & 0.12 & 0.11 & 0.16 & 0.22 & 0.09 & 0.24 & 0.37 & 0.01 & 0.37 & 0.55 & 0.56 & 0.79 \\
\hline 600 & 0.46 & 0.51 & 0.69 & 0.09 & 0.12 & 0.15 & 0.28 & 0.10 & 0.30 & 0.38 & 0.01 & 0.38 & 0.54 & 0.60 & 0.81 \\
\hline 800 & 0.28 & 0.21 & 0.35 & 0.07 & 0.15 & 0.17 & 0.12 & 0.24 & 0.27 & 0.38 & 0.00 & 0.38 & 0.35 & 0.29 & 0.46 \\
\hline 1,000 & 0.28 & 0.08 & 0.29 & 0.03 & 0.18 & 0.18 & 0.08 & 0.06 & 0.10 & 0.38 & 0.00 & 0.38 & 0.35 & 0.13 & 0.37 \\
\hline 1,200 & 0.27 & 0.04 & 0.28 & 0.01 & 0.16 & 0.16 & 0.07 & 0.04 & 0.08 & 0.38 & 0.00 & 0.38 & 0.37 & 0.10 & 0.38 \\
\hline 1,400 & 0.27 & 0.02 & 0.27 & 0.01 & 0.13 & 0.13 & 0.09 & 0.03 & 0.10 & 0.38 & 0.00 & 0.38 & 0.36 & 0.08 & 0.37 \\
\hline 1,600 & 0.27 & 0.38 & 0.47 & 0.01 & 0.10 & 0.10 & 0.08 & 0.07 & 0.11 & 0.38 & 0.03 & 0.38 & 0.35 & 0.42 & 0.55 \\
\hline 2,000 & 0.63 & 0.61 & 0.88 & 0.01 & 0.18 & 0.18 & 0.54 & 0.52 & 0.75 & 0.36 & 0.03 & 0.36 & 0.58 & 0.80 & 0.99 \\
\hline 2,200 & 0.33 & 0.06 & 0.33 & 0.01 & 0.12 & 0.12 & 0.07 & 0.06 & 0.09 & 0.38 & 0.00 & 0.38 & 0.29 & 0.09 & 0.31 \\
\hline 2,400 & 0.28 & 0.35 & 0.45 & 0.01 & 0.10 & 0.10 & 0.08 & 0.12 & 0.14 & 0.38 & 0.03 & 0.38 & 0.33 & 0.39 & 0.51 \\
\hline 5,000 & 0.27 & 0.00 & 0.27 & 0.04 & 0.05 & 0.06 & 0.08 & 0.10 & 0.13 & 0.38 & 0.00 & 0.38 & 0.35 & 0.04 & 0.35 \\
\hline 7,000 & 0.27 & 0.00 & 0.27 & 0.06 & 0.08 & 0.10 & 0.08 & 0.07 & 0.10 & 0.38 & 0.00 & 0.38 & 0.35 & 0.08 & 0.36 \\
\hline 10,000 & 0.27 & 0.00 & 0.27 & 0.08 & 0.15 & 0.17 & 0.07 & 0.07 & 0.10 & 0.38 & 0.00 & 0.38 & 0.35 & 0.13 & 0.37 \\
\hline 20,000 & 0.27 & 0.00 & 0.27 & 0.12 & 0.10 & 0.16 & 0.08 & 0.04 & 0.09 & 0.38 & 0.00 & 0.38 & 0.35 & 0.07 & 0.36 \\
\hline 50,000 & 0.27 & 0.00 & 0.27 & 0.12 & 0.16 & 0.19 & 0.09 & 0.04 & 0.10 & 0.38 & 0.00 & 0.38 & 0.37 & 0.07 & 0.37 \\
\hline 100,000 & 0.27 & 0.00 & 0.27 & 0.12 & 0.22 & 0.25 & 0.08 & 0.04 & 0.09 & 0.38 & 0.00 & 0.38 & 0.37 & 0.08 & 0.38 \\
\hline Interval (yr) & Grp 1 & Grp 2 & $\begin{array}{l}\text { Grp } \\
1+2\end{array}$ & Grp 1 & Grp 2 & $\begin{array}{l}\text { Grp } \\
1+2\end{array}$ & Grp 1 & Grp 2 & $\begin{array}{l}\text { Grp } \\
1+2 \\
\end{array}$ & Grp 1 & Grp 2 & $\begin{array}{l}\text { Grp } \\
1+2\end{array}$ & Grp 1 & Grp 2 & $\begin{array}{l}\text { Grp } \\
1+2\end{array}$ \\
\hline $0-100,000$ & 0.39 & 0.23 & 0.48 & 0.12 & 0.16 & 0.22 & 0.23 & 0.11 & 0.26 & 0.38 & 0.01 & 0.38 & 0.47 & 0.30 & 0.58 \\
\hline $150-600$ & 0.45 & 0.43 & 0.63 & 0.24 & 0.24 & 0.34 & 0.29 & 0.12 & 0.32 & 0.38 & 0.01 & 0.38 & 0.61 & 0.51 & 0.80 \\
\hline $600-2,000$ & 0.42 & 0.23 & 0.51 & 0.03 & 0.14 & 0.14 & 0.20 & 0.14 & 0.25 & 0.37 & 0.01 & 0.37 & 0.45 & 0.31 & 0.58 \\
\hline $2,000-100,000$ & 0.32 & 0.12 & 0.37 & 0.06 & 0.13 & 0.15 & 0.13 & 0.11 & 0.18 & 0.38 & 0.01 & 0.38 & 0.37 & 0.19 & 0.44 \\
\hline
\end{tabular}


Table 6.2-5. Comparison of Standard Deviations in Water and Gas Compositions Between Group 1 and Group 2 Simulations Predicted at the Boiling/Wetting Front in Fractures above the Drift Crown (FRONT-TOP, Fractures) (Continued)

\begin{tabular}{|c|c|c|c|c|c|c|c|c|c|c|c|c|}
\hline \multirow[b]{2}{*}{ Time (yr) } & \multicolumn{3}{|c|}{$\mathrm{SO}_{4} / \mathrm{Cl}$} & \multicolumn{3}{|c|}{$\mathrm{Na} / \mathrm{Cl}$} & \multicolumn{3}{|c|}{$\mathrm{Ca} / \mathrm{CO}_{3}$} & \multicolumn{3}{|c|}{$\mathrm{Ca} / \mathrm{Cl}$} \\
\hline & Grp 1 & Grp 2 & $\begin{array}{l}\text { Grp } \\
1+2\end{array}$ & Grp 1 & Grp 2 & $\begin{array}{l}\text { Grp } \\
1+2\end{array}$ & Grp 1 & Grp 2 & $\begin{array}{c}\text { Grp } \\
1+2\end{array}$ & Grp 1 & Grp 2 & $\begin{array}{l}\text { Grp } \\
1+2\end{array}$ \\
\hline 等 & 0.22 & 0.00 & 0.22 & 0.36 & 0.00 & 0.36 & 0.19 & 0.00 & 0.19 & 0.24 & 0.00 & 0.24 \\
\hline 53 & 0.22 & 0.00 & 0.22 & 0.27 & 0.01 & 0.27 & 1.28 & 0.50 & 1.37 & 1.19 & 0.29 & 1.22 \\
\hline 100 & 0.22 & 0.01 & 0.22 & 0.30 & 0.04 & 0.30 & 0.46 & 0.38 & 0.59 & 0.21 & 0.14 & 0.25 \\
\hline 150 & 0.21 & 0.04 & 0.21 & 0.31 & 0.11 & 0.32 & 0.51 & 0.54 & 0.74 & 0.36 & 0.15 & 0.39 \\
\hline 200 & 0.22 & 0.01 & 0.22 & 0.32 & 0.07 & 0.32 & 0.51 & 0.33 & 0.61 & 0.15 & 0.08 & 0.17 \\
\hline 400 & 0.22 & 0.06 & 0.23 & 0.18 & 0.08 & 0.20 & 0.63 & 0.50 & 0.80 & 0.15 & 0.08 & 0.17 \\
\hline 500 & 0.22 & 0.10 & 0.24 & 0.14 & 0.07 & 0.16 & 0.54 & 0.54 & 0.76 & 0.16 & 0.06 & 0.17 \\
\hline 600 & 0.22 & 0.11 & 0.24 & 0.14 & 0.07 & 0.16 & 0.60 & 0.60 & 0.85 & 0.21 & 0.07 & 0.22 \\
\hline 800 & 0.22 & 0.13 & 0.25 & 0.18 & 0.04 & 0.19 & 0.26 & 0.43 & 0.51 & 0.14 & 0.22 & 0.26 \\
\hline 1,000 & 0.22 & 0.01 & 0.22 & 0.20 & 0.02 & 0.20 & 0.22 & 0.11 & 0.25 & 0.14 & 0.06 & 0.16 \\
\hline 1,200 & 0.22 & 0.01 & 0.22 & 0.21 & 0.01 & 0.21 & 0.23 & 0.10 & 0.25 & 0.15 & 0.04 & 0.15 \\
\hline 1,400 & 0.22 & 0.00 & 0.22 & 0.21 & 0.01 & 0.21 & 0.24 & 0.09 & 0.26 & 0.13 & 0.02 & 0.13 \\
\hline 1,800 & 0.34 & 0.04 & 0.34 & 0.16 & 0.01 & 0.16 & 0.69 & 0.09 & 0.70 & 0.31 & 0.07 & 0.31 \\
\hline 2,000 & 0.39 & 0.20 & 0.44 & 0.12 & 0.14 & 0.19 & 0.81 & 1.05 & 1.32 & 0.50 & 0.42 & 0.65 \\
\hline 2,200 & 0.22 & 0.01 & 0.22 & 0.17 & 0.03 & 0.17 & 0.19 & 0.12 & 0.23 & 0.11 & 0.04 & 0.12 \\
\hline 2,400 & 0.22 & 0.04 & 0.22 & 0.21 & 0.06 & 0.21 & 0.20 & 0.41 & 0.45 & 0.13 & 0.07 & 0.15 \\
\hline 5,000 & 0.22 & 0.00 & 0.22 & 0.22 & 0.02 & 0.23 & 0.20 & 0.11 & 0.23 & 0.15 & 0.08 & 0.17 \\
\hline 7,000 & 0.22 & 0.00 & 0.22 & 0.24 & 0.02 & 0.24 & 0.19 & 0.06 & 0.20 & 0.17 & 0.07 & 0.19 \\
\hline 10,000 & 0.22 & 0.00 & 0.22 & 0.25 & 0.03 & 0.25 & 0.16 & 0.06 & 0.17 & 0.20 & 0.09 & 0.22 \\
\hline 20,000 & 0.22 & 0.00 & 0.22 & 0.26 & 0.02 & 0.26 & 0.15 & 0.02 & 0.15 & 0.22 & 0.05 & 0.23 \\
\hline 50,000 & 0.22 & 0.00 & 0.22 & 0.27 & 0.03 & 0.27 & 0.16 & 0.06 & 0.17 & 0.23 & 0.02 & 0.23 \\
\hline 100,000 & 0.22 & 0.00 & 0.22 & 0.27 & 0.04 & 0.27 & 0.16 & 0.08 & 0.18 & 0.23 & 0.01 & 0.23 \\
\hline
\end{tabular}


Table 6.2-5. Comparison of Standard Deviations in Water and Gas Compositions Between Group 1 and Group 2 Simulations Predicted at the Boiling/Wetting Front in Fractures above the Drift Crown (FRONT-TOP, Fractures) (Continued)

\begin{tabular}{|c|c|c|c|c|c|c|c|c|c|c|c|c|}
\hline Interval (yr) & Grp 1 & Grp 2 & $\begin{array}{l}\text { Grp } \\
1+2\end{array}$ & Grp 1 & Grp 2 & $\begin{array}{l}\text { Grp } \\
1+2 \\
\end{array}$ & Grp 1 & Grp 2 & $\begin{array}{l}\text { Grp } \\
1+2\end{array}$ & Grp 1 & Grp 2 & $\begin{array}{l}\text { Grp } \\
1+2 \\
\end{array}$ \\
\hline $0-100,000$ & 0.23 & 0.04 & 0.24 & 0.23 & 0.04 & 0.23 & 0.40 & 0.29 & 0.51 & 0.24 & 0.09 & 0.27 \\
\hline $150-600$ & 0.22 & 0.05 & 0.23 & 0.23 & 0.08 & 0.24 & 0.59 & 0.49 & 0.77 & 0.21 & 0.08 & 0.22 \\
\hline $600-2,000$ & 0.26 & 0.07 & 0.27 & 0.18 & 0.05 & 0.19 & 0.41 & 0.36 & 0.58 & 0.21 & 0.11 & 0.25 \\
\hline $2,000-100,000$ & 0.24 & 0.03 & 0.24 & 0.22 & 0.04 & 0.23 & 0.25 & 0.22 & 0.34 & 0.22 & 0.09 & 0.24 \\
\hline Maximum & 0.39 & 0.20 & 0.44 & 0.36 & 0.14 & 0.36 & 1.28 & 1.05 & 1.37 & 1.19 & 0.42 & 1.22 \\
\hline
\end{tabular}

Input DTNs: LB0302DSCPTHCS.002 [DIRS 161976]; LB0307DSTTHCR2.002 [DIRS 165541].

Output DTN: LB0311ABSTHCR2.001 [DIRS 166714].

NOTES: Standard deviation values are shown for two sets of simulation results (Grp 1 and Grp 2) and their combined effect (Grp 1+2):

(1) Runs using input water compositions W0, W4, W5, W6, and W7 (Grp 1 column).

(2) Runs using input water composition (W0) and different conceptualization and ranges of input data (Grp 2 column) (stepped up infiltration rate 6-16-25 mm/yr, constant $6 \mathrm{~mm} / \mathrm{year}$, constant $25 \mathrm{~mm} / \mathrm{yr}$, with and without vapor pressure lowering, and with 6-times difference in $\mathrm{CO}_{2}$ diffusion coefficient; see BSC 2004 [DIRS 169856] Section 6.5.3).

(3) Combined standard deviation (SD) as $S D_{(G r p ~ 1+2)}=\left(S D_{(G r p ~ 1)}{ }^{2}+S D_{(G r p ~ 2)}\right)^{0.5}$ (Grp 1+2 column). Both $S D_{(G r p ~ 1)}$ and $S D_{(G r p ~ 2)}$ are extracted from spreadsheet stdev, respectively in "top-front_f1.xls" and "top-front_f2.xIs" (DTN: LB0311ABSTHCR2.001 [DIRS

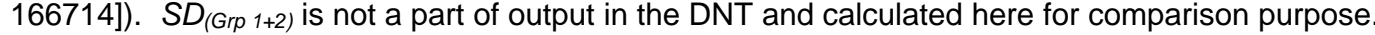

Standard deviation values and units are given as follow:

(1) For $\mathrm{pH}$, standard deviation in $( \pm) \mathrm{pH}$ units.

(2) For other data, standard deviation of logarithmic values of total molality for aqueous species, volume fraction for $\mathrm{CO}_{2}$, and unitless molal ratios; thus $( \pm$ ) change in $\log 10$ values of concentrations and concentration ratios around mean of $\log 10$ values (e.g., 0.5 corresponds to total spread of one order of magnitude).

The bottom of the table shows averages of individual standard deviations over the time intervals shown. See Appendix B for details. 


\subsection{JUSTIFICATION OF POST-PROCESSING ANALYSIS}

\subsubsection{Justification of Selected Results}

Justification of the selection itself is discussed here in accordance with applicable scientific analyses found at AP-SIII.9Q, Section 5.2.1. Limitations to the selection of THC model results are discussed in Section 1.3.

This scientific analysis and associated tasks were performed in accordance with AP-SIII.9Q and the TWP (BSC 2004 [DIRS 171334]). The development of the selection concept and approach was documented in accordance with AP-SIII.9Q, Section 5.2.1, and in Section 1.2.3 of the TWP (BSC 2004 [DIRS 171334]). The report was documented in accordance with Attachment 2 of AP-SIII.9Q, "Scientific Analysis Outline." Input data were obtained, through the TDMS, from results of previously validated model (BSC 2004 [DIRS 169856]). Qualified software was used in this report, as described in Section 3.

As already mentioned in Section 1.1, selected results from this report are not directly used in TSPA-LA. Instead, the results feed abstraction models documented in Engineered Barrier System: Physical and Chemical Environment (BSC 2004 [DIRS 169860]). Results of the P\&CE model are then used in TSPA-LA.

Discussion of the impacts of input uncertainties is included in Section 6.2.4. The spread of process model results was evaluated for simulations using five different input water compositions (Group 1 simulations), and simulations considering variations in conceptualization and certain input parameters other than input water composition (Group 2 simulations). Minimum, maximum, mean, and standard deviations of predicted concentrations of aqueous species and $\mathrm{CO}_{2}$ gas were presented, including the aggregate uncertainty (combined Group 1 and Group 2) of possible seepage waters resulting from adding the spread of Group 1 and Group 2 simulation results.

The selection process presented in Section 6.2.2 considers which waters are most likely to enter the drift as seepage. These waters originate from locations (model grid blocks) near the drift opening where it is wet (significant liquid saturation). The methodology initially selects waters from both fractures and the matrix. For seepage, the selection justifies selecting only waters from above the drift and from the fractures, as these are the most likely to be mobilized due to gravity and lower capillary retention. For times when imbibition could influence in-drift chemistry of the invert, the selection justifies use of the matrix waters from the lower quadrant and selecting chemistries from those volumes of host-rock immediately adjacent to the invert. These selection criteria are based on justified based on well-understood physical (capillarity) processes.

The selected waters constitute a representative subset of the THC seepage model output, for representing potential seepage. The post-processing analyses presented in Section 6.2.3 do not result in modifications of predicted data from the process model, and therefore the selected data can provide results sufficiently close to the predictions of the supporting process model. Uncertainties associated with the compositions of the selected data are derived from uncertainty of the process model based on sensitivity analyses (Section 6.2.4). These uncertainties are 
assessed, and a description of uncertainty is passed on to abstractions presented in Engineered Barrier System: Physical and Chemical Environment (BSC 2004 [DIRS 169860]).

\subsubsection{Repository-Wide Applicability of THC Model Results}

The repository design includes an array of parallel, equidistant, and horizontal waste emplacement drifts laid out over a large area. Assuming that the relevant rock properties are laterally homogeneous within stratigraphic units across this area, the array is represented in two dimensions using a drift-scale symmetry model (THC seepage model). The drift-scale model represents one half-drift opening in cross-section, with no-flux (heat, mass) vertical boundaries (BSC 2004 [DIRS 169856], Section 6.2.3). The THC seepage model simulates THC processes around a drift, at a repository center location. As discussed in Section 6.2.3 of Drift-Scale THC Seepage Model (BSC 2004 [DIRS 169856]), this “chimney” model represents coupled THC processes at the drift scale in areas that are not affected by repository-edge effects (i.e., effects resulting from the cooler temperatures at the repository edge).

Predicted THC model seepage water compositions are passed to the model developed in Engineered Barrier System: Physical and Chemical Environment (BSC 2004 [DIRS 169860]), which further abstracts them into eleven groups based on chemistry. Representative waters for these bins are then used to develop "bin-history" maps, or maps of the changes in potential seepage water chemistry with time. Although the THC model results are based on a repositorycenter location and thermal history, the bin-history maps are used in TSPA-LA to represent potential seepage throughout the repository. This is acceptable because the potential effects of edge conditions (cooler thermal history) on water chemistry are limited, and because using the hotter repository-center water compositions are more aggressive relative to potentially cooler edge waters with respect to corrosion of the drip shield and waste packages.

The chemistry of seepage waters that might potentially form in response to the cooler repository-edge thermal histories fall within the range of water compositions predicted by the repository-center THC seepage model. Elements that behave conservatively in the solutions (e.g., chloride, nitrate, sulfate, and to a lesser degree, sodium; Figures 6.2-7, 6.2-8, 6.2-10, respectively) are dominantly affected by condensation (dilution) and evaporation (concentration) processes. The relative proportions of these elements remain nearly constant (e.g. Figures 6.2-9, and 6.2-11). The concentrations of more reactive species (e.g., $\mathrm{pH}$, calcium, potassium, and silica) are controlled by water-rock interactions (precipitation-dissolution reactions), and converge with time to a narrow range of values. As rock mineralogy is relatively uniform throughout the repository block (Peterman and Cloke 2002 [DIRS 162576], p. 683; see Assumption 1 for a more complete description), water-rock interactions serve to buffer water compositions to similar values throughout the repository. Repository-edge locations that do not reach boiling show a narrower range of compositions than the simulations in this report (BSC 2004 [DIRS 169856], Section 6.2.3). Even with large-scale gas transport at the repository-scale, the range of gas composition (e.g., $\mathrm{CO}_{2}$ concentration) over time is less than for the repositorycenter locations (BSC 2004 [DIRS 169866], Figure 6.4-16).

The extent of any repository edge effects is also limited. The mountain-scale THC model, as described in Mountain-Scale Coupled Processes (TH/THC/THM) (BSC 2004 [DIRS 169866], Section 6.4), uses a model grid cutting perpendicularly across eight drifts. Predicted drift 
temperatures near drift temperature gradients are nearly identical over the region modeled, with only the outermost drift differing significantly from the rest. Both mountain-scale THC model and Multi-scale Thermohydrologic model (BSC 2004 [DIRS 169565], Figure 6.4-1) shows that the temperature higher and boiling period is longer at the center than at the edge. The evolution of $\mathrm{pH}$ in the waters surrounding repository drifts is strongly coupled to the exsolution of $\mathrm{CO}_{2}$ from pore waters during heating, followed by dissolution of the transported $\mathrm{CO}_{2}$ back into condensate water and cooler matrix pore water. The predicted $\mathrm{pH}$ values within tens of meters of the repository drifts vary by a maximum of about one-half $\mathrm{pH}$ unit at any given time, with higher $\mathrm{pH}$ waters in the area near the repository edge, where $\mathrm{CO}_{2}$ gas concentrations are depressed similarly. Thus, predicted thermal histories and water compositions do not vary greatly over most of the repository; significant edge effects are constrained to a narrow zone, affecting only a small proportion of waste package locations.

Using the bin-history maps and water compositions generated for repository-center thermal histories throughout the repository is conservative with respect to predicted rationuclide releases. The chemistry of seepage water that may contact the waste package is evaluated in Engineered Barrier System: Physical and Chemical Environment (BSC 2004 [DIRS 169860]). Waters that are most corrosive with respect to the waste package have one or more of the following characteristics: high temperature, low $\mathrm{pH}$, high chloride concentration, and high chloride/nitrate ratio (BSC 2004 [DIRS 169984], Section 6.4.4). These waters occur during the hottest periods of the predicted thermal history (BSC 2004 [DIRS 169860], Figure 6.13-1), because high degrees of evaporation yield concentrated brines that in some cases can evolve into acidic compositions. At the repository-center location, these waters never contact the waste package because they occur when wall temperatures are above boiling, and vaporization (combined with capillary diversion) prevents seepage. At the respository edge, high temperatures will persist for a shorter time, temperatures drop below boiling much sooner, and under some conditions seepage can contact the engineered barriers. The composition of that seepage is taken from bin-history maps using repository-center THC results, thus the water compositions are potentially more corrosive than would actually occur.

Because the use of water compositions (bin histories) from hotter repository center locations is conservative with respect to corrosion of the engineered barriers, relative to cooler repository-edge waters, the use of output from the THC seepage model to represent all waste package locations is justified. 


\section{CONCLUSIONS}

This post-processing analysis was completed in accordance with the TWP (BSC 2004 [DIRS 171334]). Output data generated in this report were submitted to the TDMS as described in Appendix A.

A selection of THC seepage model results is presented and implemented using water compositions and $\mathrm{CO}_{2}$ gas concentrations predicted with the THC seepage model (the process model as reported in Drift-Scale THC Seepage Model (BSC 2004 [DIRS 169856]). Results of this selection were submitted to the TDMS under DTN: LB0311ABSTHCR2.001 [DIRS 166714].

This post-processing analysis provides a full documentation in support of water selection for further evaluation in Engineering Barrier System: Physical and Chemical Environment (BSC 2004 [DIRS 169860]). The goal of the THC seepage model is to analyze the effect of THC processes in the rock around waste emplacement drifts. This includes the predictions of aqueous species and $\mathrm{CO}_{2}$ gas concentrations in fluids that could seep into drifts. However, the THC seepage model does not simulate actual seepage of water into a drift because the range of simulated infiltration rates, including high rates for future climate conditions, remains below the seepage threshold for rocks around the modeled drift (e.g., BSC 2004 [DIRS 170338], Section 6.2.2.1.2). For this reason, this selection analysis first considers which locations (around the modeled drift) are most likely to yield water that could seep into the drift.

Around a typical drift, under thermal loading conditions, the predicted concentrations in space around the drift are variable. This local spatial variability is generally greater than the variability associated with the drift location within the repository units (e.g., Tptpll versus Tptpmn; see BSC 2004 [DIRS 169856], Section 7.1), because these units have similar bulk chemical composition.

Taking into account the spatial variability of predicted water compositions around the modeled drift, this analysis considers the following waters as best candidates for in-drift seepage:

- Waters in zones of highest liquid saturations in fractures above the drift (HISAT-TOPfracture water)

- Waters at the boiling/wetting front in fractures above the drift (FRONT-TOP-fracture water)

- Waters at the boiling/wetting front in fractures below the drift (FRONT-BASE-fracture)

- Waters at the boiling/wetting front in matrix at the base of the drift (FRONT-BASEmatrix).

THC seepage model output is available for 5 runs using different starting water compositions, based on natural variability of observed pore-water compositions. Besides the input water uncertainty, more uncertainty analyses on a large number of input parameters are provided in Drift-Scale THC Seepage Model (BSC 2004 [DIRS 169856, Section 6.6]). The selection concept is then used to evaluate the spread in process model results caused by considering five different input water compositions (Group 1 simulations) representing natural variability. The spread 
resulting from specific uncertainties other than input water compositions (Group 2 simulations) is also evaluated (Section 6.2.4). The spread (as two standard deviations) for Group 1 is about one order of magnitude, and is generally greater than for Group 2. The combined spread from both groups (estimated as two times the combined Group 1 and Group 2 standard deviations) also remains mostly within one order of magnitude, but is typically less (Section 6.2.4). Although this uncertainty analysis is not an output of this report, it serves to justify the selection of group simulations for downstream application.

The data generated by the selection procedure implemented for each chemical constituent consists of 30 data points extracted at each point in time (five runs in each group of simulations, with six points indexed INDX=1 through 6) for each run and each time step. The number of sampling points is dependent on the grid resolution. Evaluations using the selected data are used to show that subsets of data using only points with INDX $=4$ for waters at the boiling/wetting front (FRONT-TOP-fracture and FRONT-BASE-matrix waters) provide reasonable representations of the full data sets for these waters.

This post-processing analysis selects THC Seepage model water compositions even during the time interval when the drift-wall temperatures are above boiling, and seepage into the drift is not expected to occur (BSC 2004 [DIRS 169131]). At drift wall temperatures above boiling, the vaporization barrier prevents seepage from entering the drift.

These selected water compositions may be more concentrated than seepage water compositions that could evolve under cooler conditions than considered, for example at the repository edge. Based on evaluation of THC seepage model output, as a function of drift-wall temperature and liquid saturation, the spread in process-model results typically increases with increasing temperature and decreasing liquid saturation. Also as discussed in Section 6.2.3 of Drift-Scale THC Seepage Model (BSC 2004 [DIRS 169856]), the “chimney” model at repository center is a reasonable representation of conditions throughout the repository, because the potential effects of edge conditions, as represented by a differing thermal history, on water chemistry are expected to be small, and of limited extent, and because using the hotter repository-center water compositions is conservative relative to potentially cooler edge waters with respect to corrosion of the drip shield and waste package. More concentrated conditions are generally more deleterious for degradation of the engineered barriers, so application of repository-center results from the THC seepage model to entire repository layout is conservative (Section 6.3.2).

In this post-processing analysis, a set of criteria must be applied to determine which model area is to be selected to obtain water and gas compositions representative of potential in-drift seepage. These criteria represent the main limitation of this report itself (Section 6.2.1). The limitations and uncertainties of the process model have been discussed in detail in Drift-Scale THC Seepage Model (BSC 2004 [DIRS 169856], Sections 1.3, 6.6 and 8.4). These limitations also apply to this post-processing analysis. Downstream users of data generated by this report should be familiar with the process-model limitations and with other details of the process model as well. 


\section{INPUTS AND REFERENCES}

The following is a list of the references cited in this document. Column 2 represents the unique six-digit numerical identifier (the document input reference system (DIRS) number), which is placed in the text following the reference callout. The purpose of these numbers is to assist the reader in locating a specific reference. Within the reference list, multiple sources by the same author (e.g., BSC 2002) are sorted alphabetically by title.

\subsection{DOCUMENTS CITED}

BSC 2003. Total System Performance Assessment-License Application Methods 166296 and Approach. TDR-WIS-PA-000006 REV 00 ICN 01. Las Vegas, Nevada: Bechtel SAIC Company. ACC: DOC.20031215.0001.

BSC 2004. Abstraction of Drift Seepage. MDL-NBS-HS-000019, Rev. 01. Las 169131 Vegas, Nevada: Bechtel SAIC Company.

BSC 2004. Drift-Scale Coupled Processes (DST and TH Seepage) Models. 170338 MDL-NBS-HS-000015, Rev. 01. Las Vegas, Nevada: Bechtel SAIC Company.

BSC 2004. Drift-Scale THC Seepage Model. MDL-NBS-HS-000001, Rev. 03. Las Vegas, Nevada: Bechtel SAIC Company.

BSC 2004. Engineered Barrier System: Physical and Chemical Environment 169860 Model. ANL-EBS-MD-000033, Rev. 03. Las Vegas, Nevada: Bechtel SAIC Company.

BSC 2004. General Corrosion and Localized Corrosion of Waste Package 169984 Outer Barrier. ANL-EBS-MD-000003, Rev. 02. Las Vegas, Nevada: Bechtel SAIC Company.

BSC 2004. In-Drift Precipitates/Salts Model. ANL-EBS-MD-000045, Rev. 02. Las Vegas, Nevada: Bechtel SAIC Company.

BSC 2004. Mountain-Scale Coupled Processes (TH/THC/THM). MDL-NBSHS-000007 REV 02. Las Vegas, Nevada: Bechtel SAIC Company.

169856

BSC 2004. Multiscale Thermohydrologic Model. ANL-EBS-MD-000049, Rev.

02. Las Vegas, Nevada: Bechtel SAIC Company.

169565

BSC 2004. Q-List. 000-30R-MGR0-00500-000-000 REV 00. Las Vegas, 168361 Nevada: Bechtel SAIC Company. ACC: ENG.20040721.0007. 
BSC 2004. Technical Work Plan for: Near-Field Environment and Transport:

Coupled Processes (Mountain-Scale TH/THC/THM, Drift-Scale THC Seepage, and Post-Processing Analysis for THC Seepage) Report Integration.

TWP-MGR-PA-000017 REV 01 ICN 01. Las Vegas, Nevada: Bechtel SAIC Company. ACC: DOC.20040816.0003.

Canori, G.F. and Leitner, M.M. 2003. Project Requirements Document.

166275 TER-MGR-MD-000001 REV 02. Las Vegas, Nevada: Bechtel SAIC Company. ACC: DOC.20031222.0006.

CRWMS M\&O 2000. Abstraction of Drift-Scale Coupled Processes. ANL-NBS-HS-000029 REV 00. Las Vegas, Nevada: CRWMS M\&O. ACC: MOL.20000525.0371.

Jury, W.A.; Gardner, W.R.; and Gardner, W.H. 1991. Soil Physics. 5th Edition. 102010 New York, New York: John Wiley \& Sons. TIC: 241000.

NRC (U.S. Nuclear Regulatory Commission) 2003. Yucca Mountain Review 163274 Plan, Final Report. NUREG-1804, Rev. 2. Washington, D.C.: U.S. Nuclear Regulatory Commission, Office of Nuclear Material Safety and Safeguards. TIC: 254568.

Peterman, Z.E. and Cloche, P.L. 2002. "Geochemistry of Rock Units at the 162576 Potential Repository Level, Yucca Mountain, Nevada (includes Erratum).” Applied Geochemistry, 17, ([6, 7]), 683-698, 955-958. New York, New York: Paragon. TIC: 252516; 252517.

Wang, J.S. 2003. "Scientific Notebooks Referenced in Model Report N0125, Abstraction of Drift-Scale Coupled Processes, MDL-NBS-HS-000018 REV 00.” Correspondence from J.S. Wang (BSC) to File, December 15, 2003, with attachments. ACC: MOL.20031217.0389.

\subsection{CODES, STANDARDS, REGULATIONS, AND PROCEDURES}

66 FR 55732. Disposal of High-Level Radioactive Wastes in a Proposed 156671 Geologic Repository at Yucca Mountain, NV, Final Rule. 10 CFR Parts 2, 19, 20, 21, 30, 40, 51, 60, 61, 63, 70, 72, 73, and 75. Readily available.

10 CFR Part 63. Energy: Disposal of High-Level Radioactive Wastes in a 156605 Geologic Repository at Yucca Mountain, Nevada. Readily available.

AP-2.14Q, Rev. 3, ICN 0. Document Review. Washington, D.C.: U.S. Department of Energy, Office of Civilian Radioactive Waste Management. ACC: DOC.20030827.0018. 
AP-2.22Q, Rev. 1, ICN 1. Classification Analyses and Maintenance of the Q-List. Washington, D.C.: U.S. Department of Energy, Office of Civilian Radioactive Waste Management. ACC: DOC.20040714.0002.

AP-2.27Q, Rev. 1, ICN 4. Planning for Science Activities. Washington, D.C.: U.S. Department of Energy, Office of Civilian Radioactive Waste Management. ACC: DOC.20040610.0006.

AP-3.15Q, Rev. 4, ICN 5. Managing Technical Product Inputs. Washington, D.C.: U.S. Department of Energy, Office of Civilian Radioactive Waste Management. ACC: DOC.20040812.0004.

AP-SI.1Q, Rev. 3, ICN 4. Software Management. Washington, D.C.: U.S. Department of Energy, Office of Civilian Radioactive Waste Management. ACC: MOL.20020520.0283.

AP-SIII.9Q, Rev. 1, ICN 7. Scientific Analyses. Washington, D.C.: U.S. Department of Energy, Office of Civilian Radioactive Waste Management. ACC: DOC.20040920.0001.

AP-SV.1Q, Rev. 01, ICN 01. Control of the Electronic Management of Information. Washington, D.C.: U.S. Department of Energy, Office of Civilian Radioactive Waste Management. ACC: DOC.20040308.0001.

LP-SI.11Q-BSC, Rev. 0, ICN 0. Software Management. Washington, D.C.: U.S. Department of Energy, Office of Civilian Radioactive Waste Management. ACC: DOC.20040225.0007.

YMP-LBNL-QIP-SV.0, Rev. 2, Mod. 1. Management of YMP-LBNL Electronic 171082 Data. Berkeley, California: Lawrence Berkeley National Laboratory. ACC: MOL.20020717.0319.

\subsection{SOURCE DATA, LISTED BY DATA TRACKING NUMBER}

GS020808312272.004. Analysis of Water-Quality Samples for the Period from 166569 July 1999 to July 2002. Submittal date: 09/18/2002.

LB0011DSTTHCR1.002. Model Input and Output Files, Excel Spreadsheets 161282 and Resultant Figures which are Presented in AMR U0110/N0120, "Drift-Scale Coupled Processes (DST and THC Seepage) Models REV 01.” Submittal date: 12/19/2000.

LB0302DSCPTHCS.001. Drift-Scale Coupled Processes (THC Seepage) Model: Simulations. Submittal date: 02/11/2003.

LB0302DSCPTHCS.002. Drift-Scale Coupled Processes (THC Seepage) 161976 Model: Data Summary. Submittal date: 02/11/2003. 
LB0307DSTTHCR2.001. Drift-Scale Coupled Processes (DST Seepage) Model:

166054

Simulations. Submittal date: 07/24/2003.

LB0307DSTTHCR2.002. Drift-Scale Coupled Processes (DST Seepage) Model:

165541

Data Summary. Submittal date: 07/24/2003.

MO0407SEPFEPLA.000. LA FEP List. Submittal date: 07/20/2004.

\subsection{OUTPUT DATA, LISTED BY DATA TRACKING NUMBER}

LB0311ABSTHCR2.001. Drift Scale Coupled Process Abstraction Model (for Intact-Drift Case). Submittal date: 11/07/2003.

\subsection{SOFTWARE CODES}

CUTCHEM. V1.0. DEC ALPHA/OSF1 V5.1, PC /WINDOWS 2000/NT

161127 4.0/98. 10898-1.0-00.

TOUGHREACT. V3.0. DEC-Alpha with Unix OSF1 V5.1 and OSF1 V5.0, 161256 Sun UltraSparc w/Solaris 5.5.1, PC with Linux Redhat 7.2. 10396-3.0-00. 
APPENDIX A

LIST OF MODEL INPUT AND OUTPUT FILES 


\section{LIST OF INPUT AND OUTPUT FILES}

These files were submitted to the TDMS under DTN: LB0311ABSTHCR2.001 [DIRS 166714].

These files consist of MS Excel97 spreadsheets used to calculate summary statistics (Appendix B) presented in Tables 6.2-2 and 6.2-3 and Figures 6.2-4 through 6.2-20 for predicted aqueous species and $\mathrm{CO}_{2}$ gas concentrations. Original data sets are also included, and were compiled from data already submitted to the TDMS under DTNs: LB0302DSCPTHCS.002 [DIRS 161976] and LB0307DSTTHCR2.002 [DIRS 165541].

- top-front_f1.xls (11/6/2003 6:00PM, 8,100,352)-Data for FRONT waters in TOP quadrant in fractures, Group 1 runs

- top-hisat_f1.xls (11/6/2003 6:07PM, 8,104,448)-Data for HISAT waters in TOP quadrant in fractures, Group 1 runs

- base-front_f1.xls (11/6/2003 5:53PM, 8,097,280)-Data for FRONT waters in BASE quadrant in fractures, Group 1 runs

- $\quad$ base-front_m1.xls (11/6/2003 5:51PM, 8,250,880)-Data for FRONT waters in BASE quadrant in matrix, Group 1 runs

- top_front_f2.xls (11/6/2003 6:06PM, 8,096,768)-Data for FRONT waters in TOP quadrant in fractures, Group 2 runs

- top-hisat_f2.xls (11/6/2003 6:10PM,8,104,960)-Data for HISAT waters in TOP quadrant in fractures, Group 2 runs

- w04567_f.xls (11/6/2003 5:54PM, 6,433,792)-Complete original data set for fracture water, Group 1 simulations

- w04567_m.xls (11/6/2003 5:54PM, 6,454,272)-Complete original data set for matrix water, Group 1 simulations

- w0sensi_f.xls (11/6/2003 5:55PM, 6,391,296)-Complete original data set for fracture water, Group 2 simulations

Note: input to this post-processing analysis report for intact-drift simulations consists of process model output already submitted to the TDMS under DTNs: LB0302DSCPTHCS.001 [DIRS 164744] and LB0307DSTTHCR2.001 [DIRS 166054]. 


\section{INTENTIONALLY LEFT BLANK}




\section{APPENDIX B}

SELECTED DATA STATISTICAL CALCULATIONS 
Minimum, maximum, average, and standard deviations of abstracted concentrations of aqueous species and $\mathrm{CO}_{2}$ gas were calculated using standard MS Excel97 functions. These calculations refer to materials discussed in Section 6.2.3 of this report.

\section{Outputs}

The calculations were implemented and output in the following spreadsheets, submitted to the TDMS under DTN: LB0311ABSTHCR2.001 [DIRS 166714]:

- top-front_f1.xls (11/6/2003 6:00PM, 8,100,352)-Data for FRONT waters in TOP quadrant in fractures, Group 1 runs

- top-hisat_f1.xls (11/6/2003 6:07PM, 8,104,448)-Data for HISAT waters in TOP quadrant in fractures, Group 1 runs

- base-front_f1.xls (11/6/2003 5:53PM, 8,097,280)-Data for FRONT waters in BASE quadrant in fractures, Group 1 runs

- base-front_m1.xls (11/6/2003 5:51PM, 8,250,880)- Data for FRONT waters in BASE quadrant in matrix, Group 1 runs

- top_front_f2.xls (11/6/2003 6:06PM, 8,096,768)-Data for FRONT waters in TOP quadrant in fractures, Group 2 runs

- top-hisat_f2.xls (11/6/2003 6:10PM,8,104,960)-Data for HISAT waters in TOP quadrant in fractures, Group 2 runs

\section{Inputs}

Inputs to the above spreadsheets consisted of records from the following data files, also submitted to the TDMS under DTN: LB0311ABSTHCR2.001 [DIRS 166714]:

- w04567_f.xls (11/6/2003 5:54PM, 6,433,792)-Complete original data set for fracture water, Group 1 simulations

- $\quad$ w04567_m.xls (11/6/2003 5:54PM, 6,454,272)-Complete original data set for matrix water, Group 1 simulations

- w0sensi_f.xls (11/6/2003 5:55PM, 6,391,296)-Complete original data set for fracture water, Group 2 simulations

Records from these files were filtered for the desired specific attributes (FRONT, HISAT, TOP, BASE, and INDX values) using the MS Excel97 menu "Data/Auto Filter," then cut and pasted into the calculation (and output) spreadsheets listed earlier.

\section{Functions}

The function LOG10() was used to log the input data.

The following array functions were used to calculate summary statistics:

Mean:

Maximum:

Minimum:
$\{=$ AVERAGE $($ IF $($ time_range $=$ time, data_range $))\}$

$\{=\mathrm{MAX}(\mathrm{IF}($ time_range $=$ time, data_range $))\}$

$\{=\mathrm{MIN}(\mathrm{IF}($ time_range $=$ time, data_range $))\}$ 
Std. Deviation: $\quad\{=\mathrm{STDEV}(\mathrm{IF}($ time_range $=$ time , data_range $))\}$

Count (for info only): $\{=$ COUNT (IF (time_range $=$ time, data_range $))\}$

with arguments defined as

time_range Array of input data containing the time values for all points

time $\quad$ The specific desired time value for which to apply the function

data_range Array of input data on which to apply the function (e.g., $\mathrm{pH}, \mathrm{CO}_{2}$ concentrations)

Calculations for multiple time periods were implemented by cutting and pasting the above array functions next to a column containing the desired specific time values. 


\section{APPENDIX C}

INPUT WATER COMPOSITIONS 
This appendix summarizes pore-water compositions (Table C-1 and Figure C-1) used as input to the THC seepage model simulations presented in Drift-Scale THC Seepage Model (BSC 2004 [DIRS 169856], Table 6.2-1). Results of these simulations are abstracted in the present report (Section 6.2.3). 
Table C-1. Input Pore-Water Compositions for the THC Seepage Model

\begin{tabular}{|c|c|c|c|c|c|c|c|c|c|c|c|}
\hline \multicolumn{2}{|c|}{ Sample ID: } & \multicolumn{2}{|c|}{$\begin{array}{c}\text { HD-PERM } \\
\text { (Alcove 5) }\end{array}$} & \multicolumn{2}{|c|}{$\begin{array}{c}\text { ECRB-SYS- } \\
\text { CS1000/7.3-7.7/UC }\end{array}$} & \multicolumn{2}{|c|}{$\begin{array}{c}\text { ECRB-SYS- } \\
\text { CS2000/16.5-21.1/UC }\end{array}$} & \multicolumn{2}{|c|}{ SD-9/990.4-991.7/UC } & \multicolumn{2}{|c|}{$\begin{array}{c}\text { ECRB-SYS- } \\
\text { CS500/12.0-16.7/UC }\end{array}$} \\
\hline \multicolumn{2}{|c|}{ Lithostratigraphic Unit: } & \multicolumn{2}{|c|}{ Tptpmn } & \multicolumn{2}{|c|}{ Tptpul (base) } & \multicolumn{2}{|c|}{ Tptpll } & \multicolumn{2}{|c|}{ TptpII } & \multicolumn{2}{|c|}{ Tptpul } \\
\hline & \multicolumn{2}{|c|}{ wo } & \multicolumn{2}{|c|}{ W5 } & \multicolumn{2}{|c|}{ W4 } & \multicolumn{2}{|c|}{ W6 } & \multicolumn{2}{|c|}{ W7 } \\
\hline & Water Input Type: & Fract/Matrix & Boundary & Fract/Matrix & Boundary & Fract/Matrix & Boundary & Fract/Matrix & Boundary & Fract/Matrix & Boundary \\
\hline & Units & & & & & & & & & & \\
\hline Temperature & ${ }^{\circ} \mathrm{C}$ & 25 & 17 & 25 & 17 & 25 & 17 & 25 & 17 & 25 & 17 \\
\hline $\mathrm{pH}$ (measured) & $\mathrm{pH}$ & 8.31 & - & 7.6 & - & 7.4 & & 7.9 & - & 8.0 & \\
\hline pH (calc) & $\mathrm{pH}$ & - & 7.750 & 8.062 & 8.026 & 8.175 & 8.140 & 8.001 & 7.964 & 8.073 & 8.038 \\
\hline $\mathrm{Na}^{+}$ & $\mathrm{mg} / \mathrm{L}$ & 61.5 & 61.5 & 39 & 39 & 130 & 130 & 84 & 84 & 57 & 57 \\
\hline $\mathrm{K}^{+}$ & $\mathrm{mg} / \mathrm{L}$ & 8 & 8 & 7.6 & 7.6 & 10.6 & 10.6 & 7.9 & 7.9 & 10.3 & 10.3 \\
\hline $\mathrm{Ca}^{+2}$ & $\mathrm{mg} / \mathrm{L}$ & 101 & 101 & 94 & 94 & 82 & 82 & 56 & 56 & 120 & 120 \\
\hline $\mathrm{Mg}^{+2}$ & $\mathrm{mg} / \mathrm{L}$ & 17 & 17 & 18.1 & 18.1 & 5.3 & 5.3 & 0.9 & 0.9 & 19.3 & 19.3 \\
\hline $\mathrm{SiO}_{2}$ & $\mathrm{mg} / \mathrm{L}$ & 70.5 & 70.5 & 42.0 & 42.0 & 48 & 48 & 50 & 50 & 49 & 49 \\
\hline $\mathrm{Cl}^{-}$ & $\mathrm{mg} / \mathrm{L}$ & 117 & 117 & 21 & 21 & 26 & 26 & 23 & 23 & 54 & 54 \\
\hline $\mathrm{SO}_{4}^{-2}$ & $\mathrm{mg} / \mathrm{L}$ & 116 & 116 & 36 & 36 & 39 & 39 & 10 & 10 & 78 & 78 \\
\hline $\mathrm{HCO}_{3}^{-}$(measured) & $\mathrm{mg} / \mathrm{L}$ & - & - & 333 & - & 382 & 382 & 313 & - & 286 & ] \\
\hline $\mathrm{HCO}_{3}^{-}$(calc) & $\mathrm{mg} / \mathrm{L}$ & 200 & 216 & 395 & 400 & 515 & 515 & 335 & 338 & 412 & 417 \\
\hline $\mathrm{NO}_{3}{ }^{-}$ & $\mathrm{mg} / \mathrm{L}$ & 6.5 & 6.5 & 2.6 & 2.6 & 4.2 & 4.2 & 17 & 17 & 6.1 & 6.1 \\
\hline $\mathrm{F}^{-}$ & $\mathrm{mg} / \mathrm{L}$ & 0.86 & 0.86 & 3.4 & 3.4 & $6.01(11)^{\mathrm{a}}$ & 5.52 & 2.5 & 2.5 & 4.8 & 4.8 \\
\hline $\mathrm{Al}^{+3}$ (calc) & molal & $6.173 E-10$ & $9.775 \mathrm{E}-11$ & 1.112E-09 & $3.415 \mathrm{E}-10$ & 1.082E-09 & 3.305E-10 & 1.00E-09 & $3.08 \mathrm{E}-10$ & $8.061 \mathrm{E}-10$ & $2.477 \mathrm{E}-10$ \\
\hline $\mathrm{Fe}^{+3}$ (calc) & molal & 1.155E-12 & 5.162E-13 & 1.138E-12 & $5.000 \mathrm{E}-13$ & 1.143E-12 & 4.984E-13 & 1.14E-12 & 5.02E-13 & 1.138E-12 & 5.006E-13 \\
\hline $\log \left(\mathrm{PCO}_{2}\right)$ & bar & -3.1 & -2.5 & -2.5 & -2.5 & -2.5 & -2.5 & -2.5 & -2.5 & -2.5 & -2.5 \\
\hline $\mathrm{CO}_{2}$ (approx) & ppmv & 900 & 3100 & 3100 & 3100 & 3100 & 3100 & 3100 & 3100 & 3100 & 3100 \\
\hline
\end{tabular}

Source: BSC 2004 [DIRS 169856], Table 6.2-1.

NOTE: Compositions shown are those used for initial fracture and matrix water (column labled "Fract/Matrix") and infiltration water at the model top boundary (column labeled "Boundary"). ${ }^{2}$ Value shown is calculated at equilibrium with fluorite at $25^{\circ} \mathrm{C}$. Value in parentheses is measured value. 
Yucca Mountain Pore Waters

Tptpul (red), Tptpmn (blue), Tptpll (green), Tptpln (orange)

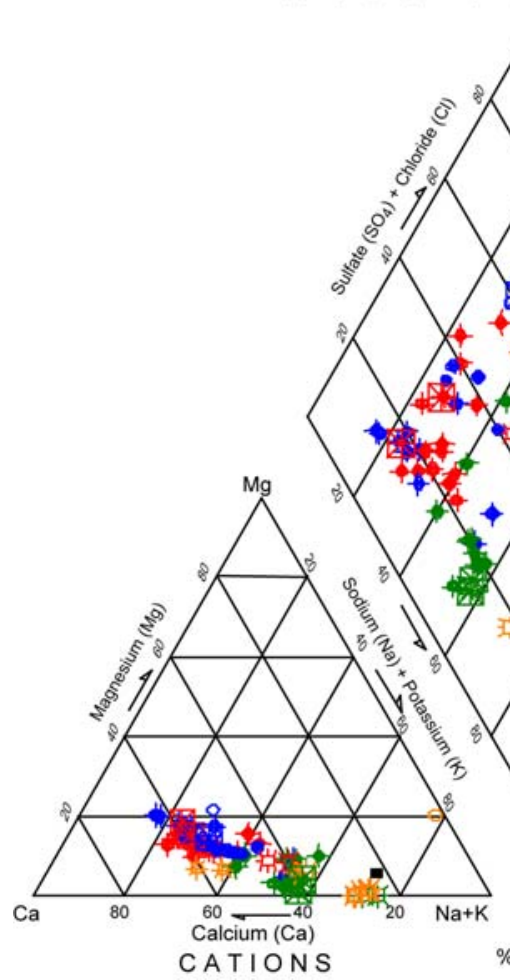

SYS.CS400

THERMALK-017

- THERMALK.017

- THERMALK.017

- Thermalk-017

SYS-CS900

SYS-CS 850 THERMALK-017

- SYS.CS850

SYS-CS 1000

SYS-CS1000
SYS-CS450

SYS-CS2300

SYS.CS500

SYS-CS2000

SYS-CS2000

SYS-CS950

SYT-CS1250

SYS-CS800 * UZ-14

SYS-CS2300

-SYS-CS2250 उo UZ-16

- SYS-CS2350 ख W7 (CS-500-12.0)

W5 (CS1000/7.3)

W6 (SD-9/990 -4)

SYS-CS900

SYS-CS 1000

⿶ WO (HD-PERM

0 HD-PERM-1

HD.PERM-3

SYS-CS2000

(y)

- SAD-GTB\#1

- SAD-GTBH1

- SAD-GTB\#1

Measured $\mathrm{HCO}_{3}$ when

available (except for WO

W4, W5, W6, W7 inputs

and HD-PERM samples)

00433DC_006a.ai

Source: BSC 2004 [DIRS 169856], Figure 6.2-4.

NOTE: Samples labeled HD-PERM are pore waters from the Tptpmn unit in Alcove 5 of the ESF. Sample IDs starting with SYS-CS represent pore waters from the ECRB cross drift and are listed in order of increasing distance $(\mathrm{m})$ into the drift (down stratigraphy). Additional borehole interval information after each SYS-CS sample labeling is sample interval distances from borehole collar given in feet. CS is the abbreviation for Construction Station, indicating distance along the ECRB cross drift in meters. THERMALK pore waters are from near the south bend of the ESF drift. SAD-GTB pore water samples are from the Alcove 7 area of the ESF. Sample ID's starting with SD-9, UZ-14, and UZ-16 represent pore waters from surface boreholes with the same names. The 5 starting waters are indicated (see text). These data are included here to show full spread of measured waters.

Figure C-1. Piper Plot of Water Compositions (meq/L) from Repository Units 


\section{INTENTIONALLY LEFT BLANK}

